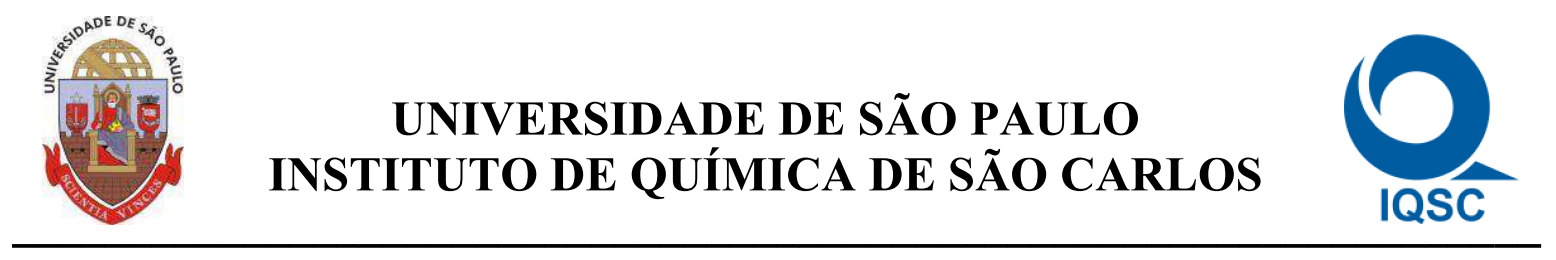

Departamento de Química e Física Molecular

Laboratório de Cromatografia

Adriel Martins Lima

\title{
MICROEXTRAÇÕES EM FASE LÍQUIDA: ANTIMICROBIANOS EM AMOSTRAS AQUOSAS AMBIENTAIS
}

São Carlos 
Adriel Martins Lima

\section{Microextrações em Fase Líquida: Antimicrobianos em Amostras Aquosas Ambientais}

Tese apresentada ao Instituto de Química de São Carlos, da Universidade de São Paulo, para obtenção do Título de Doutor em Ciências.

Área de Concentração: Química Analítica e Inorgânica.

\section{Exemplar revisado}

O exemplar original encontra-se em acervo reservado na Biblioteca do IQSC-USP

Orientador: Prof. Dr. Álvaro José dos Santos Neto

São Carlos

2017 


\section{AGRADECIMENTOS}

Gostaria de agradecer primeiramente a Deus acima de tudo, pois sem ele não somos nada.

Aos meus pais Zenair e Euripedes sem eles eu não seria ninguém, se hoje estou aqui é graças a eles que sempre me deram muito amor, carinho e ótimos conselhos.

Ao meu irmão Carlos pelas várias brigas e desentendimentos na infância, que só serviram para fortalecer mais esses laços fraternais que unem a gente.

À minha namorada Leticia que sempre foi minha companheira e me ajudou muito para chegar até aqui nesse dia de vitória, Eu Te Amo Minha Galega!!!

Ao professor, orientador e amigo Álvaro José dos Santos Neto pela paciência que teve comigo durante o período de desenvolvimento deste trabalho, pelos vários conselhos dados tanto na área acadêmica como na vida pessoal, tenho certeza que cresci muito sob sua orientação.

Aos professores da banca que se dispuseram a vir contribuir para melhora deste trabalho.

Não poderia me esquecer de agradecer aos meus amigos de "cervejada", pois esses momentos com toda certeza me ajudaram a vencer os momentos difíceis que passei.

Ao grande amigo Alexandre Petrilli (In memoriam), que teve uma grande contribuição para a construção deste doutoramento;

A todos os meus companheiros de laboratório, Felipe, Maraissa, Rodrigo, Bruno, Pipe, Arley entre outros que passaram pelo laboratório, pela ajuda e pelo tempo que passamos juntos nesses quatro anos.

Não poderia deixar de agradecer também aos meus amigos de Pontes e Lacerda, principalmente aos Leomir e Ricardo Vanjura, pois na reta final da escrita desta tese colaboraram muito para eu não "pirar", obrigado meus amigos. 
A todos os meus amigos do IQSC (que não são poucos) pelos momentos alegres que me proporcionaram nos corredores, na hora do café e em diversos outros lugares.

A FAPESP pelo apoio financeiro concedido ao laboratório para a execução deste trabalho. Ao CNPq pela concessão da bolsa de estudos.

A todos os professores e funcionários do Instituto de Química de São Carlos que contribuíram para minha formação.

A todos da secretária da Pós-Graduação em especial à Gislei, Silvia, Andréia e Gustavo que sempre estiveram dispostos a ajudar e me "aguentaram" por esse tempo.

Enfim, a todos que de alguma forma contribuíram para a realização deste trabalho. 
Aos meus queridos pais Zenair e Euripedes que são minha fonte de inspiração, são meu porto seguro, um só muito obrigado seria pouco por tudo que vocês fizeram e fazem por mim, por isso vou passar a vida toda agradecendo. 


\section{RESUMO}

Águas residuárias são continuamente contaminadas por fármacos. Dentre estes fármacos, os antimicrobianos causam grande preocupação pelos impactos sobre o desenvolvimento de resistência bacteriana. As principais fontes de contaminação destes fármacos são efluentes urbanos, hospitalares, de fazendas e de algumas indústrias. A complexidade das matrizes ambientais tais como águas residuárias é uma das principais dificuldades para extrair e detectar fármacos, fazendo-se necessário o uso de técnicas de preparo de amostra para a extração destes compostos de interesse. Técnicas clássicas como a extração líquido-líquido (LLE) e a extração em fase sólida (SPE) são largamente usadas para extração de fármacos nesse tipo de matriz, porém estas técnicas não atendem amplamente aos princípios da química verde. Dessa forma, novas técnicas, mais alinhadas à responsabilidade ambiental, têm sido desenvolvidas. Neste âmbito apresenta-se o desenvolvimento e a validação de um método de microextração líquido-líquido para extração e detecção de sulfonamidas e o desenvolvimento e otimização de um método utilizando planejamento experimental para a extração de fluoroquinolonas em águas residuárias. Foi possível obter-se o limite de detecção de $0,2 \mathrm{ng} \mathrm{mL}-1$ para as sulfonamidas analisadas, este LD é relativamente baixo considerando que o detector que foi utilizado não possuía a possibilidade de fazer análises no modo MS/MS, o que certamente reduziria ainda mais o LD. Com os desenvolvimentos desse trabalho tornou-se possível a utilização de apenas $1 \mathrm{~mL}$ de solvente orgânico para a préconcentração off-line. Esta etapa, adicionada a uma outra pré-concentração online (column switching) permitiu a extração dos analitos com a obtenção de um LD relativamente baixo, a partir de apenas $7 \mathrm{~mL}$ de amostra.

Palavras-chave: Microextração líquido-líquido, sulfonamidas, fluoroquinolonas, cromatografia capilar. 


\begin{abstract}
Drugs are continuously contaminating wastewater. Among these drugs antimicrobials cause great concern for the impacts on the development of bacterial resistance. The main sources of contamination by these drugs are urban effluents, hospitals, farms and some industries. The complexity of the environmental matrices such as wastewater is one of the main difficulties in extracting and detecting drugs, bringing up the need to use sample preparation techniques for the extraction of the interest compounds. Classical techniques such as liquid-liquid extraction (LLE) and solid phase extraction (SPE) are widely used for drug extraction in this type of matrix, but these techniques do not largely meet the principles of green chemistry. In this way, new techniques, more aligned with environmental responsibility, have been developed. In this context, this thesis presents the development and validation of a liquid-liquid microextraction method for sulfonamide extraction and detection and the development and optimization of a method using experimental design for the extraction of fluoroquinolones presented in wastewater. It was possible to obtain a limit of detection (LD) of $0.2 \mathrm{ng} \mathrm{mL}^{-1}$ for the sulfonamides analyzed, this LD is relatively low considering that the detector that was used did not have the possibility to perform analyzes in the MS/MS mode, which certainly would further reduce the LD. With the development of this thesis, it became possible to use only $1 \mathrm{~mL}$ of organic solvent for the off-line preconcentration of the analytes. This step, added to another online preconcentration (column switching) allowed the extraction of the analytes obtaining relatively low LDs, from just $7 \mathrm{~mL}$ of the sample.
\end{abstract}

Keywords: Liquid-liquid microextraction, sulfonamides, fluoroquinolones, capillary chromatography. 


\section{ÍNDICE DE FIGURAS}

Figura 1: Representação esquemática do sistema cromatográfico com columnswitching. 31

Figura 2: Monômero do polímero da fase extratora Strata-X. 32

Figura 3: Seringa de vidro com adaptação na ponta para fazer a extração. 36

Figura 4 - Otimização univariada para avaliar o melhor solvente de extração. *Resultados significativamente diferentes.

Figura 5: Otimização univariada para avaliar o volume do solvente de extração. *Resultados significativamente diferentes.

Figura 6: Otimização univariada para avaliar a concentração de $\mathrm{Na}_{2} \mathrm{SO}_{4}$ (salting out). *Resultados significativamente diferentes.

Figura 7 - Cromatograma para as sulfas obtido a partir da extração da matriz isenta de analitos fortificada com $5 \mathrm{ng} \mathrm{mL}^{-1}$ de sulfas, matriz isenta de sulfas e matriz fortificadas com ibuprofeno e cafeína.

Figura 8 - Curvas analíticas ponderadas para as sulfonamidas processadas por LLMECS-ULC-MS.

Figura 9 - Gráficos de resíduos relativos em relação à concentração das sulfonamidas.

Figura 10 - Efeito dos parâmetros de robustez sobre a concentração das sulfonamidas.

Figura 11 A - Cromatograma da amostra fortificada e não fortificada com sulfacetamida. B) Local onde a amostra foi coletada.

Figura 12 - Comparação entre a coluna labmade Strata-X e a coluna comercial Oasis HLB. .55

Figura 13: Tubo cônico utilizado para fazer extração das FQs 56

Figura 14 - Avaliação do melhor solvente de extração para as FQs

Figura 15 - Diagrama de Pareto do planejamento experimental $2^{3}$ composto central representando a extração das FQs.

Figura 16 - Superfícies de respostas para a desejabilidade do método desenvolvido.

Figura 17: Gráficos do modelo proposto para norfloxacina: A) Médias Quadráticas, B)

Testes F, C) Resíduos e D) Significância dos coeficientes. 
Figura 18: Gráficos do modelo proposto para ciprofloxacina: A) Médias Quadráticas, B) Testes F, C) Resíduos e D) Significância dos coeficientes.

Figura 19 - Gráficos do modelo proposto para pefloxacina: A) Médias Quadráticas, B) Testes F, C) Resíduos e D) Significância dos coeficientes.

Figura 20 - Gráficos do modelo proposto para enrofloxacina: A) Médias Quadráticas,

B) Testes F, C) Resíduos e D) Significância dos coeficientes.

Figura 21 - Gráficos do modelo proposto para ofloxacina: A) Médias Quadráticas, B)

Testes F, C) Resíduos e D) Significância dos coeficientes. 65

Figura 22 - Superfícies de Respostas paras as FQs avaliadas. 66

Figura 23: Superfície de resposta para a desejabilidade. 67

Figura 24: Ponto ótimo para o modelo proposto.

Figura 25: Curvas analíticas para as fluoroquinolonas processadas por LLME-LC-CSQTRAP/MS.

Figura 26: Gráficos de resíduos em relação a concentração das fluoroquinolonas. .70 Figura 27: Cromatogramas obtido no método LLME-LC-CS-QTRAP/MS para extração de fluoroquinolonas em amostras de água coletadas no ponto 1 da amostragem: Foram monitoradas duas transições de m/z 320-276 e 320-233 para a norfloxacina, 332-288, 332-245 e 332-231 para a ciprofloxacina e 362-318 e 362-261 para a ofloxacina. a), c), e) Amostra real fortificada com $500 \mathrm{ng} \mathrm{L^{-1 }}$ de NOR, CIP e OFLO respectivamente e b), d), f) amostra real sem fortificação. As demais fluoroquinolonas ficaram abaixo do limite de detecção do método desenvolvido. .74 Figura 28: Cromatogramas obtido no método LLME-LC-CS-QTRAP/MS para extração de fluoroquinolonas em amostras de água coletadas no ponto 1 da amostragem: Foram monitoradas duas transições de m/z 332-288, 332-245 e 332-231 para a ciprofloxacina e 362-318 e 362-261 para a ofloxacina. a), c) Amostra real fortificada com $500 \mathrm{ng} \mathrm{L}^{-1}$ de CIP e OFLO respectivamente e b), d) amostra real sem fortificação. As demais fluoroquinolonas ficaram abaixo do limite de detecção do método desenvolvido. .75

Figura 29: Cromatogramas obtido no método LLME-LC-CS-QTRAP/MS para extração de fluoroquinolonas em amostras de água coletadas no ponto 1 da amostragem: Foram monitoradas duas transições de m/z 332-288, 332-245 e 332-231 para a ciprofloxacina e 362-318 e 362-261 para a ofloxacina. a), c) Amostra real fortificada com $500 \mathrm{ng} \mathrm{L}^{-1}$ de CIP e OFLO respectivamente e b), d) amostra real sem fortificação. 
As demais fluoroquinolonas ficaram abaixo do limite de detecção do método desenvolvido.

Figura 30: Cromatogramas obtido no método LLME-LC-CS-QTRAP/MS para extração de fluoroquinolonas em amostras de água coletadas no ponto 1 da amostragem: Foram monitoradas duas transições de m/z 320-276 e 320-233 para a norfloxacina, 332-288, 332-245 e 332-231 para a ciprofloxacina, 360-316, 360-245 e 360-286 para a enrofloxacina e 362-318 e 362-261 para a ofloxacina. a), c), e), g) Amostra real fortificada com $500 \mathrm{ng} \mathrm{L}^{-1}$ de NOR, CIP e OFLO respectivamente e b), d), f), h) amostra real sem fortificação. As demais fluoroquinolonas ficaram abaixo do limite de detecção do método desenvolvido. .76

Figura 31: Avaliação do melhor solvente de extração para de sulfas e FQs............78

Figura 32: Microextração em gota suspensa..................................................79

Figura 33: Diagrama de Pareto para as sulfas e FQs avaliadas. ...........................81

Figura 34: Superfícies de respostas paras as sulfas e FQs avaliadas. ...................82

Figura 35: Desejabilidade e ponto ótimo para o modelo proposto ...........................83

Figura 36: Curvas analíticas para as sulfas e FQs processadas por LLME-LC-MS/MS.

Figura 37: Gráficos de resíduos absolutos em relação a concentração das Sulfas e FQs. 86

Figura 38: Mapa representativo, para indicação dos pontos de coleta realizados na cidade de São Carlos-SP. Tais amostras foram aplicados nos métodos LLME-LCMS/MS

Figura 39: Cromatogramas obtido no método LLME-LC-MS/MS para extração de Sulfas e FQs simultaneamente em amostras de água coletadas no ponto 1 da amostragem: a) Foram monitoradas duas transições de m/z 362-318 e 362-261 para a ofloxacina; b) transições de $\mathrm{m} / \mathrm{z}$ 311-156 e 311-92 para a Sulfadimetoxina e c) transições de m/z 254-156 e 254-92 para o Sulfametoxazol..................................90 Figura 40: Cromatogramas obtido no método LLME-LC-MS/MS para extração de Sulfas e FQs simultaneamente em amostras de água coletadas no ponto 2 da amostragem: a) Foram monitoradas duas transições de m/z 362-318 e 362-261 para a ofloxacina; b) transições de $\mathrm{m} / \mathrm{z}$ 311-156 e 311-92 para a Sulfadimetoxina e c) transições de m/z 254-156 e 254-92 para o Sulfametoxazol..................................91 
Figura 41: Cromatogramas obtido no método LLME-LC-MS/MS para extração de Sulfas e FQs simultaneamente em amostras de água coletadas no ponto 3 da amostragem: a) Foram monitoradas duas transições de m/z 362-318 e 362-261 para a ofloxacina; b) transições de m/z 311-156 e 311-92 para a Sulfadimetoxina. .........92 


\section{ÍNDICE DE TABELAS}

Tabela 1 - Propriedades das sulfonamidas utilizadas neste trabalho. 29

Tabela 2 - Parâmetros utilizados para análise das fluoroquinolonas por LC-ESIQTRAP/MS no modo de ionização ESI+.

Tabela 3 - Parâmetros utilizados para análise das FQs e Sulfas por LC-ESI-MS/MS no modo de ionização ESI+.

Tabela 4 - Composição do esgoto labmade utilizado neste trabalho (44) .................35

Tabela 5 - Fatores avaliados na robustez do método. ...........................................39

Tabela 6 - Matriz de Youden. 39

Tabela 7 - Soma dos resíduos percentuais (\%) para as curvas de calibrações não

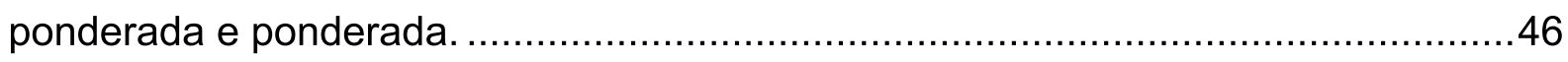

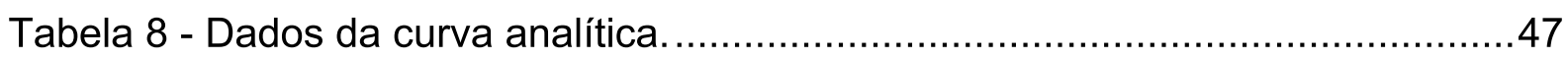

Tabela 9 - Precisão intra-dia, inter-dias e exatidão para o método desenvolvido. ....49 Tabela 10 - Resultados para recuperação, efeito de matriz e eficiência total do processo. .50

Tabela 11 - Resultados da reprodutibilidade intralaboratorial. .51

Tabela 12 - Resultados da avaliação da robustez para método desenvolvido. .53

Tabela 13 - Avaliação da precisão, exatidão e determinação da concentração em uma amostra real fortificada.

Tabela 14 - Aumento da área bruta comparando as duas colunas de SPE online (Strata-X e Oasis HLB).

Tabela 15 - Valores de t calculado para a eficiência de extração dos solventes orgânicos.

Tabela 16 - Variáveis e fatores do planejamento experimental $2^{3}$ composto central.58 Tabela 17 - Variáveis e fatores do planejamento experimental composto central $2^{2}$ estrela. 60

Tabela 18: Tabela ANOVA para a norfloxacina. 61

Tabela 19: Coeficientes significativos do modelo proposto para a norfloxacina. ......61

Tabela 20: Tabela ANOVA para a ciprofloxacina.

Tabela 21 - Coeficientes significativos do modelo proposto para a ciprofloxacina....62

Tabela 22 - Tabela ANOVA para a pefloxacina. .63

Tabela 23 - Coeficientes significativos do modelo proposto para a pefloxacina. 63

Tabela 24 - Tabela ANOVA para a enrofloxacina. 
Tabela 25 - Coeficientes significativos do modelo proposto para a enrofloxacina. ...64

Tabela 26 - Tabela ANOVA para a ofloxacina..............................................65

Tabela 27 - Coeficientes significativos do modelo proposto para a ofloxacina. .......65

Tabela 28: Avaliação da desejabilidade proposta pelo modelo............................68

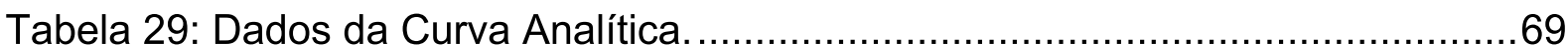

Tabela 30: Valores de precisão e exatidão obtidos para o método LLME desenvolvido.

Tabela 31: Valores de recuperação, efeito matriz e eficiência total do método LLME validado.

Tabela 32: Concentração dos antibióticos detectados nas amostras de água coletadas nos pontos 1 ao 4 indicados na figura 3

Tabela 33: Variáveis e fatores do planejamento experimental composto central $2^{2} \mathrm{com}$ estrela.

Tabela 34: Dados da curva analítica.

85

Tabela 35: Valores de precisão e exatidão obtidos para o método SDME desenvolvido.

Tabela 36: Resultados para recuperação, efeito de matriz e eficiência total do processo.

Tabela 37: Concentração dos antibióticos detectados nas amostras de água coletadas nos pontos 1 ao 3 indicados na Figura 38. 


\section{LISTA DE ABREVIATURAS}

ACN - Acetonitrila (acetonitrile)

ANVISA - Agência Nacional de Vigilância Sanitária

$\mathrm{APCl}$ - Ionização Química à Pressão Atmosférica (Atmospheric Pressure

Chemicallonization)

CE - Energia de colisão (Collision Energy)

CIP - Ciprofloxacina

CLC - Cromatografia líquida capilar (Capillary Liquid Chromatography)

CS - Comutação de colunas (Column Switching)

CXP - Potencial de saída da cela de colisão (Collision Cell Exit Potential)

DC - Corrente contínua (Direct Current)

DLLME - Microextração líquido-líquido dispersiva (Dispersive Liquid-Liquid Microextraction)

DPR - Desvio Padrão Relativo

DNA - Ácido desoxirribonucleico (Deoxyribonucleic Acid)

ENR - Enrofloxacina

ESI - Ionização por electrospray (Electrospray lonization)

ETE - Estação de Tratamento de Esgoto

FDA - Food and Drug Administration

FQs - Fluoroquinolonas

GC - Cromatografia Gasosa (Gas Chromatography)

HPLC - Cromatografia Líquida de Alta Eficiência (High Performance Liquid

Chromatography)

INMETRO - Instituto Nacional de Metrologia, Qualidade e Tecnologia

ISO - International Organization of Standardization

LC - Cromatografia Líquida

LD - Limite de detecção

LLE - Extração líquido-líquido (Liquid-Liquid Extraction)

LPB - Laboratório de Processos Biológicos

LLME - Microextração líquido-líquido

LQ - Limite de Quantificação

MAPA - Ministério da Agricultura, Pecuária e Abastecimento

$\mathrm{MeOH}-$ Metanol 
MEPS - Microextração por sorvente empacotado (Microextraction by packed sorbent)

MS - Espectrometria de massas (Mass Spectrometry)

NOR - Norfloxacina

OFL - Ofloxacina

PEF - Pefloxacina

RSD - Desvio-padrão relativo (Relative Standard Deviation)

S/R - Razão Sinal/Ruído (Signal to noise ratio)

SBSE - Extração por sorção em barra de agitação (Stir Bar Sorptive Extraction)

SCT - Sulfacetamida

SCZ - Sulfacloropiridazina

SDX - Sulfadimetoxina

SDZ - Sulfadiazina

SE - Solução-Estoque

SI - Solução Intermediária

SIM - Monitoramento de íon selecionado (Selected lon Monitoring)

SMR - Sulfamerazina

SMT - Sulfametazina

SMX - Sulfametoxazol

SMZ - Sulfametizol

SPE - Extração em fase sólida (Solid Phase Extraction)

SPME - Microextração em fase sólida (Solid Phase Microextraction)

SQN - Sulfaquinoxalina

SRM - Monitoramento de reações selecionadas (Selected Reaction Monitoring)

STZ - Sulfatiazol

TMP - Trimetoprima

ToF - Tempo de voo (Time of Flight)

UHPLC - Cromatografia líquida de ultra-alta eficiência (Ultra High Performance Liquid Chromatography)

UV - Ultraviolet (Ultravioleta)

VWSE - Extração por sorção nas paredes do frasco (Vial Wall Sorptive Extraction) 


\section{Sumário}

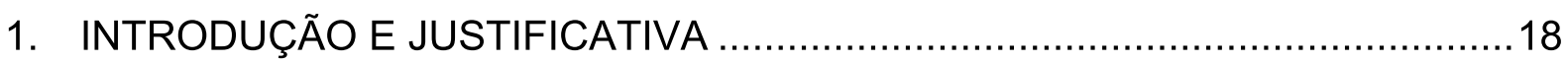

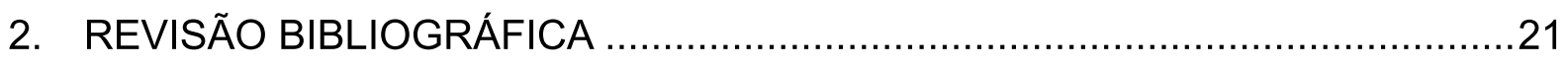

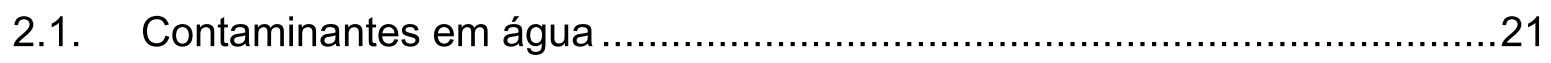

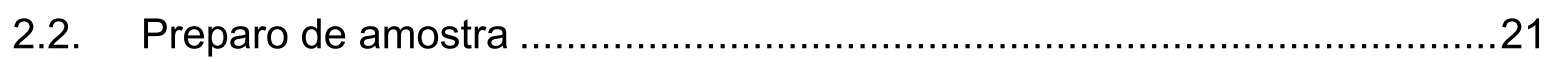

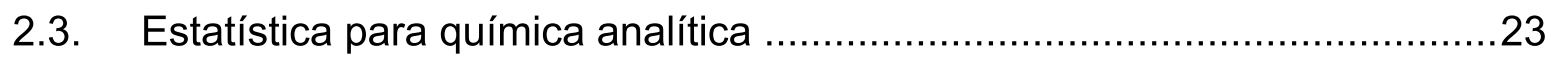

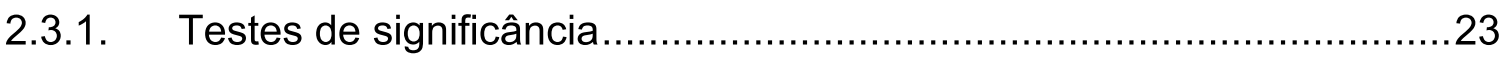

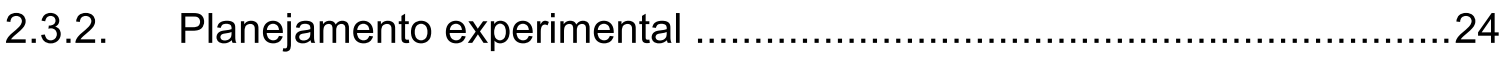

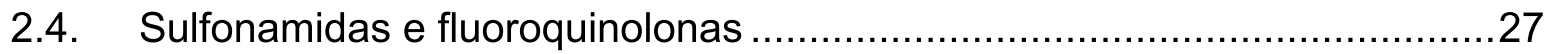

3. OBJETIVOS

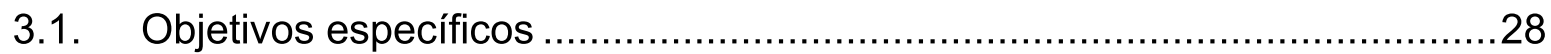

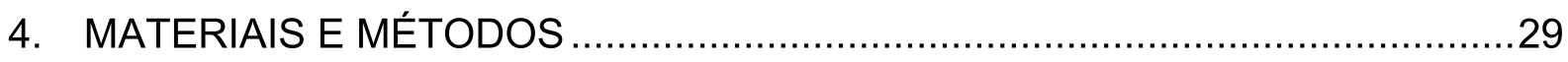

4.1. Padrões analíticos, solventes e reagentes ..............................................29

4.2. Condições das separações cromatográficas ..........................................31

4.2.1. Microextração líquido-líquido (LLME-CS-cLC-MS) aplicada a

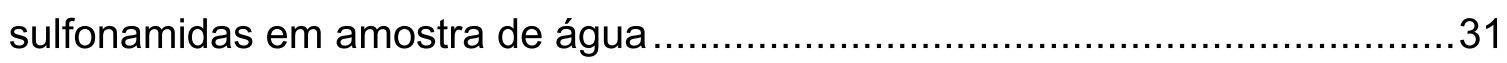

4.2.2. Microextração líquido-líquido (LLME-CS-LC-MS/MS) aplicada a

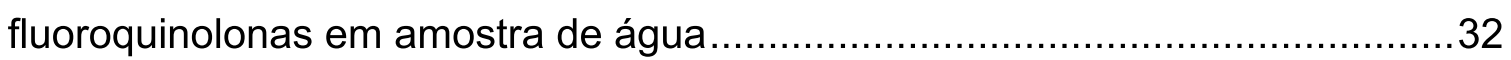

4.2.3. Microextração em gota suspensa (SDME-LC-MS/MS) para a determinação de sulfonamidas e fluoroquinolonas em amostra de água ............33

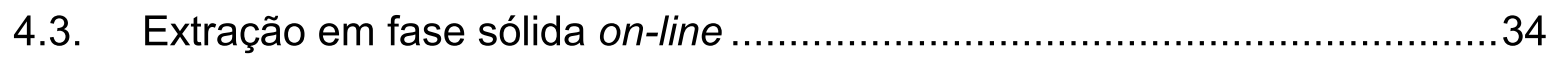

4.4. Métodos desenvolvidos de microextração liquído-líquido ............................35

4.4.1. Microextração líquido-líquido aplicada a sulfonamidas em amostras aquosas 35

4.4.2. Microextração líquido-líquido aplicada a fluoroquinolonas em amostras aquosas 36

4.4.3. Microextração em gota suspensa para a determinação de sulfonamidas

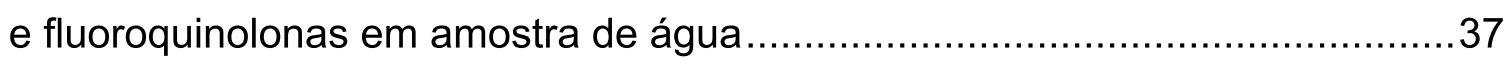


4.5.1. Microextração líquido-líquido aplicada a sulfas............................. 37

4.5.2. Microextração líquido-líquido aplicada a FQs ...............................40

4.5.3. Microextração em gota suspensa para a determinação de sulfas e FQs 41

5. RESULTADOS E DISCUSSÃO

5.1. Microextração líquido-líquido aplicada a sulfas.....................................41

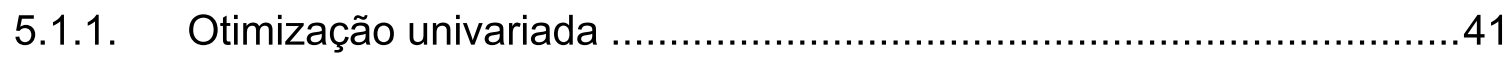

5.1.2. Validação do método desenvolvido ........................................44

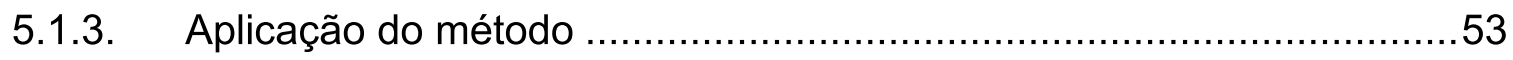

5.2. Microextração líquido-líquido aplicada a FQs ................................... 55

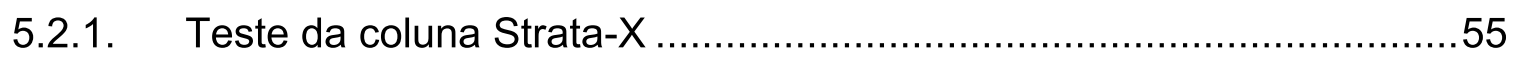

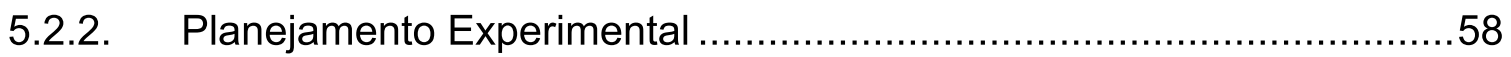

5.2.3. Validação do método desenvolvido .............................................68

5.2.4. Aplicação do Método ............................................................... 73

5.3. Microextração em gota suspensa (SDME-LC-MS/MS) para a determinação de sulfonamidas e fluoroquinolonas em amostra de água .............................77

5.3.1. Avaliação do melhor solvente de extração .....................................77

5.3.2. Automatização do método de microextração em gota suspensa.........78

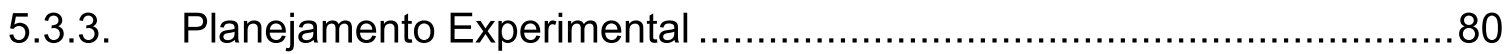

5.3.4. Validação do método desenvolvido ............................................. 84

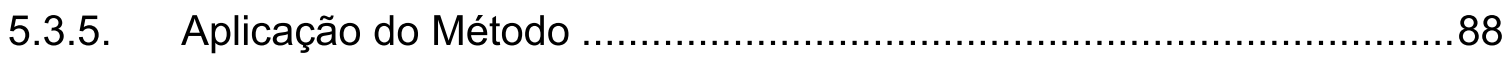

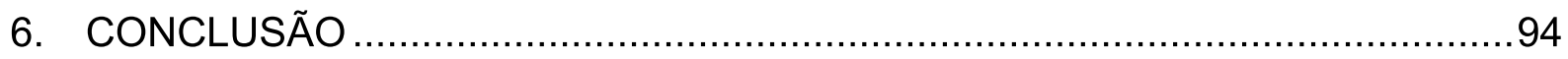




\section{INTRODUÇÃO E JUSTIFICATIVA}

São cada vez mais frequentes as notícias sobre poluição ambiental e principalmente fatos relacionados à contaminação da água, tais como, poluição por esgoto sanitário, resíduos industriais e agroquímicos. Portanto existe a preocupação quanto aos cuidados com os ecossistemas aquáticos e ao risco de contaminação das fontes de abastecimento público. Tal preocupação tem incentivado estudos com o intuito de identificar e quantificar esses compostos nocivos para que se possa minimizar o descarte e desenvolver processos eficientes para removê-los (1).

Os fármacos têm um papel de inquestionável relevância na sociedade. Segundo Kummerer (2) alguns grupos de fármacos residuais merecem uma atenção especial, dentre eles estão os antimicrobianos e os hormônios. Os antimicrobianos têm sido amplamente discutidos na literatura, devido ao seu potencial desenvolvimento de bactérias resistentes no meio ambiente e por serem usados em grandes quantidades $(3,4,5)$. Wise estimou um consumo mundial de antimicrobianos entre 100.000 e 200.000 toneladas por ano (6). Tanto o uso humano quanto animal faz com que essas substâncias cheguem ao meio ambiente de diversas maneiras, tornando estes compostos ubíquos na atualidade.

Na literatura são encontrados artigos e revisões que mostram a ineficiência dos tratamentos convencionais em remover os antimicrobianos, principalmente as classes das sulfonamidas e fluoroquinolonas $(7,8,9)$. Calisto e Esteves relataram que diversos métodos de tratamento tiveram eficiência muito baixa na remoção de alguns psicofármacos (7). Le-Minh et al. também relataram a ineficiência dos tratamentos convencionais na remoção dessas classes de antimicrobianos em amostras de águas residuárias (8). Tal situação tem incentivado a busca de métodos mais eficientes, capazes de promover ao menos a transformação desses contaminantes em produtos que não apresentem efeitos adversos ao ambiente (10). Geralmente as indústrias farmacêuticas utilizam processos aeróbios de tratamento, porém nem sempre com bons resultados no que se refere à degradação de antimicrobianos. Segundo revisão de Le-Minh et al. (8) a biotecnologia anaeróbia surge como alternativa potencial para degradação de fármacos devido à versatilidade e diversidade de bactérias e arqueias anaeróbias e facultativas. Além dessa versatilidade as estações de tratamento são mais simples e compactas comparando com as estações de tratamentos 
convencionais. Reatores biológicos têm demonstrado boa eficiência e viabilidade no tratamento de águas contendo contaminantes orgânicos diversos, sendo, portanto, uma tecnologia promissora para a degradação desses fármacos $(11,12,13)$.

Uma das maiores dificuldades nas análises de fármacos em matrizes ambientais tais como amostras aquosas ambientais, baseia-se na complexidade das amostras, sendo essa uma das razões da exigência de técnicas analíticas com resolução elevada e limites de quantificação extremamente baixos. Wu et al. (14) apresentaram várias vantagens no uso das técnicas miniaturizadas em comparação com as técnicas convencionais de preparo de amostra. Com a miniaturização consomem-se quantidades irrisórias de solventes e amostras, além de possibilitar-se a obtenção de maior fator de concentração e maior seletividade na extração de compostos de interesse. Como mostram Armenta, Farré e seus respectivos colaboradores a etapa de preparo de amostras e a análise cromatográfica miniaturizadas podem ser usadas vantajosamente em conjunto $(15,16)$.

Uma das técnicas de microextração mais utilizadas é a microextração líquidolíquido dispersiva (DLLME) que consiste no emprego de uma mistura de dois solventes, um de alta densidade (extrator) e um solvente polar miscível em água (dispersor) (17). Outra dessas técnicas são: (i) a microextração em fase líquida com fibras ocas (HF-LPME) que utiliza um solvente orgânico imobilizado nos poros da parede da fibra oca que funciona como suporte para a fase extratora (18); (ii) a extração por sorção em barra de agitação (SBSE) que tem sido aplicada com sucesso para extrair compostos orgânicos em diversas matrizes complexas (19); (iii) a extração por sorção nas paredes do frasco (VWSE) que recebeu essa nomenclatura em 2009, em um trabalho realizado por Kawaguchi et al. (20), e ampliou a área superficial da SBSE, contribuindo para aumentar a recuperação da extração (20). Por sua vez, a microextração líquido-líquido (LLME) é a miniaturização da tradicional técnica de extração líquido-líquido, que tem como vantagem o baixo consumo de amostra e solvente orgânico. A principal etapa nesta técnica é a seleção do solvente orgânico, de modo que algumas propriedades são necessárias para um solvente orgânico ser empregado em LLME, dentre elas: baixa solubilidade ou insolubilidade em água, prevenindo a dissolução da fase orgânica na aquosa (doadora). A adição de sais à matriz pode aumentar a eficiência da extração, particularmente para analitos mais polares, devido ao efeito denominado "salting-out". 
A cromatografia líquida capilar ( $C L C$ ) tem várias vantagens em relação a cromatografia líquida convencional, como baixo consumo de solventes, amostras e reagentes e pouca formação de resíduos. Além disso, oferece a possibilidade de atingir alta eficiência e sensibilidade fazendo uso de várias técnicas miniaturizadas de extração (21). Rosales-Conrado et al. (21) fizeram a comparação entre um HPLC convencional e um CLC para a análise de herbicidas em urina, foram introduzidas as mesmas quantidades de amostras e os limites de deteç̧ão (LD) atingidos com a técnica capilar foram de 1 a $6 \mu \mathrm{g} \mathrm{L}^{-1}$, enquanto com a técnica convencional foram de 30 e $75 \mu \mathrm{g} \mathrm{L}^{-1}$.

No intuito de analisar fármacos em matrizes complexas têm se destacado o desenvolvimento e a aplicação de técnicas miniaturizadas de preparo de amostras e separação cromatográfica. Diversas estratégias como o emprego de microextrações em fase líquida ou sólida e o uso de cromatografia capilar tem sido desenvolvidas para aplicação em águas residuárias, em concordância com a preconização da Química Analítica Verde. 


\section{REVISÃO BIBLIOGRÁFICA}

\subsection{Contaminantes em água}

O crescimento populacional acelerado e as transformações econômicas ocorridas nos últimos tempos alavancaram um grande desenvolvimento industrial e grandes avanços na ciência e tecnologia. A química tem tomado um papel muito importante nessa evolução tecnológica principalmente na elaboração de novos produtos e bens de consumo indispensáveis para humanidade. Porém, este grande crescimento não foi acompanhado de políticas de controle de resíduos, os quais muitas vezes são tóxicos e de difícil descarte.

$\mathrm{Na}$ indústria do ramo farmacêutico tem destacado mundialmente pela grande produção de medicamentos, produtos de higiene pessoal e cosméticos, desta maneira produzindo uma grande quantidade de resíduo. Os fármacos têm um papel de inquestionável relevância na sociedade, todavia, alguns grupos de fármacos residuais merecem uma atenção especial, dentre eles estão os antibióticos e os hormônios. A contaminação por antibióticos em ambientes aquáticos é de preocupação ecotoxicológica por causa da potencial alteração do ecossistema. A exposição prolongada a baixas concentrações de antibióticos pode causar a proliferação seletiva de bactérias resistentes, o que pode transferir os genes de resistência para outras espécies bacterianas (22). A preocupação com a contaminação de águas superficiais por antibióticos e outros compostos farmacêuticos tem sido relatado em estudos recentes $(23,24)$.

\subsection{Preparo de amostra}

O preparo de amostra evoluiu muito nos últimos anos com avanços significativos na instrumentação analítica, contudo o preparo de amostra ainda é uma das partes mais críticas em uma análise química. Um bom preparo de amostra consiste em remover potenciais interferentes, fazer 0 isolamento e préconcentração dos analitos de interesse para efetuar uma melhor detecção (25).

São vários os fatores que impedem uma análise cromatográfica adequada em amostras ambientais. Uma das maiores dificuldades nas análises de fármacos 
em matrizes ambientais tais como águas residuárias baseia-se na complexidade das amostras, sendo essa uma das razões da exigência de técnicas analíticas com resolução elevada e limites de quantificação extremamente baixos. O preparo de amostra exige uma série de etapas, limpeza de interferentes que atrapalham a detecção e pré-concentração; de maneira que, nos últimos anos, grandes esforços têm sido feitos para o desenvolvimento de novas técnicas de preparo de amostra que reduzam o tempo, trabalho, consumo de solvente e que permitam melhor desempenho analítico do processo.

Para obter um método eficiente de preparo de amostra a ser aplicado na análise de fármacos em amostras ambientais complexas, o método deve apresentar algumas características importantes entre elas, um único procedimento, a extração de uma grande variedade de analitos com propriedades distintas. O método desenvolvido deve atingir recuperação próximas a 100\%, ter a capacidade de remover os compostos interferentes da amostra, o método dever ser robusto, possuir boa precisão, exatidão e baixo custo do processo e para contribuir para Química Verde deve utilizar um baixo volume de solventes orgânicos $(15,26)$.

Uma das técnicas mais utilizadas para fazer preparo de amostra é a extração líquido-líquido (LLE), esta técnica consiste no uso de uma gama de solventes orgânicos em amostras aquosas, porém esta técnica é muito laboriosa e utiliza um grande volume de solventes orgânicos, que não contribui para a Química Verde. Wu et al. (14) apresentaram várias vantagens no uso das técnicas miniaturizadas em comparação com as técnicas convencionais de preparo de amostra. A miniaturização consome quantidades irrisórias de solventes e amostras, além de poder apresentar maior fator de concentração e maior seletividade na extração de compostos de interesse. Como mostra Armenta, Farré, e seus respectivos colaboradores a etapa de preparo de amostras e a análise cromatográfica miniaturizadas podem ser usadas vantajosamente em conjunto $(15,16)$.

Dentre as técnicas miniaturizadas de extração destaca-se a microextração líquido-líquido (LLME) que é a miniaturização da tradicional técnica de extração líquido-líquido, que tem como vantagem o baixo consumo de amostra e solvente orgânico (27). A microextração em gota suspensa (SDME) que é uma das 
configurações da técnica de microextração em fase líquida (LPME) e consiste em uma gota de solvente orgânico suspensa na ponta de uma agulha acoplado em uma seringa, esta técnica tem como principal vantagem o reduzido volume de solvente orgânico e a possibilidade de automação do processo de extração (2831).

\subsection{Estatística para química analítica}

\subsubsection{Testes de significância}

Uma das propriedades mais importantes de um método analítico é que idealmente ele deve ser isento de erros sistemáticos, isso é, o valor calculado pelo método deve ser igual ao valor real. Entretanto, erros aleatórios fazem com que o valor medido raramente seja exatamente igual ao valor real. Para decidir se a diferença entre o valor medido e o valor padrão pode ser atribuída a esses erros aleatórios, um teste estatístico, conhecido como teste de significância, pode ser empregado.

O teste $\mathrm{t}$ de Student é um teste de significância muito utilizado em química analítica. Quando se faz um teste de significância, na realidade testa-se se uma hipótese é verdadeira, essa hipótese é conhecida como hipótese nula. O termo nulo é utilizado para informar que não há diferença significativa entre o valor observado e o valor conhecido, considerando os erros aleatórios. Normalmente, rejeita-se a hipótese nula quando a diferença é considerada significativa no nível de significância de $95 \%$ (32). O teste $t$ que abrange a diferença entre duas médias em qualquer direção, ou seja, negativo ou positivo, é chamado teste t bicaudal. Este tipo de teste é o mais utilizado, pois o analista quase sempre não tem ideia, antes do experimento, se o valor encontrado será maior ou menor que o valor comparado (32).

Outro teste de significância muito utilizado em química analítica é o teste $\mathrm{F}$ que tem a função de comparar as variâncias (e, portanto, os desvios padrões), isto é, os erros aleatórios de dois conjuntos de dados. $O$ teste $F$ é definido como a razão entre as variâncias de dois conjuntos de dados. Se este valor de $\mathrm{F}$ for maior que o $\mathrm{F}$ tabelado os desvios padrões são significativamente diferentes, se o valor de $\mathrm{F}$ calculado for menor que o $\mathrm{F}$ tabelado os desvios padrões não possuem diferenças significativas (32). 


\subsubsection{Planejamento experimental}

Um dos problemas mais comuns para os químicos é determinar a influência de uma ou mais variáveis sobre uma outra variável de interesse. Considerando, por exemplo, uma síntese de ácido acetil salicílico (AAS) com o intuito de obter um melhor rendimento na reação variando a temperatura da reação e o catalisador utilizado. $\mathrm{Na}$ linguagem da estatística, o rendimento da reação é chamado de resposta e a temperatura e o catalizador são denominados de variáveis. Quando se deseja fazer um planejamento experimental primeiramente deve-se decidir quais são os fatores e as respostas de interesse. Os fatores são normalmente as variáveis que o experimentador tem condições de controlar, estes fatores podem ser qualitativos como por exemplo, catalizadores ou quantitativos como a temperatura. $O$ planejamento experimental que deve ser realizado vai depender do objetivo de cada experimentador, por esta razão deve-se ter consciência dos objetivos a serem atingidos, pois objetivos diferentes vão necessitar de planejamentos diferentes $(33,34)$.

Para começar um planejamento fatorial é necessário especificar os níveis em que cada fator deve ser avaliado. Para k fatores, ou seja, $\mathrm{k}$ variáveis controladas pelo analista, um planejamento fatorial completo de dois níveis exige a realização de $2 \times 2$ x $2 \ldots \times 2=2^{k}$ ensaios diferentes, denominado planejamento fatorial $2^{k}$. Em um planejamento com dois níveis costuma-se identificar os níveis superior e inferior com os sinais (+) e (-), respectivamente. No planejamento fatorial é importante avaliar o efeito principal de cada variável sobre o sistema, como mostra a equação 1.

$$
\begin{array}{ll}
\text { Efeito Principal }=\frac{\left(\bar{y}_{2}+\bar{y}_{4}\right)}{2}-\frac{\left(\bar{y}_{1}+\bar{y}_{3}\right)}{2} & \text { Equação } 1
\end{array}
$$

Onde $\bar{y}_{2}$ e $\bar{y}_{4}$ pertencem ao nível (+) e $\bar{y}_{1}$ e $\bar{y}_{3}$ pertencem ao nível (-) de cada variável estudada.

O valor do efeito referente a cada variável avaliada pode ser um valor positivo ou um valor negativo, o efeito positivo indica que quando se avalia a variável do nível baixo em relação ao nível alto observa-se um aumento na resposta, opostamente, uma diminuição nessa resposta implica em um efeito denominado negativo. 


\subsubsection{Modelo estatístico}

O modelo estatístico descreve as respostas de um planejamento fatorial em termos dos efeitos por unidade de variação dos fatores. Para um planejamento $2^{2}$ por exemplo, a resposta observada no nível $\left(\mathrm{x}_{1}, \mathrm{x}_{2}\right)$ é considerada como uma variável aleatória $\mathrm{y}\left(\mathrm{x}_{1}, \mathrm{x}_{2}\right)$. Essa variável se distribui em torno de uma certa média populacional $\eta\left(x_{1}, x_{2}\right)$, com uma certa variância populacional $\sigma^{2}\left(x_{1}, x_{2}\right)$. Podendo ser escrita como:

$$
y\left(x_{1}, x_{2}\right)=\eta\left(x_{1}, x_{2}\right)+\varepsilon\left(x_{1}, x_{2}\right) \quad \text { Equação } 2
$$

Onde $\varepsilon\left(x_{1}, x_{2}\right)$ representa o erro aleatório com que as respostas flutuam em torno da média populacional definida pelos valores de $x_{1}$ e $x_{2}$. Para um planejamento $2^{2}$ a expressão que melhor representa o modelo é:

$$
b_{0}+b_{1} x_{1}+b_{2} x_{2}+b_{12} x_{1} x_{2}
$$

Equação 3

Onde $\mathrm{B}_{0}$ é o valor populacional da média de todas as respostas do planejamento, $\mathrm{b}_{1}$, $b_{2}$ e $b_{12}$ são os valores populacionais dos dois efeitos principais e do efeito de interação, por unidade de $x_{1}$ e x2. Substituindo a equação 2 na equação 3 temos:

$$
y\left(x_{1}, x_{2}\right)=\beta_{0}+\beta_{1} x_{1}+\beta_{2} x_{2}+\beta_{12} x_{1} x_{2}+\varepsilon\left(x_{1}, x_{2}\right) \quad \text { Equação } 4
$$

Onde $\varepsilon\left(\mathrm{x}_{1}, \mathrm{x}_{2}\right)$ é o erro aleatório associado à resposta $\mathrm{y}\left(\mathrm{x}_{1}, \mathrm{x}_{2}\right)$.

No tratamento dos dados do planejamento experimental é importante analisar os resíduos do modelo, ou seja, a diferença entre os valores observados e os valores previstos pelo modelo e verificar se estes resíduos possuem algum tipo de tendência ou são distribuídos aleatoriamente.

\subsubsection{Método de superfícies de resposta}

O método de superfícies de resposta (ou RSM, de Response Surface Methodology) é baseado em uma técnica de otimização por meio de planejamentos fatoriais que foi introduzida por G.E.P. Box nos anos cinquenta. As superfícies de respostas são utilizadas quando as variáveis de resposta são influenciadas por muitas variáveis independentes e o objetivo é otimizar essas respostas. Considerando por exemplo, a maximização do rendimento de uma determinada síntese que seja função de dois fatores, $x_{1}$ e $x_{2}(32)$.

$$
y=f\left(x_{1}, x_{2}\right)+\varepsilon
$$

Equação 5 
Sendo $\varepsilon$, o erro observado ou ruído na resposta y. A superfície que representa a equação 5 é chamada de superfície de resposta.

A primeira etapa no uso do método de superfície de resposta é determinar a relação matemática entre a resposta e as variáveis. Primeiramente deve-se supor que essa relação seja simples como uma reta, chamado de modelo de primeira ordem:

$$
y=\beta_{0}+\beta_{1} x_{1}+\beta_{2} x_{2}+\ldots+\beta_{k} x_{k}+\varepsilon \quad \text { Equação } 6
$$

Se o modelo de primeira ordem não for corresponder com a superfície obtida, então é necessário um modelo de segunda ordem ou quadrático (Equação 7)

$$
y\left(x_{1}, x_{2}\right)=\beta_{0}+\beta_{1} x_{1}+\beta_{2} x_{2}+\beta_{11} x_{1}^{2}+\beta_{22} x_{2}^{2}+\beta_{12} x_{1} x_{2}+\varepsilon \quad \text { Equação } 7
$$

O procedimento de uso de superfícies de resposta é sequencial, isto é, quando o ponto ótimo de resposta está distante de ser obtido, o modelo de primeira ordem ajusta bem os dados atuais. No entanto o objetivo de utilizar superfícies de resposta é encontrar o ponto ótimo para o experimento, portanto uma vez que o modelo quadrático ajusta bem seus dados, este modelo deve ser adotado. Para determinar o ponto ótimo de resposta para o planejamento é necessário utilizar o planejamento composto central, planejamento que possui um ponto central, onde idealmente o modelo indique-o como ponto ótimo para a resposta. Porém para utilizar-se de um modelo quadrático, o qual possui seis parâmetros, não há como usar-se o planejamento descrito acima, pois este possui apenas cinco "níveis", ou seja, cinco combinações possíveis entre as duas variáveis, sendo dois altos, dois baixos e o ponto central. A ampliação deste planejamento pode ser feita de várias maneiras, porém a mais utilizada é a construção do chamado planejamento em estrela.

Para ser feito um planejamento do tipo estrela é necessário apenas acrescentar ao planejamento inicial um planejamento idêntico, porém girado de $45^{\circ}$ em relação à orientação de partida. Para o caso de duas variáveis, usualmente sugere-se que estes novos pontos estejam a uma distância de $\sqrt{2}$ unidade codificada do ponto central. Portanto, um planejamento do tipo estrela com ponto central, para 2 variáveis, possui os seguintes níveis: $-\sqrt{2},-1,0,+1,+\sqrt{2}$ e nove possíveis combinações entre as variáveis $\mathrm{x}_{1}$ e $\mathrm{x}_{2}$. 


\subsection{Sulfonamidas e fluoroquinolonas}

Com relação à escolha das classes de antibióticos para esta tese, as sulfonamidas estão entre as mais prevalentes no ambiente, tanto por causa de um consumo elevado quanto por sua baixa degradação ambiental (35). Por sua vez, as fluoroquinolonas também são bastante encontradas e estão relacionadas a genotoxicidade em concentrações tipicamente encontradas em efluentes hospitalares $(36,37)$. Não obstante, Le-Minh et al. apresentam uma boa degradação de antibiótico da classe das sulfonamidas em processos anaeróbicos em fluxo e a possibilidade das fluoroquinolonas serem removidas por processos adsortivos sobre a biomassa dos reatores biológicos $(8,38)$.

As classes das sulfonamidas e fluoroquinolonas possuem compostos dentre os antimicrobianos veterinários mais comumente usados (39). Estas duas classes atuam contra um vasto espectro de bactérias gram-positivas e gram-negativas, além de possuírem propriedades antifúngicas, antiprotozoárias e herbicidas quando utilizadas em associação com outros fármacos (40). As sulfonamidas são amidas derivadas de ácidos sulfônicos ligados a um grupamento amino aromático com uma grande variedade de radicais, o que possibilita que a classe possua um amplo espectro de ação.

As quinolonas surgiram, acidentalmente, como produto secundário da síntese de um agente antimalárico, de atividade antibacteriana conhecida e comprovada, a cloroquina. A substância foi descoberta no ano de 1962 por George Lesher e colaboradores em uma destilação, durante a síntese de cloroquina. Esse produto secundário revelou possuir também atividade antimicrobiana, surgindo assim a primeira quinolona: o ácido nalidíxico (41).

Devido ao uso excessivo destes antimicrobianos, tanto na medicina humana como na veterinária, o problema de contaminação do meio ambiente é de grande preocupação. Desta maneira métodos que consigam extrair e detectar em concentrações baixas e em consonância com a química verde, ou seja com uso de pequenas quantidades de solventes orgânicos $(25,42,43)$. 


\section{OBJETIVOS}

Esta tese tem como objetivo avaliar diferentes técnicas miniaturizadas de preparo de amostras aquosas complexas com o intuito de extrair e detectar duas classes de antimicrobianos (sulfonamidas e fluoroquinolonas). A técnica de microextração avaliada foi a microextração líquido-líquido (LLME) em diferentes vertentes e associada à análise por cromatografia líquida hifenada à espectrometria de massas.

\subsection{Objetivos específicos}

- Desenvolver métodos baseados na técnica de microextração líquido-líquido para análise das sulfonamidas (sulfacloropiridina, sulfametazina, sulfametizol, sulfamerazina, sulfatiazol, sulfametoxazol, sulfadiazina, sulfacetamida) e das fluoroquinolonas (ofloxacina, enrofloxacina, pefloxacina, ciprofloxacina, norfloxacina) separadamente e para finalizar desenvolver um método para analise simultânea das duas classes de antimicrobianos;

- Otimizar os métodos de microextração utilizando planejamento experimental;

- Validação dos métodos avaliando parâmetros como seletividade, linearidade, precisão, exatidão, robustez, limite de detecção, limite de quantificação e recuperação em amostras aquosas. 


\section{MATERIAIS E MÉTODOS}

\subsection{Padrões analíticos, solventes e reagentes}

A estrutura de todos os compostos utilizados neste trabalho e suas principais propriedades físico-químicas são apresentadas na Tabela 1,0 pKa1 refere-se à protonação do grupamento amina ligado ao grupamento benzênico, enquanto o pKa2 refere-se à desprotonação da amida sulfônica. Foi utilizado como padrão interno para as sulfonamidas os compostos isotopicamente marcados sulfametoxazol-(fenil-13 ${ }^{13} \mathrm{C}_{6}$ ) e para as fluoroquinolonas a norfloxaxina- $\mathrm{d}_{5}$ uma vez que sua presença no ambiente é desprezível se comparado com sua forma mais abundante. As soluções-estoque de cada analito foram preparadas pela diluição dos padrões analíticos em $\mathrm{ACN}$ contendo $0,1 \%$ de ácido fosfórico $(\mathrm{v} / \mathrm{v})$, de modo que ficassem em concentrações próximas a $1,0 \mathrm{mg} \mathrm{mL}^{-1}$ e pudessem ser mantidas a $-4^{\circ} \mathrm{C}$ durante todo o estudo. Para diminuir o manuseio das soluções-estoque foram feitas soluções intermediárias a partir das primeiras e então mantidas sob refrigeração. Os frascos utilizados para armazenamento das soluções-estoque eram de alta qualidade. Os solventes utilizados (acetonitrila, metanol, acetato de etila e diclorometano) foram adquiridos da Tedia (grau HPLC). O ácido fórmico utilizado para as soluções estoques foi adquirido da Synth.

Tabela 1 - Propriedades das sulfonamidas utilizadas neste trabalho.

\begin{tabular}{|c|c|c|c|c|}
\hline Analito & Estrutura & $\begin{array}{l}\text { Massa } \\
\text { Molecular } \\
\left(\mathrm{g} \mathrm{mol}^{-1}\right)\end{array}$ & pKa & $\begin{array}{l}\text { Log } \\
P\end{array}$ \\
\hline $\begin{array}{l}\text { Sulfacetamida } \\
\text { (SCT) }\end{array}$ & 11 & 214,2 & $\begin{array}{l}\mathrm{pK}_{\mathrm{a} 1}=1,8 \\
\mathrm{pK}_{\mathrm{a} 2}=5,3\end{array}$ & $-1,0$ \\
\hline $\begin{array}{l}\text { Sulfadiazina } \\
\text { (SDZ) }\end{array}$ & & 250,3 & $\begin{array}{l}\mathrm{pK}_{\mathrm{a} 1}=2,1 \\
\mathrm{pK}_{\mathrm{a} 2}=6,5\end{array}$ & $-1,30$ \\
\hline $\begin{array}{l}\text { Sulfametoxazol } \\
(\mathrm{SMX})\end{array}$ & $\mathrm{H} N$ & & $\begin{array}{l}\mathrm{pK}_{\mathrm{a} 1}=2,0 \\
\mathrm{pK}_{\mathrm{a} 2}=5,6\end{array}$ & 0,90 \\
\hline $\begin{array}{l}\text { Sulfatiazol } \\
\text { (STZ) }\end{array}$ & & 255,3 & $\begin{array}{l}\mathrm{pK}_{\mathrm{a} 1}=2,0 \\
\mathrm{pK}_{\mathrm{a} 2}=5,5\end{array}$ & $-0,40$ \\
\hline
\end{tabular}




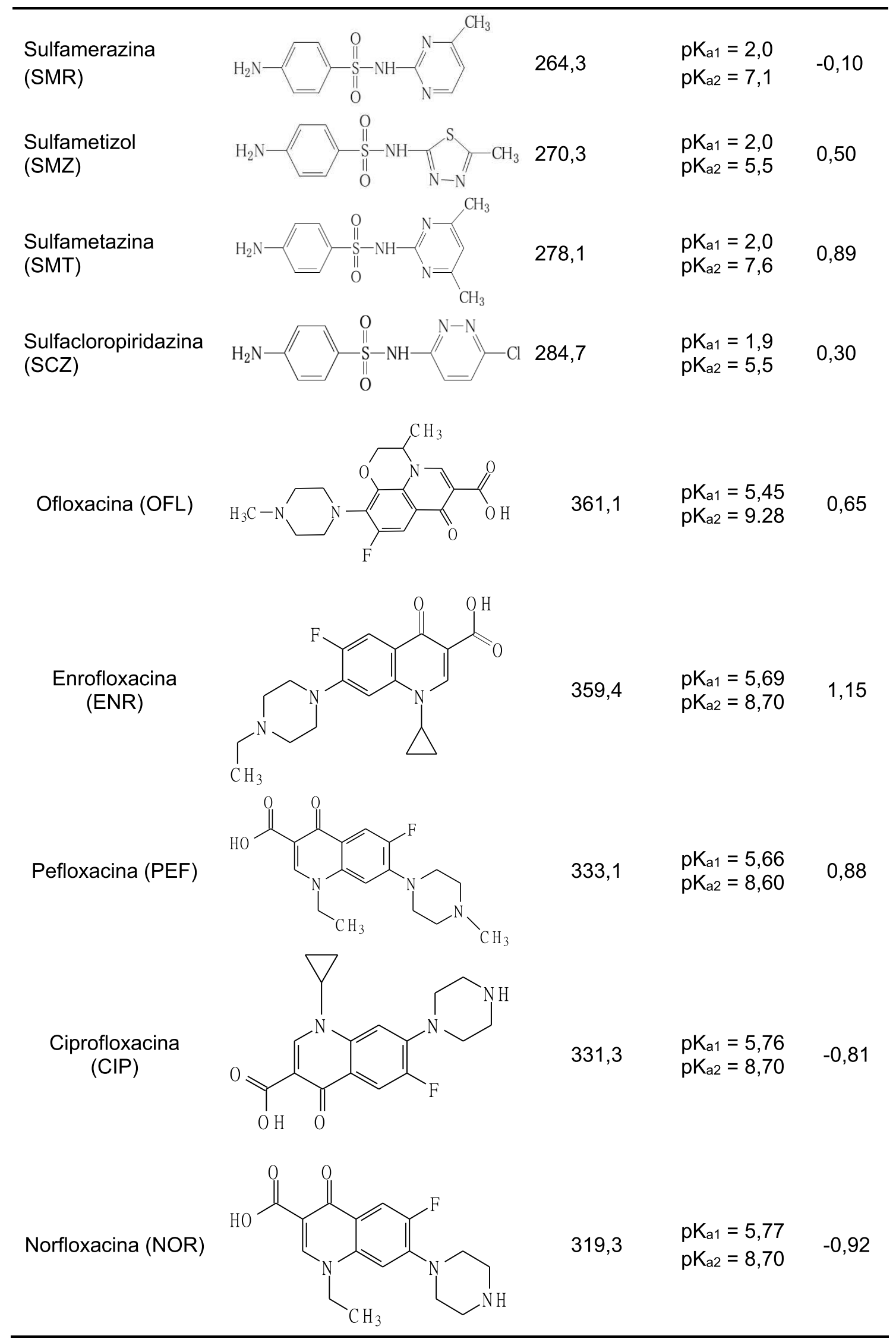

Fonte: (http://www.chemicalize.org/) 


\subsection{Condições das separações cromatográficas}

\subsubsection{Microextração líquido-líquido (LLME-CS-cLC-MS) aplicada a sulfonamidas em amostra de água}

O sistema de cromatografia online em "column-switching" constituiu-se de um UHPLC Thermo/Dionex RSLC nano com bomba binária de alta pressão para escala nano/capilar/micro, bomba de carregamento ternária de baixa pressão, bomba UHPLC analítica, forno para colunas com válvulas para comutação entre colunas, injetor automático e detector espectrométrico de massas Micromass modelo Platform LC. O esquema do sistema cromatográfico é demonstrado na Figura 1, o loop de injeção utilizado foi de $60 \mu \mathrm{L}$.

Figura 1: Representação esquemática do sistema cromatográfico com column-switching.
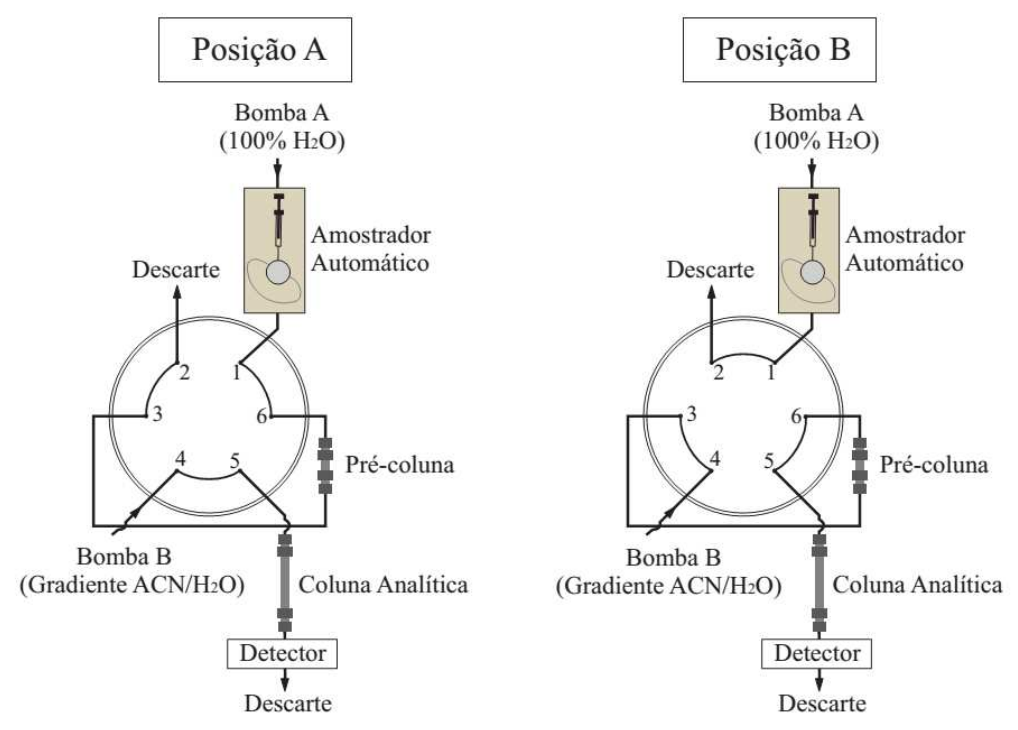

Inicialmente, o sistema era mantido na posição A, na qual a amostra (60 $\mu \mathrm{L})$ era conduzida pela bomba de carregamento (Bomba $A$, apenas com água) com fluxo de $60 \mu \mathrm{L} \mathrm{min}{ }^{-1}$ para a coluna de extração, na qual os analitos ficaram retidos, enquanto a Bomba Cromatográfica (Bomba B) permanecia condicionando a coluna. Depois de 4 min, a válvula era mudada para a posição $B$, no qual os analitos eram conduzidos para a separação cromatográfica pela Bomba B com fluxo de $9 \mu \mathrm{L} \mathrm{min}{ }^{-1}$, enquanto o solvente da bomba A era direcionado para o descarte. Após 12 min da injeção, a válvula voltava para a posição $A$, condicionando assim a coluna de extração para uma 
nova injeção. A coluna cromatográfica utilizada foi uma C18 com partículas de $2 \mu \mathrm{m}$, diâmetro interno de $300 \mu \mathrm{m}$ e $15 \mathrm{~cm}$ de comprimento. A fase extratora utilizada na coluna de extração foi a Strata-X (Figura 2) fase polimérica da empresa Phenomenex, que possui partículas de $33 \mu \mathrm{m}$ de diâmetro e uma área superficial específica de 800 $\mathrm{m}^{2} \mathrm{~g}^{-1}$

Figura 2: Monômero do polímero da fase extratora Strata-X.

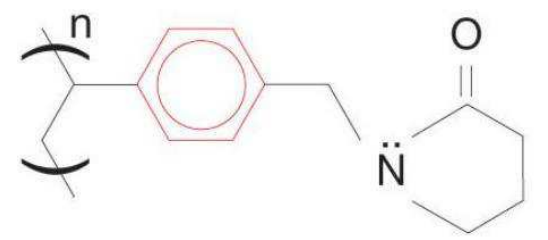

\subsubsection{Microextração líquido-líquido (LLME-CS-LC-MS/MS) aplicada a fluoroquinolonas em amostra de água}

As análises foram realizadas em um sistema LC-ESI-QTRAPTM/MS compreendido por HPLC Agilent série 1260 e espectrômetro de massas AB Sciex 5500QTRAP ${ }^{\mathrm{TM}}$ com fonte TurbolonSpray e coluna analítica Poroshell 120 EC-C18 (2,1 x $100 \mathrm{~mm} ; 2,7 \mu \mathrm{m})$ da Agilent Technologies. Nessas análises empregou-se a fonte de ionização à pressão atmosférica (API) no modo electrospray positivo (ESI+). Os parâmetros da fonte foram: gás de cortina (nitrogênio) 20 psi; temperatura da fonte $650{ }^{\circ} \mathrm{C}$; voltagem do electrospray $5500 \mathrm{~V}$; gás de aquecimento e gás nebulizador (ambos nitrogênio) 50 psi; e o potencial de entrada (EP, do inglês "entrance potential") $10 \mathrm{~V}$. Todos os dados foram adquiridos e processados utilizando o software Analyst 1.5.1. Na Tabela 2 são apresentados os parâmetros de energia de colisão (CE, do inglês "collision cell"), o potencial de orifício (DP, do inglês "declustering potential"), o potencial de saída da cela de colisão (CXP, do inglês "collision cell exit potential"), e os fragmentos selecionados, no sistema LC-ESI-QTRAPTM/MS para análise de cada um dos antimicrobianos e do padrão interno (IS, do inglês "internal standard"), com os valores de tempo de retenção (tr) correspondentes. 
Tabela 2 - Parâmetros utilizados para análise das fluoroquinolonas por LC-ESI-QTRAP/MS no modo de ionização ESI+.

\begin{tabular}{ccccccc}
\hline FQs & $\begin{array}{c}\text { Íon } \\
\text { Precursor } \\
(\mathbf{m} / \mathbf{z})\end{array}$ & $\begin{array}{c}\text { Íon } \\
\text { Produto } \\
(\mathbf{m} / \mathbf{z})\end{array}$ & $\operatorname{tr}(\mathbf{m i n})$ & DP $(\mathbf{V})$ & CE $(\mathbf{V})$ & CXP (V) \\
\hline NOR & 320 & 302 & 5,9 & 66 & 29 & 14 \\
NOR & 320 & 276 & 5,9 & 66 & 23 & 14 \\
NOR & 320 & 233 & 5,9 & 66 & 29 & 14 \\
\hline CIP & 332 & 288 & 5,9 & 96 & 25 & 25 \\
CIP & 332 & 245 & 5,9 & 31 & 27 & 14 \\
CIP & 332 & 231 & 5,9 & 96 & 49 & 16 \\
\hline ENRO & 360 & 316 & 5,9 & 81 & 37 & 12 \\
ENRO & 360 & 245 & 5,9 & 81 & 47 & 9 \\
ENRO & 360 & 286 & 5,9 & 81 & 47 & 12 \\
\hline NOR-D5 & 325 & 281 & 5,9 & 101 & 25 & 14 \\
NOR-D5 & 325 & 238 & 5,9 & 101 & 25 & 14 \\
\hline OFLO & 362 & 318 & 5,9 & 71 & 15 & 14 \\
OFLO & 362 & 261 & 5,9 & 71 & 21 & 12 \\
\hline PEF & 334 & 233 & 5,9 & 61 & 35 & 12 \\
PEF & 334 & 205 & 5,9 & 61 & 47 & 8 \\
PEF & 334 & 290 & 5,9 & 61 & 25 & 14 \\
\hline
\end{tabular}

4.2.3. Microextração em gota suspensa (SDME-LC-MS/MS) para a determinação de sulfonamidas e fluoroquinolonas em amostra de água

As análises foram realizadas em um sistema HPLC-MS/MS configurado em um equipamento Acquity Ultra Performance LC (Waters) acoplado ao espectrômetro de massas Xevo TQ MS Detector (Waters) com ionização à pressão atmosférica por electrospray (ESI) e coluna analítica Poroshell 120 EC-C18 $(2,1$ x $100 \mathrm{~mm}$ x; 2,7 $\mu \mathrm{m})$ da Agilent Technologies. As condições do ESI foram as seguintes: voltagem do capilar, $3,5 \mathrm{kV}$; cone, $10 \mathrm{~V}$; extrator, $3 \mathrm{~V}$; temperatura da fonte, $150^{\circ} \mathrm{C}$; temperatura de dessolvatação, $400^{\circ} \mathrm{C}$; vazão do gás de solvatação (gás $=\mathrm{N}_{2}$ ), $800 \mathrm{~L} \mathrm{~h}^{-1}$; modo de ionização, ESI positivo como mostra a Tabela 3. 
Tabela 3 - Parâmetros utilizados para análise das FQs e Sulfas por LC-ESI-MS/MS no modo de ionização ESI+.

\begin{tabular}{cccccc}
\hline Analitos & $\begin{array}{c}\text { Íon } \\
\text { Precursor } \\
(\mathbf{m} / \mathbf{z})\end{array}$ & $\begin{array}{c}\text { Íon Produto } \\
(\mathbf{m} / \mathbf{z})\end{array}$ & Dwell (s) & CXP (V) & CE (V) \\
\hline OFLO & 362 & 318 & 0,030 & 20 & 26 \\
OFLO & 362 & 261 & 0,030 & 20 & 22 \\
\hline PEF & 334 & 290 & 0,030 & 24 & 28 \\
PEF & 334 & 233 & 0,030 & 24 & 26 \\
\hline ENR & 360 & 316 & 0,030 & 26 & 28 \\
ENR & 360 & 245 & 0,030 & 26 & 24 \\
\hline CIP & 332 & 288 & 0,030 & 24 & 26 \\
CIP & 332 & 245 & 0,030 & 24 & 24 \\
\hline SMX & 254 & 156 & 0,030 & 26 & 26 \\
SMX & 254 & 92 & 0,030 & 26 & 24 \\
\hline SDMX & 311 & 156 & 0,030 & 30 & 34 \\
SDMX & 311 & 92 & 0,030 & 30 & 30 \\
\hline
\end{tabular}

\subsection{Extração em fase sólida on-line}

Para a microextração das sulfonamidas a coluna extratora utilizada foi preparada utilizando tubos de aço inox com 500 ID $\mu \mathrm{m}$ e 1/16' de diâmetro externo. Telas de aço inoxidável com 1/16' de diâmetro e com poros de $10 \mu \mathrm{m}$ foram adicionadas às extremidades da coluna empacotada para reter a fase estacionária. Uma bomba Shimadzu Prominence $20 \mathrm{~A}$ (Shimadzu, Japão) usou MeOH como solvente de arraste para o preenchimento do tubo da coluna com a fase estacionária (empacotamento). As suspensões foram feitas com MeOH/água (1:10), para proporcionar a melhor suspensão das partículas do sorvente comercial Strata-X. O preenchimento foi feito utilizando uma vazão de $1,0 \mathrm{~mL} \mathrm{~min}^{-1}$ por 20 minutos, até que a estabilização da pressão da bomba.

O procedimento para o preparo da coluna de SPE online para extração das fluoroquinolonas (FQs) foi o mesmo usado para as sulfonamidas, porém como o sistema cromatográfico usado foi um sistema convencional, o tubo de aço inox utilizado foi de $2,1 \mathrm{~mm}$ de d.i $x 40 \mathrm{~mm}$. A fase utilizada para o preenchimento da coluna 
também foi Strata-X. O preenchimento foi feito utilizando uma vazão de 1,0 $\mathrm{mL} \mathrm{min}^{-1}$ por 20 minutos, até a estabilização da pressão da bomba.

Para a microextração em gota suspensa das sulfonamidas e fluoroquinolonas simultaneamente não foi utilizado coluna de extração pela dificuldade de acoplamento com o cromatógrafo. Neste caso foi injetado o extrato contendo os analitos diretamente na coluna analítica.

\subsection{Métodos desenvolvidos de microextração liquído-líquido}

\subsubsection{Microextração líquido-líquido aplicada a sulfonamidas em amostras aquosas}

Os métodos desenvolvidos e validados neste trabalho utilizaram como amostras esgoto labmade, o qual foi preparado visando mimetizar o ambiente complexo em que os compostos de interesse estão presentes (44). Ele é composto por carboidratos (como a sacarose, o amido e a celulose), proteínas (extrato de carne) e lipídeos, além de sais de sódio, magnésio e cálcio, conforme mostrado na Tabela 4. As amostras foram filtradas antes de cada extração utilizando membrana de celulose com $0,22 \mu \mathrm{m}$.

Tabela 4 - Composição do esgoto labmade utilizado neste trabalho (44).

\begin{tabular}{cc}
\hline Composto & Quantidade para 1 litro de água \\
\hline Sacarose & $35 \mathrm{mg}$ \\
Amido & $114 \mathrm{mg}$ \\
Celulose & $34 \mathrm{mg}$ \\
Extrato de carne & $208 \mathrm{mg}$ \\
Óleo de soja & $51 \mathrm{mg}$ \\
$\mathrm{NaHCO}$ & $200 \mathrm{mg}$ \\
Detergente doméstico & $3 \mathrm{~mL}$ \\
$\mathrm{NaCl}$ & $250 \mathrm{mg}$ \\
$\mathrm{MgCl}_{2} \cdot 6 \mathrm{H}_{2} \mathrm{O}$ & $7 \mathrm{mg}$ \\
$\mathrm{CaCl}_{2} \cdot 2 \mathrm{H}_{2} \mathrm{O}$ & $4,5 \mathrm{mg}$ \\
\hline
\end{tabular}

Para a extração das sulfonamidas, a etapa de LLME foi realizada usando uma seringa de vidro de $10 \mathrm{~mL}$ com um tubo de vidro adaptado para fazer a coleta da fase orgânica como mostra a figura 3. 
Figura 3: Seringa de vidro com adaptação na ponta para fazer a extração.

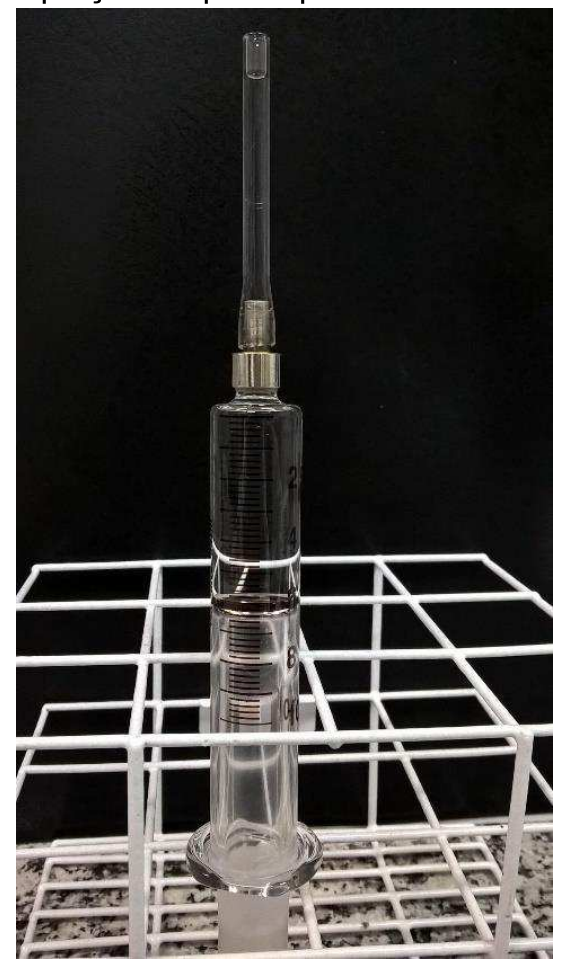

Sete mililitros $(7,0 \mathrm{~mL})$ de esgoto labmade (fase doadora) foram utilizados com $1,0 \mathrm{~mL}$ de acetato de etila (fase receptora) e 2,0 mol L-1 de $\mathrm{Na}_{2} \mathrm{SO}_{4}$ (salting-out), sob 2 min de agitação manual. A fase orgânica foi coletada, feita a secagem em $\mathrm{N}_{2}$, ressuspendida em água acidificada e injetada no sistema CLC-CS-MS. Como detector foi utilizado um espectrômetro de massas Micromass modelo Platform LC. Foi utilizado um método univariado para otimizar esta extração, variando-se o solvente orgânico de extração, o volume deste solvente e a concentração de sulfato de sódio.

\subsubsection{Microextração líquido-líquido aplicada a fluoroquinolonas em amostras aquosas}

Os métodos desenvolvidos e validados neste trabalho utilizaram como amostras, esgoto labmade, que foi preparado visando mimetizar o ambiente complexo em que compostos de interesse estão presentes (44). Ele é composto por carboidratos (como a sacarose, o amido e a celulose), proteínas (extrato de carne) e lipídeos, além 
de sais de sódio, magnésio e cálcio, como foi descrito na seção 3.2 .4 do capítulo anterior.

Para extração das fluoroquinolonas na etapa de LLME testou-se o melhor solvente para a extração. Após a escolha deste solvente foi utilizada uma otimização multivariada, sendo um planejamento experimental $2^{3}$ para direcionar a otimização e no final um planejamento composto central do tipo $2^{2}$ com estrela para refinar a otimização, variando o tempo de agitação e concentração de sulfato de sódio. Para os cálculos estatísticos foram utilizados os softwares Microsoft Office Excel 2013, Matlab R2013a e Statistica 10.0.

\subsubsection{Microextração em gota suspensa para a determinação de sulfonamidas e fluoroquinolonas em amostra de água}

Os métodos desenvolvidos e validados neste trabalho utilizaram uma matriz isenta de analitos, que foi preparado visando mimetizar o ambiente complexo em que compostos de interesse estão presentes (44). Ele é composto por carboidratos (como a sacarose, o amido e a celulose), proteínas (extrato de carne) e lipídeos, além de sais de sódio, magnésio e cálcio, como foi descrito no item 3.2.4 do capítulo 3 desta tese.

Para extração das sulfonamidas e fluoroquinolonas na etapa de SDME testouse o melhor solvente para a extração. Após a escolha deste solvente foi utilizada uma otimização multivariada, sendo um planejamento experimental $2^{2}$ tipo estrela para fazer a otimização, variando a quantidade de ciclos para formação da gota e o tempo de exposição da gota na amostra. Para os cálculos estatísticos foram utilizados os softwares Microsoft Office Excel 2013, Matlab R2013a e Statistica 10.0.

\subsection{Validação dos métodos}

\subsubsection{Microextração líquido-líquido aplicada a sulfas}

A validação de um método analítico tem a finalidade de demonstrar que este método é aceitável para a finalidade pretendida (45). Os seguintes parâmetros foram 
avaliados na validação do método: seletividade, sensibilidade, linearidade, precisão e exatidão intra e inter-dias, recuperação, limite de detecção e quantificação, reprodutibilidade intralaboratorial, efeito matriz, interferentes, efeito da diluição da amostra e robustez $(46,47)$.

A seletividade é a demonstração da capacidade do método em detectar/quantificar apenas os compostos de interesse mesmo na presença de outros componentes, como interferentes e produtos de degradação. O método é dito seletivo quando tais interferentes não são detectados no mesmo tempo de retenção do analito e/ou não são extraídos apropriadamente pelo método de preparo de amostra. A seletividade foi avaliada pela contaminação da matriz (isenta dos analitos) com alguns compostos amplamente utilizados (ibuprofeno e cafeína) e de maior potencialidade de interferência na análise das sulfonamidas ambos com concentração de $30,0 \mathrm{ng} \mathrm{mL}^{-1}$.

A linearidade do método LLME-CS-cLC-MS foi avaliada por meio de uma curva analítica construída em matriz livre de analito fortificadas em oito níveis de concentrações $\left(0,5 ; 1,0 ; 2,0 ; 5,0 ; 10,0 ; 20,0 ; 30,0\right.$ e $\left.40,0 \mathrm{ng} \mathrm{mL}^{-1}\right)$ com quintuplicatas em cada nível totalizando um $n=40$; exceto para as sulfonamidas: sulfatiazol, sulfacloropiridina, sulfametazina, em que as curvas foram feitas em sete níveis totalizando um $n=35$. O limite de detecção (LD) e o limite de quantificação (LQ) são estabelecidos a partir da concentração do analito que produz um pico com 3 e 10 vezes a amplitude do ruído, respectivamente na região de eluição do pico.

A precisão intra-dia foi avaliada em quintuplicatas em três níveis diferentes 5 $\mathrm{ng} \mathrm{mL} \mathrm{m}^{-1}$ (baixo), $30 \mathrm{ng} \mathrm{mL}^{-1}$ (médio) e $40 \mathrm{ng} \mathrm{mL}^{-1}$ (alto), e a precisão inter-dias foi avaliada com os resultados em dias diferentes. Os resultados destes ensaios foram expressos em desvio padrão relativo percentual (DPR\%), em relação à média. Similarmente ao ensaio de precisão, foi calculada a exatidão do método inter-dias nos mesmos níveis.

A reprodutibilidade intralaboratorial foi realizada em quintuplicatas para os três níveis anteriormente citados. O primeiro conjunto de amostras foram fortificadas nas condições padrões do método. O segundo conjunto foi realizado por outro analista e o terceiro conjunto alterando a temperatura da sala do equipamento.

Foram determinados também o efeito de matriz, a recuperação e a eficiência total do método nos três níveis (baixo, médio e alto). Este estudo foi realizado de acordo com o trabalho de Matuszewski $(48,49)$. Os valores de efeito de matriz foram 
calculados a partir da razão das áreas absolutas do extrato pós-fortificado e as áreas absolutas em água. A recuperação foi avaliada fazendo a razão entre os valores de áreas absolutas no extrato fortificado antes da extração e as áreas no extrato pósfortificado. Na eficiência total do processo foi avaliada a razão entre as áreas absolutas em água e no extrato fortificado antes da extração, esse estudo leva em consideração a recuperação e o efeito de matriz.

A robustez do método foi avaliada por meio do teste de Youden que possui um planejamento fatorial fracionário no qual se avalia a influência de sete variáveis em dois níveis diferentes, como mostra a Tabela 5 (50,51). As letras maiúsculas representam os valores nominais ou padronizados pelo método desenvolvido e as letras minúsculas as variações a serem estudadas. Foram realizados oito experimentos de forma aleatória com a combinação fatorial dos parâmetros avaliados. Em seguida, verificou-se quais os efeitos que influenciaram no resultado final (Tabela $6)$.

Tabela 5 - Fatores avaliados na robustez do método.

\begin{tabular}{ccccc}
\hline Parâmetros & \multicolumn{2}{c}{ Condição } \\
Nominal & \multicolumn{2}{c}{ Variação } \\
\hline Temperatura do Forno $\left({ }^{\circ} \mathrm{C}\right)$ & 40 & $\mathrm{~A}$ & 38 & $\mathrm{a}$ \\
Vazão da Bomba Analítica $(\mu \mathrm{L} / \mathrm{min})$ & 9 & $\mathrm{~B}$ & 9,2 & $\mathrm{~b}$ \\
Vazão da Bomba de Carregamento $(\mu \mathrm{L} / \mathrm{min})$ & 60 & $\mathrm{C}$ & 58 & $\mathrm{C}$ \\
Concentração de Ácido Fórmico na Fase Móvel $(\%)$ & 0,10 & $\mathrm{D}$ & 0,15 & $\mathrm{~d}$ \\
Tempo de Agitação na Extração LLME $(\mathrm{min})$ & 2 & $\mathrm{E}$ & 2,2 & $\mathrm{e}$ \\
Concentração de Ácido Fórmico na Água de Carregamento $(\%)$ & 0,10 & $\mathrm{~F}$ & 0,15 & $\mathrm{f}$ \\
Temperatura da Fonte de lonização do MS $\left({ }^{\circ} \mathrm{C}\right)$ & 70 & $\mathrm{G}$ & 68 & $\mathrm{~g}$ \\
\hline
\end{tabular}

Tabela 6 - Matriz de Youden.

\begin{tabular}{|c|c|c|c|c|c|c|c|c|}
\hline \multicolumn{9}{|c|}{ Combinação Fatorial } \\
\hline Efeito & Exp. 1 & Exp. 2 & Exp. 3 & Exp. 4 & Exp. 5 & Exp. 6 & Exp. 7 & Exp. 8 \\
\hline $\mathrm{A} / \mathrm{a}$ & A & A & $A$ & $A$ & a & a & a & a \\
\hline $\mathrm{B} / \mathrm{b}$ & B & B & $b$ & $\mathrm{~b}$ & B & B & $b$ & $\mathrm{~b}$ \\
\hline $\mathrm{C} / \mathrm{c}$ & C & c & c & c & C & c & C & c \\
\hline$D / d$ & D & $\mathrm{D}$ & $d$ & $d$ & $d$ & $d$ & $\mathrm{D}$ & $\mathrm{D}$ \\
\hline $\mathrm{E} / \mathrm{e}$ & E & e & $E$ & e & e & $E$ & e & E \\
\hline $\mathrm{F} / \mathrm{f}$ & $\mathrm{F}$ & $f$ & $f$ & $\mathrm{~F}$ & $\mathrm{~F}$ & $f$ & $f$ & $\mathrm{~F}$ \\
\hline $\mathrm{G} / \mathrm{g}$ & G & $\mathrm{g}$ & $\mathrm{g}$ & G & $\mathrm{g}$ & G & G & $\mathrm{g}$ \\
\hline $\begin{array}{c}\text { Resultado } \\
\text { (Área Relativa) }\end{array}$ & $s$ & $t$ & $u$ & $v$ & $w$ & $x$ & $y$ & $z$ \\
\hline
\end{tabular}


Para comparar a influência da variação de cada parâmetro, deve-se calcular a diferença da média dos valores correspondentes às letras maiúsculas com a média dos valores referentes às letras minúsculas, como representado pela equação 10 .

$$
\begin{aligned}
& \text { Efeito } \mathrm{A} / \mathrm{a}=D_{a}=\frac{s+t+u+v}{4}-\frac{w+x+y+z}{4} \\
& \text { Efeito } \mathrm{B} / \mathrm{b}=D_{b}=\frac{s+t+w+x}{4}-\frac{u+v+y+z}{4}
\end{aligned}
$$

Para avaliar se as modificações têm influência na robustez, foi necessário calcular o desvio padrão das diferenças $\left(S_{D i}\right)$, por meio da equação 11.

$$
S_{D i}=\sqrt{2 \times \Sigma \frac{D i^{2}}{7}}
$$

Assim, a influência dos sete parâmetros analíticos foi avaliada em relação à área relativa dos analitos para o método proposto.

\subsubsection{Microextração líquido-líquido aplicada a FQs}

A linearidade do método LLME-CS-LC-MS/MS foi avaliada através da curva analítica construída em amostras de esgoto labmade fortificadas em oito níveis de concentrações (25; 50; 75; 100; 250; 500; 1500 e 3000 ng L-1) com quintuplicatas em cada nível totalizando um $n=40$. O limite de detecção (LD) foi estabelecido como sendo no mínimo três vezes a amplitude do ruído da linha de base e limite de quantificação (LQ) como sendo no mínimo dez vezes a amplitude do ruído da linha de base.

A precisão intra-dia foi avaliada em quintuplicata em três níveis diferentes 50 ng L-1 (baixo), $500 \mathrm{ng} \mathrm{L}^{-1}$ (médio) e $3000 \mathrm{ng} \mathrm{L}^{-1}$ (alto), em dois dias consecutivos e a precisão inter-dias foi avaliada com os resultados dos dois dias de coleta dos dados. Os resultados destes ensaios foram expressos em desvio padrão relativos percentual (DPR\%) em relação à média. A exatidão do método também foi calculada para os períodos inter-dias nos mesmos.

Foram determinados, o efeito de matriz, a recuperação e a eficiência total do método nos três níveis (baixo, médio e alto). Este estudo foi realizado de acordo com 
o trabalho de Matuszewski $(48,49)$. Os valores de efeito de matriz foram calculados a partir da razão das áreas absolutas do extrato pós-fortificado e as áreas relativas em água. A recuperação foi avaliada fazendo a razão entre os valores de áreas no extrato fortificado antes da extração e as áreas no extrato pós-fortificado. Na eficiência total do processo foi avaliada a razão entre as áreas absolutas em água e no extrato fortificado antes da extração, esse estudo leva em consideração a recuperação e o efeito de matriz. Os resultados foram expressos em percentagem de desvio do valor real.

\subsubsection{Microextração em gota suspensa para a determinação de sulfas e FQs}

A linearidade do método LLME-CS- $\mu$ LC-MS foi avaliada através da curva analítica construída em amostras de esgoto labmade fortificadas em oito níveis diferentes de concentrações com triplicata em cada nível totalizando um $n=18$. 0 limite de detecção (LD) foi estabelecido como sendo no mínimo três vezes a amplitude do ruído da linha de base e limite de quantificação (LQ) como sendo no mínimo dez vezes a amplitude do ruído da linha de base.

A precisão intra-dia foi avaliada em quintuplicatas em três níveis diferentes 500 ng L-1 (baixo), $1000 \mathrm{ng} \mathrm{L}^{-1}$ (médio) e $6000 \mathrm{ng} \mathrm{L}^{-1}$ (alto). Os resultados destes ensaios foram expressos em desvio padrão relativos percentual (DPR\%) relativo à média. Similarmente ao ensaio de precisão, foi calculada a exatidão do método inter-dias nos mesmos níveis e os resultados foram expressos também em (DPR\%).

\section{RESULTADOS E DISCUSSÃO}

\subsection{Microextração líquido-líquido aplicada a sulfas}

\subsubsection{Otimização univariada}

Foi realizada uma otimização univariada para avaliar o melhor solvente de extração, volume do solvente de extração e concentração de $\mathrm{Na}_{2} \mathrm{SO}_{4}$ (salting-out) como mostra as figuras 4,5 e 6. 
Figura 4 - Otimização univariada para avaliar o melhor solvente de extração. *Resultados significativamente diferentes.

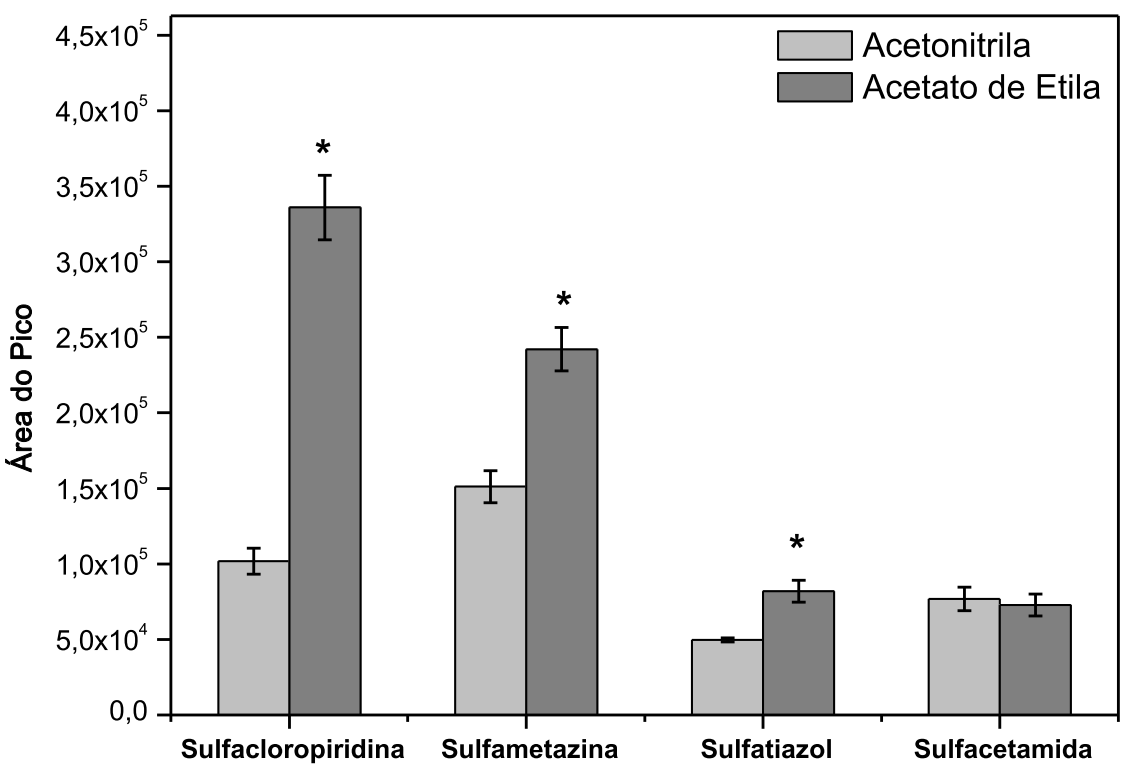

Para a otimização do tipo de fase extratora foram fixadas as condições de 7,0 $\mathrm{mL}$ de esgoto labmade com 2,0 mol L-1 de $\mathrm{Na}_{2} \mathrm{SO}_{4}, 1 \mathrm{~mL}$ de solvente orgânico (Acetonitrila ou Acetato de Etila) sob 2 min de agitação manual. Como mostra a figura 4 o solvente acetato de etila obteve um melhor resultado para a extração de quatro diferentes sulfonamidas em relação a acetonitrila, o valor elevado na extração pode ser observado para a sulfacloropiridina em relação a sulfacetamida, esta diferença pode ser explicada pelo fato do acetato de etila ser menos polar que a acetonitrila assim consequentemente extraindo em maior extensão as sulfas menos polares.

Figura 5: Otimização univariada para avaliar o volume do solvente de extração. *Resultados significativamente diferentes.

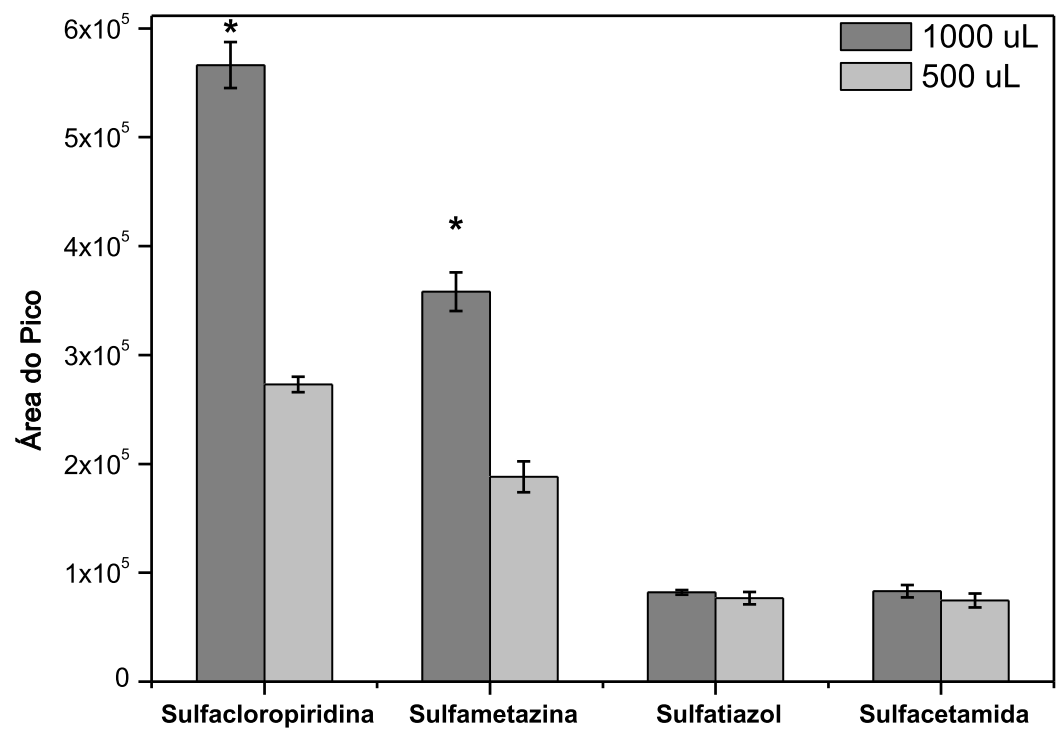


Para a otimização do volume de acetato de etila (solvente de extração) foram fixadas as condições de 7,0 mL de esgoto labmade com 2,0 mol L-1 de $\mathrm{Na}_{2} \mathrm{SO}_{4}$, variando o volume de acetato de etila, sob 2 min de agitação manual como mostra a Figura 5. Foram testados dois volumes de solvente 500 e $1000 \mu \mathrm{L}$, o maior volume foi mais eficiente para fazer a extração das sulfonamidas menos polares e para as sulfas mais polares não houve diferença significativa, desta maneira foi escolhido o volume de $1000 \mu \mathrm{L}$ de acetato de etila para realizar as extrações.

Figura 6: Otimização univariada para avaliar a concentração de $\mathrm{Na}_{2} \mathrm{SO}_{4}$ (salting out). *Resultados significativamente diferentes.

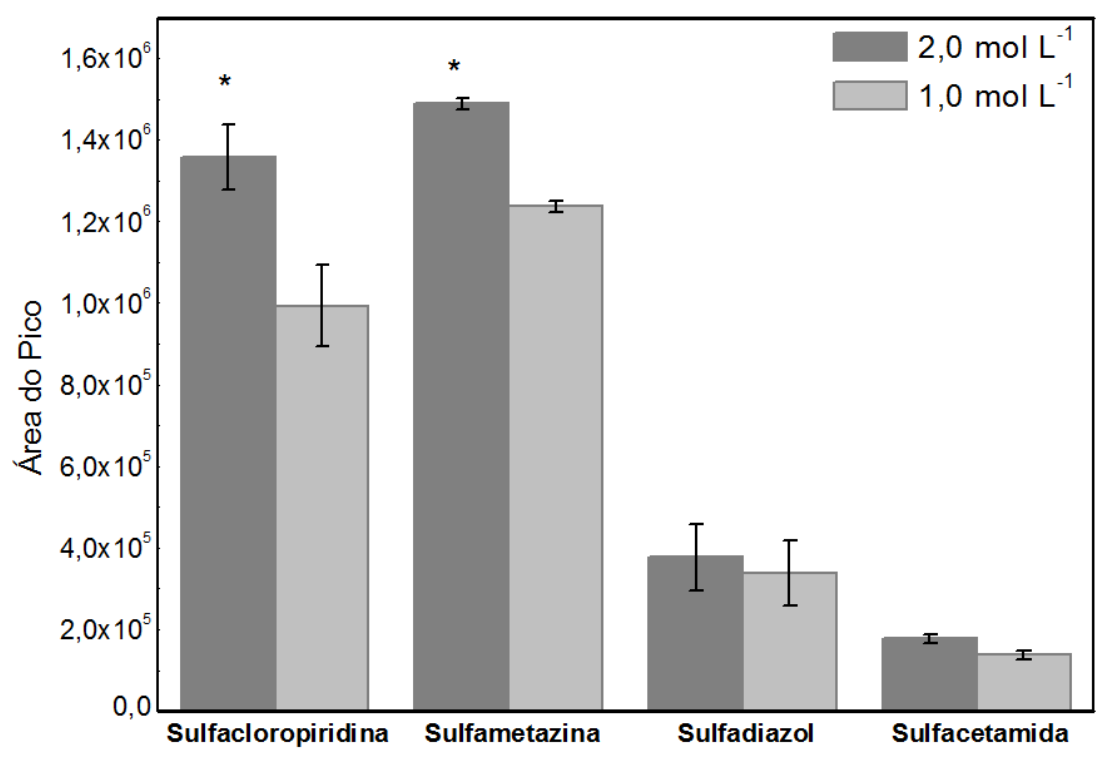

Para a otimização da concentração de $\mathrm{Na}_{2} \mathrm{SO}_{4}$ foram fixadas as condições de 7,0 $\mathrm{mL}$ de esgoto labmade, 1,0 mL de acetato de etila, variando a concentração de $\mathrm{Na}_{2} \mathrm{SO}_{4}$, sob 2 min de agitação manual como mostra a Figura 6. Utilizando duas concentrações diferentes de sal foi possível constatar o aumento na eficiência de extração conforme aumentava a concentração de $\mathrm{Na}_{2} \mathrm{SO}_{4}$, pois com o aumento do sal facilita a extração dos analitos mais polares $(52,53)$. Após a otimização univariada foi determinado como melhor solvente para extração das sulfonamidas o acetato de etila, com volume de 1,0 mL para cada extração e 2,0 mol L-1 de $\mathrm{Na}_{2} \mathrm{SO}_{4}$ como salting out. 


\subsubsection{Validação do método desenvolvido}

No desenvolvimento de métodos envolvendo a análise de vários compostos presente em uma matriz complexa, pode-se afirmar que o método é seletivo quando não há sobreposição de picos ou coeluição de interferentes com os compostos de interesse, além de quantificar com exatidão o analito na presença de interferentes existentes na amostra. Como mostra a Figura 7 os interferentes não coeluem com as sulfonamidas mostrando desta maneira que o método é seletivo para a análise destes analitos.

Figura 7 - Cromatograma para as sulfas obtido a partir da extração da matriz isenta de analitos fortificada com $5 \mathrm{ng} \mathrm{mL}^{-1}$ de sulfas, matriz isenta de sulfas e matriz fortificadas com ibuprofeno e cafeína.

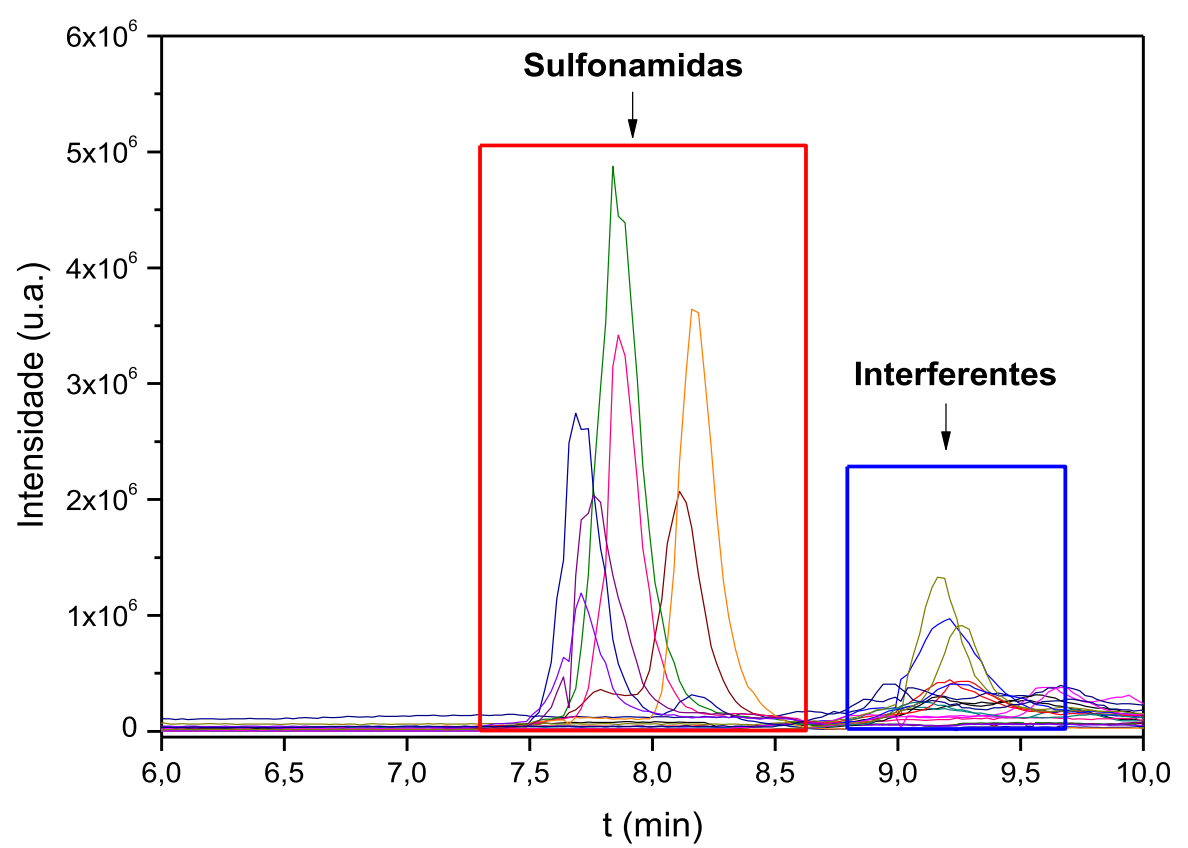

A linearidade do método LLME-CS-CLC-MS foi avaliada por meio de curva analítica (figura 8) preparada em soluções de esgoto labmade fortificadas em oito níveis diferentes; exceto para as sulfonamidas: sulfatiazol, sulfacloropiridina, sulfametazina, em que as curvas foram preparadas em sete níveis. 
Figura 8 - Curvas analíticas ponderadas para as sulfonamidas processadas por LLME-CS-uLC-MS.
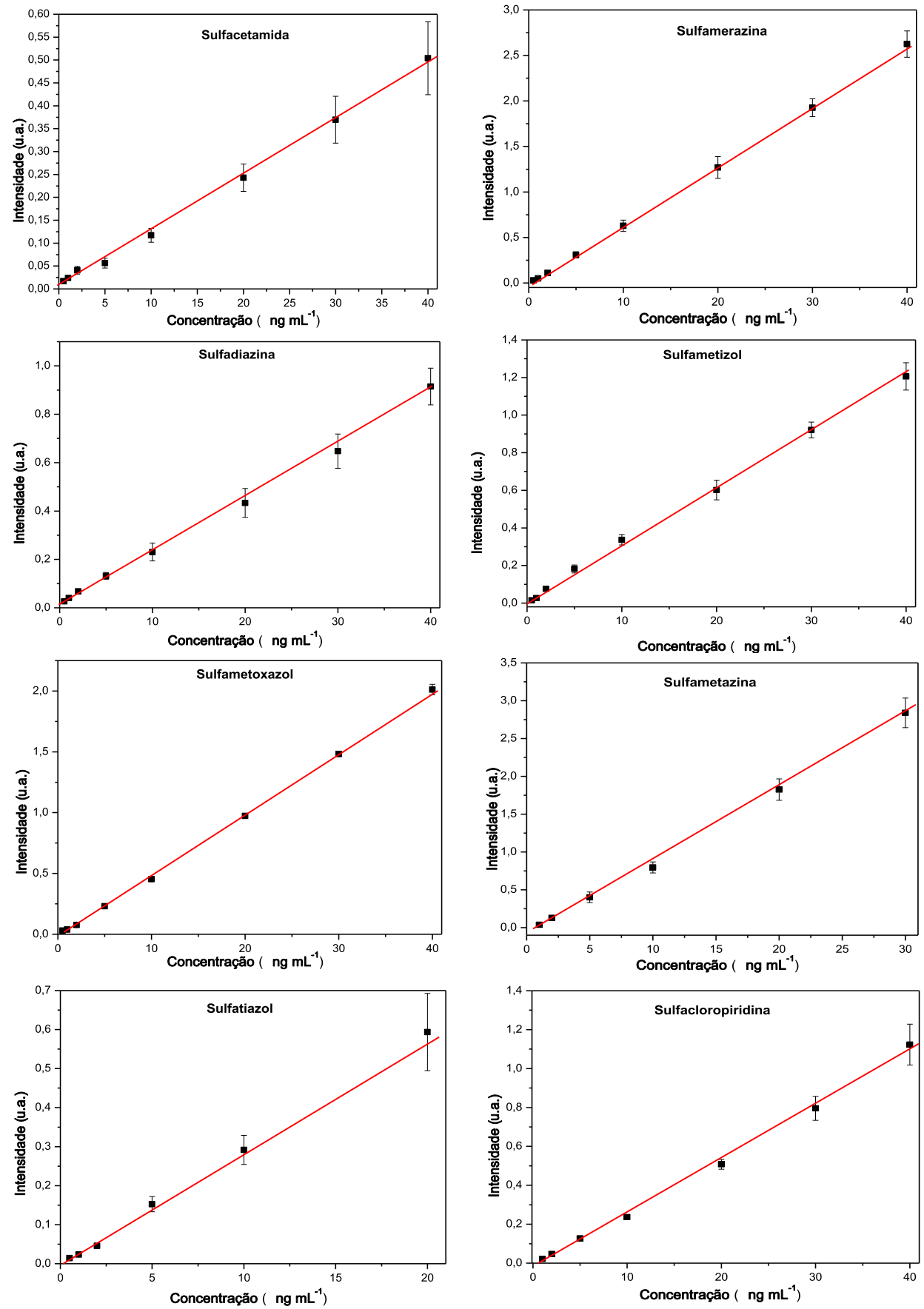

Como pode ser observado nas curvas analíticas, o desvio padrão foi aumentando com o aumento da concentração, essa característica é um indício da necessidade de ponderação da regressão linear. A necessidade de ponderação na curva de calibração foi comprovada na Tabela 7 onde, são evidenciados os valores maiores do somatório dos resíduos percentuais para a regressão sem ponderação em relação à regressão com ponderação. Portanto, a construção das curvas analíticas 
ponderadas para cada sulfonamida foi necessária, como mostram os autores Miller e Miller (32).

Tabela 7 - Soma dos resíduos percentuais (\%) para as curvas de calibrações não ponderada e ponderada.

\begin{tabular}{ccc}
\hline Sulfas & Não ponderada & Ponderada \\
\hline SCZ & 1580 & 29 \\
SMT & 622 & 77 \\
SMZ & 369 & 276 \\
SMR & 133 & 18 \\
STZ & 3711 & 246 \\
SMX & 398 & 11 \\
SDZ & 112 & 6 \\
SCT & 541 & 144 \\
\hline
\end{tabular}

Portanto, para a determinação da tangente $(b)$ e do intercepto $(a)$ da regressão ponderada foram usadas as equações 12 e 13 levando em consideração o peso ( $\left.W_{i}\right)$ (equação 14).

$$
\begin{gathered}
b=\frac{\sum_{i} w_{i} x_{i} y_{i}-n \bar{x}_{w} \bar{y}_{w}}{\sum_{i} w_{i} x_{i}^{2}-n \bar{x}_{w}^{2}} \\
a=\bar{y}_{w}-b \bar{x}_{w} \\
w_{i}=\frac{s_{i}^{-2}}{\left(\frac{\sum_{i} s_{i}^{-2}}{n}\right)}
\end{gathered}
$$

As equações anteriormente apresentadas, $\bar{x}_{w}$ e $\bar{y}_{w}$, representam as coordenadas da centroide ponderada, $\left(\bar{x}_{w}, \bar{y}_{w},\right)$ por meio da qual a linha de regressão ponderada deverá passar. Essas coordenadas são dadas, como esperado, pelas equações 15 e 16.

$$
\bar{x}_{w}=\frac{\sum_{i} w_{i} x_{i}}{n}
$$




$$
\bar{y}_{w}=\frac{\sum_{i} w_{i} y_{i}}{n}
$$

Equação 16

Os dados obtidos com a regressão linear ponderada estão contidos na Tabela 8. Os intervalos de confianças para os valores de "r2", "a" e "b" foram calculados multiplicando os seus respectivos valores de desvio padrão pelo valor de tabelado com 95\% de confiança. Os limites de detecção (LD) e limites de quantificação (LQ) estão mostrados na Tabela 7 e foram de 0,2 e $0,5 \mathrm{ng} \mathrm{mL}^{-1}$, utilizando apenas $7,0 \mathrm{~mL}$ de amostra. Dmitrienko et al utilizando SPE online atingiram um limite de detecção de $3 \mathrm{ng} \mathrm{mL}^{-1}$ para as sulfonamidas (54).

Tabela 8 - Dados da curva analítica.

\begin{tabular}{|c|c|c|c|c|c|c|c|c|}
\hline Sulfas & $\mathbf{r}^{2}$ & $\mathbf{a}$ & & b & & $\begin{array}{l}\text { Faixa Linear } \\
\left(\mathrm{ng} \mathrm{mL} \mathrm{mL}^{-1}\right)\end{array}$ & $\begin{array}{l}\text { LD } \\
\text { (ng } \\
\left.\mathrm{mL}^{-1}\right)\end{array}$ & $\begin{array}{l}\text { LQ } \\
\text { (ng mL-1) }\end{array}$ \\
\hline SCZ & $\begin{array}{l}0,9969 \pm \\
0,0120\end{array}$ & $\begin{array}{l}-0,0036 \\
0,0039\end{array}$ & \pm & $\begin{array}{l}0,0262 \\
0,0002\end{array}$ & \pm & $1,0-40$ & 0,5 & 1,0 \\
\hline SMT & $\begin{array}{l}0,9949 \pm \\
0,0580\end{array}$ & $\begin{array}{l}-0,0599 \\
0,0210\end{array}$ & \pm & $\begin{array}{l}0,0971 \\
0,0010\end{array}$ & \pm & $1,0-30$ & 0,5 & 1,0 \\
\hline SMZ & $\begin{array}{l}0,9956 \pm \\
0,0130\end{array}$ & $\begin{array}{l}-0,0027 \\
0,0044\end{array}$ & \pm & $\begin{array}{l}0,0311 \\
0,0002\end{array}$ & \pm & $0,5-40$ & 0,2 & 0,5 \\
\hline SMR & $\begin{array}{l}0,9964 \pm \\
0,0280\end{array}$ & $\begin{array}{l}-0,0153 \\
0,0103\end{array}$ & \pm & $\begin{array}{l}0,0650 \\
0,0005\end{array}$ & \pm & $0,5-40$ & 0,2 & 0,5 \\
\hline STZ & $\begin{array}{l}0,9783 \pm \\
0,0340\end{array}$ & $\begin{array}{l}-0,0009 \\
0,0123\end{array}$ & \pm & $\begin{array}{l}0,0269 \\
0,0009\end{array}$ & \pm & $0,5-20$ & 0,2 & 0,5 \\
\hline SMX & $\begin{array}{l}0,9993 \pm \\
0,0100\end{array}$ & $\begin{array}{l}-0,0146 \\
0,0041\end{array}$ & \pm & $\begin{array}{l}0,0495 \\
0,0002\end{array}$ & \pm & $0,5-40$ & 0,2 & 0,5 \\
\hline SDZ & $\begin{array}{l}0,9891 \pm \\
0,0140\end{array}$ & $\begin{array}{l}0,0174 \\
0,0048\end{array}$ & \pm & $\begin{array}{l}0,0220 \\
0,0002 \\
\end{array}$ & \pm & $0,5-40$ & 0,2 & 0,5 \\
\hline SCT & $\begin{array}{l}0,9853 \pm \\
0,0090\end{array}$ & $\begin{array}{l}0,0117 \\
0,0030 \\
\end{array}$ & \pm & $\begin{array}{l}0,0116 \\
0,0002 \\
\end{array}$ & \pm & $0,5-40$ & 0,2 & 0,5 \\
\hline
\end{tabular}

Adicionalmente, para avaliar a linearidade da curva, foi feita a construção do gráfico de resíduos em relação à área relativa (eixo y da curva) para todos os analitos avaliados. Pode-se observar que os resíduos estão bem dispersos e sem indícios de algum tipo de tendência (figura 9). 
Figura 9 - Gráficos de resíduos relativos em relação à concentração das sulfonamidas.
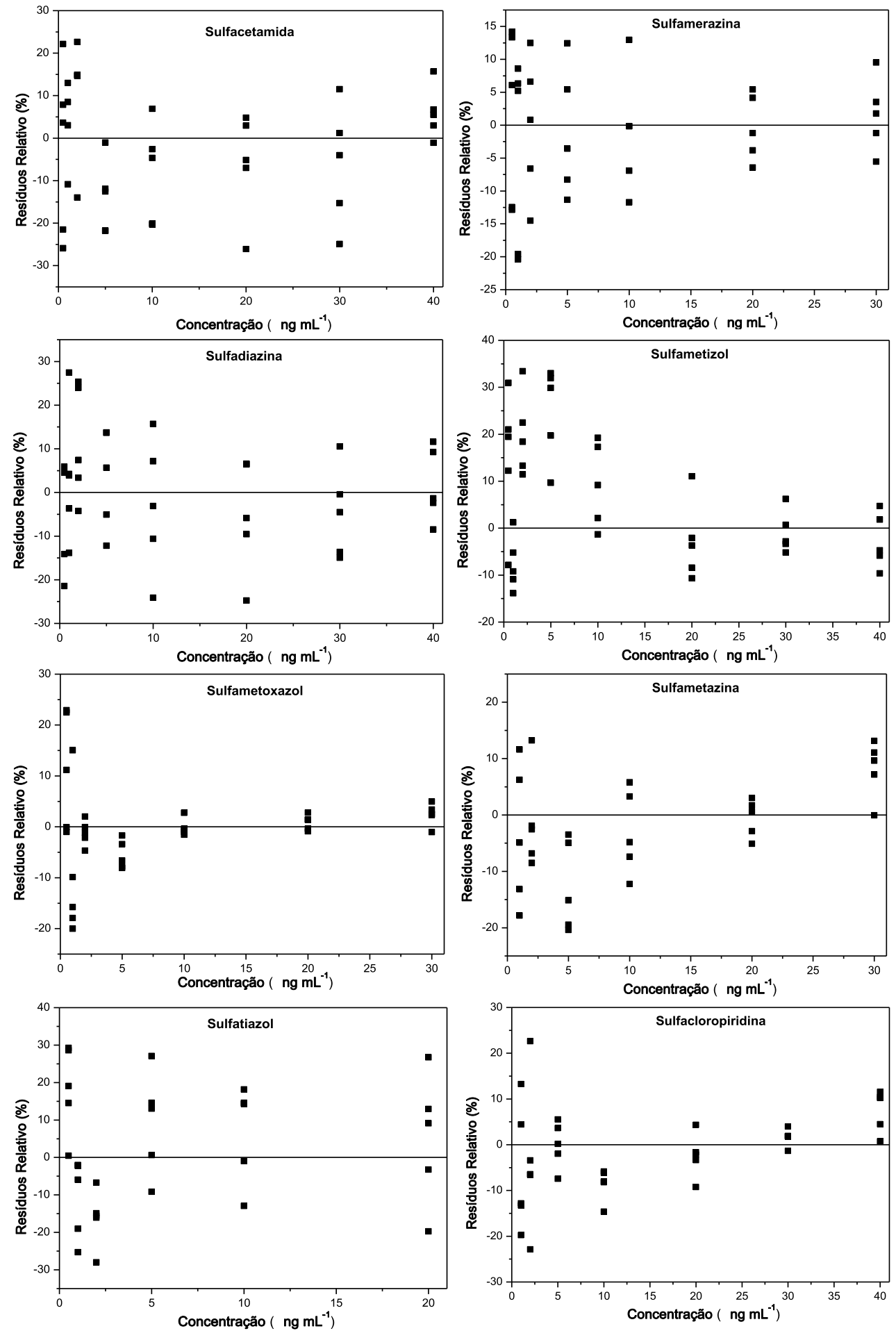

O estudo de precisão intra-dia e inter-dias foi expresso em desvio padrão relativo (DPR\%) sendo obtidos valores abaixo de $20 \%$ para o nível baixo e $15 \%$ para os demais níveis (Tabela 8). Os estudos de exatidão apresentaram valores aceitáveis, (abaixo de $\pm 20 \%$ ) para o nível baixo e $\pm 15 \%$ para os demais níveis (Tabela 8 ). 
Um teste adicional foi feito para confirmar se o valor de exatidão obtido para o método desenvolvido era confiável. Portanto para fazer esta avaliação foi utilizado um teste t bicaudal com 4 graus de liberdade e $95 \%$ de confiança, para estas condições o valor de $t$ tabelado é 2,7764. Para fazer estes cálculos foi utilizado a equação abaixo:

$$
|t|=\frac{(\text { ymedido }- \text { ypredito }) * \sqrt{n}}{s}
$$

Equação 17

Tabela 9 - Precisão intra-dia, inter-dias e exatidão para o método desenvolvido.

\begin{tabular}{|c|c|c|c|c|c|}
\hline Sulfas & Níveis & $\begin{array}{l}\text { Precisão } \\
\text { intra-dia } \\
\text { DPR (\%) } \\
(n=5)\end{array}$ & $\begin{array}{l}\text { Precisão } \\
\text { inter- } \\
\text { dias } \\
\text { DPR (\%) } \\
(n=10)\end{array}$ & $\begin{array}{c}\text { Exatidão } \\
\text { (\% bias) } \\
(n=5)\end{array}$ & t calculado \\
\hline \multirow{3}{*}{ SCZ } & Baixo & 5,2 & 7,9 & $-1,1$ & 0,327 \\
\hline & Médio & 1,9 & 4,7 & $-2,4$ & 0,567 \\
\hline & Alto & 4,3 & 8,0 & 0,5 & 0,127 \\
\hline \multirow{3}{*}{ SMT } & Baixo & 17,4 & 14,5 & $-6,4$ & 0,980 \\
\hline & Médio & 3,4 & 9,0 & $-7,7$ & 1,616 \\
\hline & Alto & 4,7 & 11,1 & $-1,2$ & 0,242 \\
\hline \multirow{3}{*}{ SMZ } & Baixo & 11,7 & 12,6 & 16,4 & 2,502 \\
\hline & Médio & 4,6 & 11,4 & $-8,2$ & 1,675 \\
\hline & Alto & 6,0 & 11,6 & $-11,5$ & 2,493 \\
\hline \multirow{3}{*}{ SMR } & Baixo & 10,7 & 11,2 & $-0,8$ & 0,156 \\
\hline & Médio & 5,1 & 9,9 & $-7,7$ & 1,760 \\
\hline & Alto & 5,5 & 11,5 & $-7,3$ & 1,540 \\
\hline \multirow{3}{*}{ STZ } & Baixo & 12,7 & 7,8 & 2,6 & 0,343 \\
\hline & Médio & 14,2 & 14,2 & 6,6 & 0,928 \\
\hline & Alto & 11,7 & 14,8 & 14,0 & 2,084 \\
\hline \multirow{3}{*}{ SMX } & Baixo & 2,5 & 4,3 & 0,5 & 0,257 \\
\hline & Médio & 1,5 & 5,6 & $-4,0$ & 0,891 \\
\hline & Alto & 2,1 & 5,5 & $-2,4$ & 0,998 \\
\hline \multirow{3}{*}{ SDZ } & Baixo & 11,2 & 12,8 & 1,2 & 0,201 \\
\hline & Médio & 10,9 & 12,2 & $-11,3$ & 2,191 \\
\hline & Alto & 8,3 & 14,0 & $-8,9$ & 1,562 \\
\hline \multirow{3}{*}{ SCT } & Baixo & $-19,2$ & 15,0 & $-14,2$ & 2,591 \\
\hline & Médio & 14,1 & 12,1 & $-10,3$ & 2,060 \\
\hline & Alto & 5,9 & 13,8 & $-7,1$ & 1,082 \\
\hline
\end{tabular}

$\mathrm{t}$ tabelado para exatidão $=2,7764$

$5 \mathrm{ng} \mathrm{mL}^{-1}$ (baixo), $30 \mathrm{ng} \mathrm{mL}^{-1}$ (médio) e $40 \mathrm{ng} \mathrm{mL}^{-1}$ (alto)

Analisando os valores de $\mathrm{t}$ calculados, pode-se afirmar que o método desenvolvido possui exatidão nos três níveis avaliados, pois todos os valores de $\mathrm{t}$ calculados foram menores do que o valor de $t$ tabelado para 4 graus de liberdade 
$(2,7764)$, portanto os valores de y (área relativa) medidos não tem diferença significativa em relação aos valores de y preditos pela curva analítica.

Foi avaliada a recuperação, efeito de matriz e a eficiência total do processo para os três níveis da curva analítica (Tabela 10). A recuperação e a eficiência total do processo variaram nos três níveis, no nível baixo os valores de recuperação e eficiência total foram menores do que no nível alto. Já o efeito de matriz não teve muita variação nos três níveis avaliados.

Tabela 10 - Resultados para recuperação, efeito de matriz e eficiência total do processo.

\begin{tabular}{|c|c|c|c|c|}
\hline Sulfas & Níveis & $\begin{array}{c}\text { Recuperação } \\
(\%) \\
(n=3)\end{array}$ & $\begin{array}{c}\text { Efeito de } \\
\text { Matriz (\%) } \\
(n=3)\end{array}$ & $\begin{array}{c}\text { Eficiência total } \\
\text { do Processo (\%) } \\
(n=3)\end{array}$ \\
\hline \multirow{3}{*}{ SCZ } & Baixo & 60,2 & 83,4 & 50,2 \\
\hline & Médio & 91,4 & 71,7 & 65,6 \\
\hline & Alto & 98,1 & 68,9 & 67,6 \\
\hline \multirow{3}{*}{ SMT } & Baixo & 62,1 & 76,6 & 47,6 \\
\hline & Médio & 91,5 & 70,3 & 64,4 \\
\hline & Alto & 94,8 & 68,7 & 65,1 \\
\hline \multirow{3}{*}{ SMZ } & Baixo & 61,1 & 81,1 & 49,6 \\
\hline & Médio & 91,7 & 72,3 & 66,3 \\
\hline & Alto & 88,7 & 75,7 & 67,1 \\
\hline \multirow{3}{*}{ SMR } & Baixo & 74,2 & 77,1 & 57,2 \\
\hline & Médio & 50,2 & 74,0 & 37,1 \\
\hline & Alto & 35,2 & 75,3 & 26,5 \\
\hline \multirow{3}{*}{ STZ } & Baixo & 65,9 & 68,3 & 45,0 \\
\hline & Médio & 90,2 & 66,9 & 60,3 \\
\hline & Alto & 88,0 & 65,2 & 57,3 \\
\hline \multirow{3}{*}{ SMX } & Baixo & 57,6 & 84,9 & 48,9 \\
\hline & Médio & 93,0 & 62,3 & 57,9 \\
\hline & Alto & 98,9 & 64,0 & 63,3 \\
\hline \multirow{3}{*}{ SDZ } & Baixo & 70,8 & 81,5 & 57,7 \\
\hline & Médio & 103,5 & 74,7 & 77,3 \\
\hline & Alto & 101,4 & 78,7 & 79,7 \\
\hline \multirow{3}{*}{ SCT } & Baixo & 62,4 & 58,3 & 36,4 \\
\hline & Médio & 91,9 & 67,6 & 62,1 \\
\hline & Alto & 93,0 & 72,7 & 67,6 \\
\hline
\end{tabular}

$5 \mathrm{ng} \mathrm{mL}^{-1}$ (baixo), $30 \mathrm{ng} \mathrm{mL}^{-1}$ (médio) e $40 \mathrm{ng} \mathrm{mL}^{-1}$ (alto)

A reprodutibilidade intralaboratorial também foi avaliada conforme descrito anteriormente no item 2.5. Os valores de precisão deste experimento ficaram abaixo de $20 \%$ para o nível baixo e $15 \%$ para os demais níveis (Tabela 11 ). 
Tabela 11 - Resultados da reprodutibilidade intralaboratorial.

\begin{tabular}{|c|c|c|}
\hline Sulfas & Níveis & $\begin{array}{l}\text { Precisão } \\
\text { DPR (\%) }\end{array}$ \\
\hline \multirow{3}{*}{ SCZ } & Baixo & 7,4 \\
\hline & Médio & 4,4 \\
\hline & Alto & 9,3 \\
\hline \multirow{3}{*}{ SMT } & Baixo & 16,7 \\
\hline & Médio & 8,3 \\
\hline & Alto & 12,4 \\
\hline \multirow{3}{*}{ SMZ } & Baixo & 16,4 \\
\hline & Médio & 10,0 \\
\hline & Alto & 12,8 \\
\hline \multirow{3}{*}{ SMR } & Baixo & 13,4 \\
\hline & Médio & 8,9 \\
\hline & Alto & 11,5 \\
\hline \multirow{3}{*}{ STZ } & Baixo & 19,6 \\
\hline & Médio & 14,6 \\
\hline & Alto & 14,3 \\
\hline \multirow{3}{*}{ SMX } & Baixo & 4,0 \\
\hline & Médio & 5,6 \\
\hline & Alto & 6,9 \\
\hline \multirow{3}{*}{ SDZ } & Baixo & 14,4 \\
\hline & Médio & 10,7 \\
\hline & Alto & 14,8 \\
\hline \multirow{3}{*}{ SCT } & Baixo & 18,3 \\
\hline & Médio & 12,1 \\
\hline & Alto & 14,7 \\
\hline
\end{tabular}

Por meio do teste de Youden, foi possível verificar, de uma forma geral, os parâmetros que apresentam mais influência no resultado final para as sulfonamidas (figura 10). 
Figura 10 - Efeito dos parâmetros de robustez sobre a concentração das sulfonamidas.
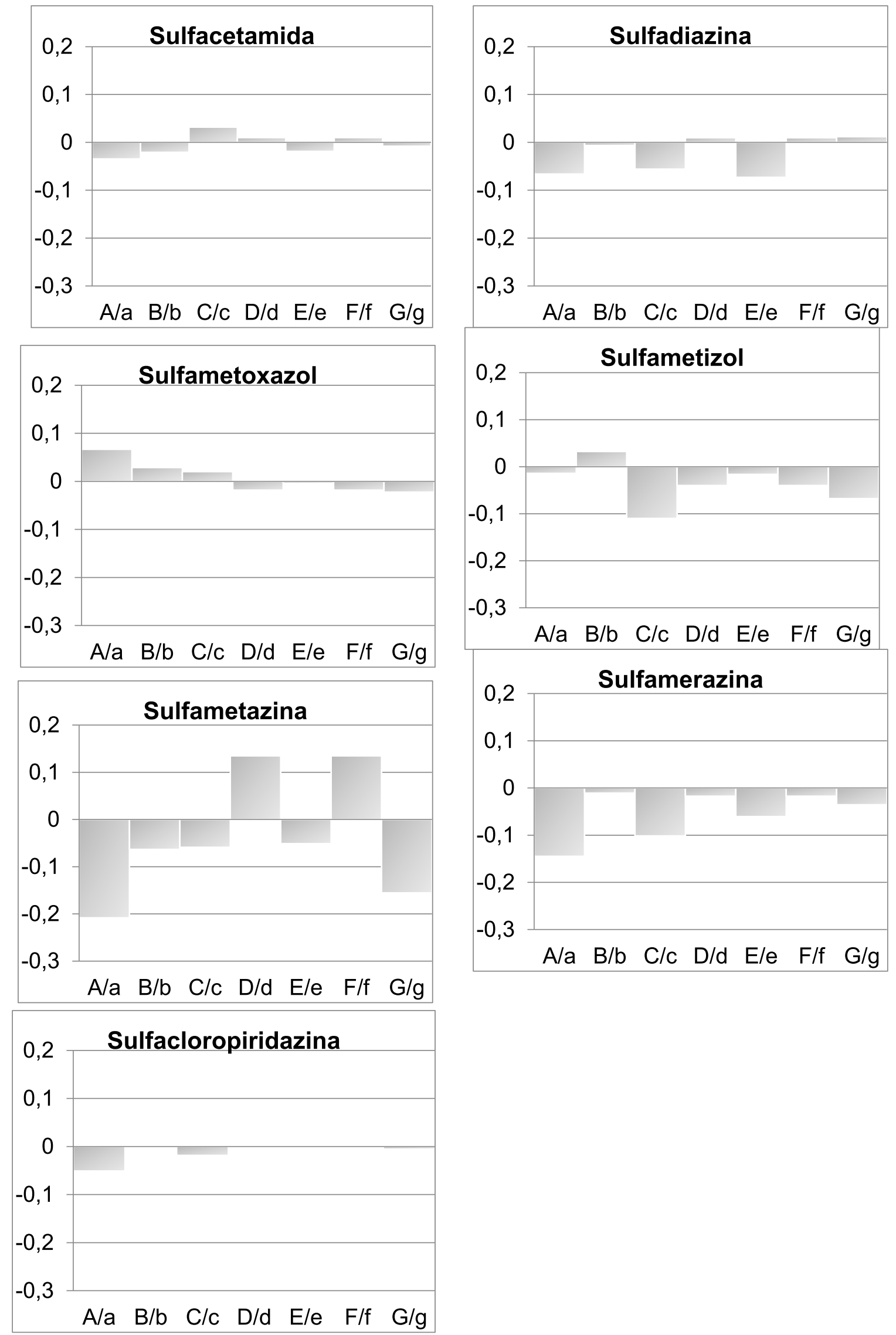
Como pode ser observado na figura 10 , as sulfonamidas que apresentaram maiores efeitos com as pequenas variações no método foram a sulfamerazina e a sulfametazina. Porém, comparando-se os desvios padrões da reprodutibilidade intralaboratorial e da robustez, o método se mostrou robusto pois os valores dos DP da robustez não superaram os valores de DP da reprodutibilidade intralaboratorial (Tabela 12).

Tabela 12 - Resultados da avaliação da robustez para método desenvolvido.

\begin{tabular}{ccc}
\hline Sulfas & $\begin{array}{c}\text { Reprodutibilidade } \\
\text { Intralaboratorial } \\
\text { DP }\end{array}$ & $\begin{array}{c}\text { Robustez } \\
\text { DP }\end{array}$ \\
\hline SCZ & 0,033 & 0,029 \\
SMT & 0,219 & 0,181 \\
SMZ & 0,083 & 0,078 \\
SMR & 0,161 & 0,155 \\
STZ & 0,125 & 0,103 \\
SMX & 0,078 & 0,044 \\
SDZ & 0,064 & 0,061 \\
SCT & 0,038 & 0,031 \\
\hline
\end{tabular}

\subsubsection{Aplicação do método}

As amostras foram coletadas em frascos de polietileno (PET) previamente higienizados e mantidos a $-4{ }^{\circ} \mathrm{C}$ até o momento da extração. Antes da extração as amostras foram filtradas em papel de filtro convencional de $0,45 \mu \mathrm{m}$ e submetidas ao procedimento de análise. Estas amostras foram coletadas do rio Monjolinho, próximo ao shopping da cidade de São Carlos-SP (Figura 11B). Para comprovar a eficiência do método de extração, estas amostras foram fortificadas com $20 \mathrm{ng} \mathrm{mL}^{-1}$ de cada analito e foram avaliadas precisão, exatidão e recuperação. Como pode ser observado na Tabela 13, o método é eficiente para fazer a extração em amostras de águas residuárias com bons resultados de precisão, exatidão e recuperação. 
Tabela 13 - Avaliação da precisão, exatidão e determinação da concentração em uma amostra real fortificada.

\begin{tabular}{|c|c|c|c|}
\hline Sulfas & $\begin{array}{c}\text { Precisão } \\
\text { intradia } \\
\text { DPR (\%) } \\
(n=3)\end{array}$ & $\begin{array}{c}\text { Exatidão } \\
\text { DPR (\%) } \\
(n=3)\end{array}$ & $\begin{array}{c}\text { Recuperação } \\
(\%) \\
(n=3)\end{array}$ \\
\hline SCZ & 6,5 & 1,4 & 98,5 \\
\hline SMT & 9,1 & $-19,7$ & 123,5 \\
\hline SMZ & 12,3 & 19,4 & 83,7 \\
\hline SMR & 9,5 & 0,4 & 99,5 \\
\hline STZ & 18,4 & 19,0 & 84,0 \\
\hline SMX & 0,5 & $-2,9$ & 103,1 \\
\hline SDZ & 11,3 & 6,6 & 93,5 \\
\hline SCT & 11,0 & 35,1 & 73,0 \\
\hline
\end{tabular}

Para avaliar a aplicabilidade do método desenvolvido foi feita a extração da amostra real fortificada e não fortificada com padrões de sulfonamidas. $O$ único analito detectado e quantificado foi a sulfacetamida, pode ser observado na Figura $11 \mathrm{~A}$ que o perfil cromatográfico da amostra real não fortificada é compatível com a amostra real fortificada. A concentração de sulfacetamida encontrada foi de $8,59 \pm 0,57 \mathrm{ng} \mathrm{mL}^{-1}$. O método desenvolvido se mostrou eficiente para extração e quantificação da sulfacetamida em amostra de água, utilizando um volume pequeno de amostra (7,0 $\mathrm{mL})$ e um pequeno volume de solvente orgânico $(1,0 \mathrm{~mL})$ em relação à extração líquido-líquido convencional.

Figura $11 \mathrm{~A}$ - Cromatograma da amostra fortificada e não fortificada com sulfacetamida. B) Local onde a amostra foi coletada.

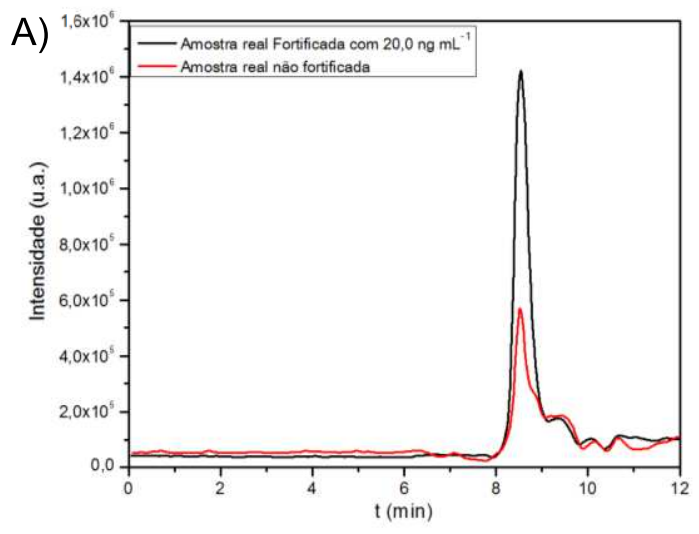

B) 


\subsection{Microextração líquido-líquido aplicada a FQs}

\subsubsection{Teste da coluna Strata-X}

Foi feito a comparação entre uma coluna comercial de SPE online e uma coluna labmade com um preço reduzido em relação ao valor da coluna comercial, cerca de $10 \%$ do valor da coluna comercial. A coluna de SPE comercial usada para a comparação foi a coluna Oasis HLB $(2,1 \mathrm{~mm}$ d.i. x $20 \mathrm{~mm}$ e partículas de $25 \mu \mathrm{m})$ adquirida da Waters (Milford, MA). A coluna labmade foi preparada usando a fase polimérica comercial Strata-X com partículas de $33 \mu \mathrm{m}$ e empacotada usando um tubo de $2,1 \mathrm{~mm} \times 40 \mathrm{~mm}$. A comparação foi feita injetando nas duas colunas $60 \mu \mathrm{L}$ (triplicata) de uma solução padrão contendo $75 \mathrm{ng} \mathrm{L}^{-1}$ das $\mathrm{FQs}$ e depois comparando a área bruta para cada analito.

A diferença entre a extração de cada coluna de SPE foi testada usando um teste $\mathrm{t}$ bicaudal pareado com $95 \%$ de confiança (equações 3 e 4). A coluna Strata-X teve uma melhor capacidade de extração das FQs, exceto para a ENRO (Tabela 14), em que o resultado não foi significativamente superior ao da coluna comercial. As transições de m/z avaliadas para cada FQs foram: NOR (320-302 m/z), CIP (332-288 m/z), PEF (334-233 m/z), ENR (360-316), OFL (362-318 m/z). Para a diferença entre as extrações das duas colunas serem significativas o valor de $\mathrm{t}$ calculado deve ter maior que o valor de $t$ tabelado (2,776 para 4 g.I). Como mostra a Figura 12, o perfil cromatográfico utilizando a coluna Strata-X não foi alterado, somente o tempo de retenção que aumentou 0,13 $\mathrm{min}$.

Figura 12 - Comparação entre a coluna labmade Strata-X e a coluna comercial Oasis HLB.
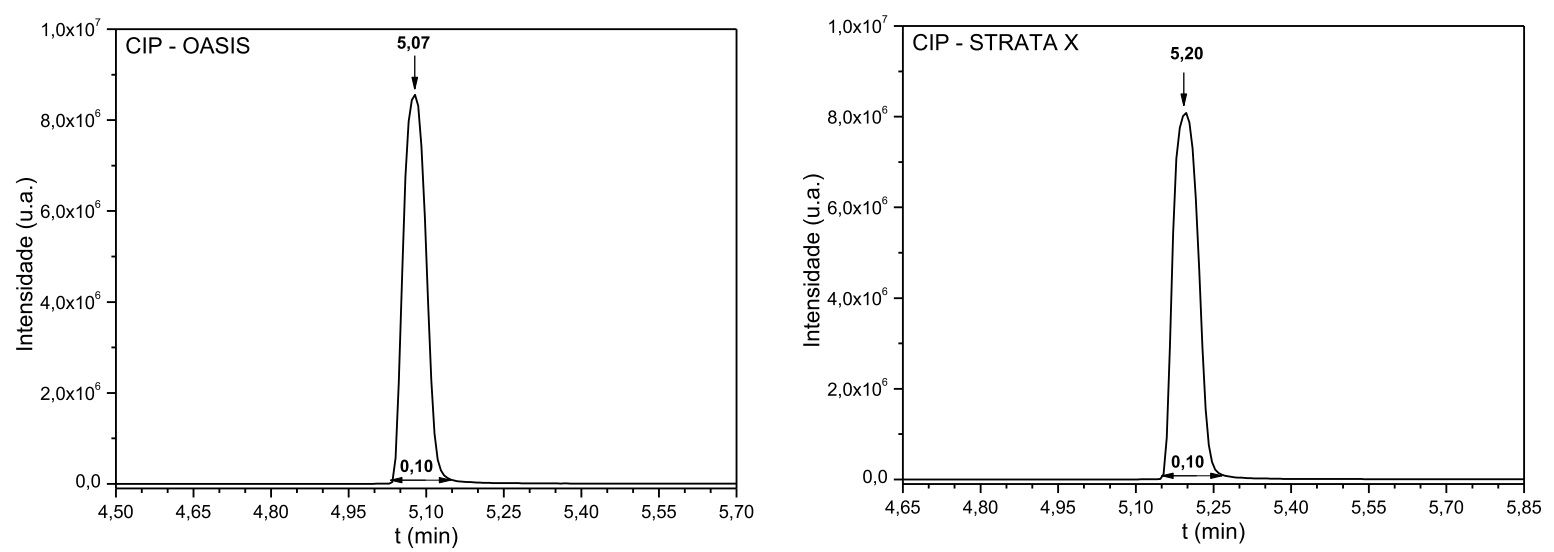
Tabela 14 - Aumento da área bruta comparando as duas colunas de SPE online (Strata-X e Oasis HLB).

\begin{tabular}{ccc}
\hline \multicolumn{3}{c}{ Aumento da área bruta (\%) } \\
X/Oasis) \\
\hline FQs & Área Bruta & Valor de t \\
NOR & 5,3 & 4,41 \\
CIP & 3,9 & 7,11 \\
PEF & 3,3 & 2,86 \\
ENR & 1,7 & $1,18^{*}$ \\
OFL & 5,2 & 4,81 \\
\hline
\end{tabular}

*Valor de $\mathrm{t}$ calculado menor que o $\mathrm{t}$ tabelado.

Para a extração das fluoroquinolonas, a etapa de LLME foi realizada usando um tubo cônico de $15 \mathrm{~mL}$ e a para agitação foi utilizada uma mesa agitadora orbital VXR BASIC VIBRAX como mostra a Figura 13.

Figura 13: Tubo cônico utilizado para fazer extração das FQs

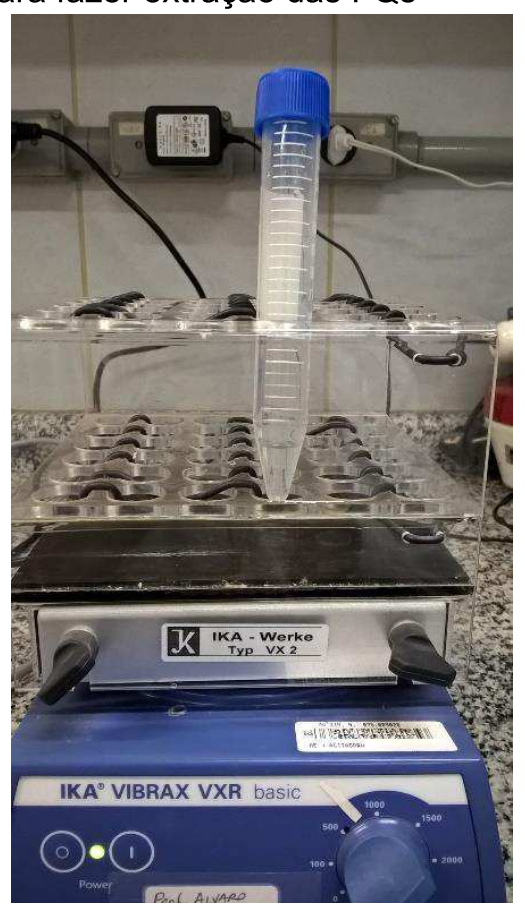

Foram avaliados três solventes orgânicos para fazer a extração das cinco fluoroquinolonas em esgoto labmade, os solventes testados foram diclorometano, clorofórmio e acetato de etila, os resultados estão apresentados na Figura 14. 
Figura 14 - Avaliação do melhor solvente de extração para as FQs.

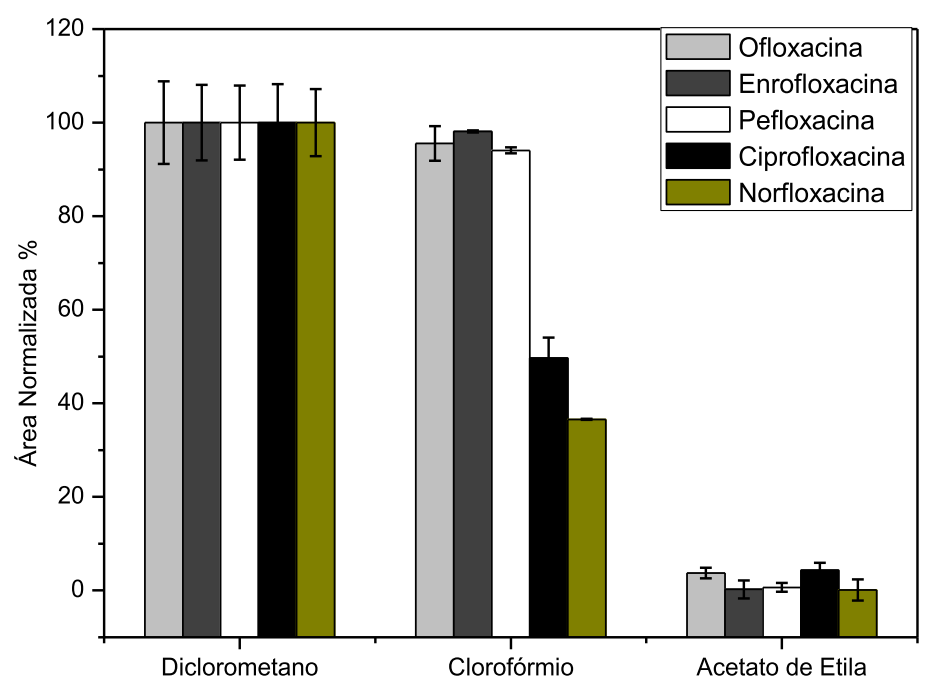

Para determinar o melhor solvente de extração foi utilizado um teste t pareado bicaudal para avaliar se as médias das extrações com os três solventes foram significativamente diferentes. Foram usadas as Equações 10 e 11 para determinar os valores de $\mathrm{t}$ calculado. $\mathrm{O}$ valor de $\mathrm{t}$ tabelado para 2 graus de liberdade e $95 \%$ de confiança é de 4,30 , comparando com valores de $t$ calculado contidos na Tabela 15 foi escolhido como melhor solvente de extração o diclorometano em relação ao clorofórmio pois a extração das FQs norfloxacina e ciprofloxacina o valor de $t$ foi maior que o valor de $\mathrm{t}$ tabelado, portanto comprovando a maior eficiência de extração optando por diclorometano em relação ao clorofórmio. Os valores de $t$ calculados comparando o diclorometano com o acetato de etila também foram maiores do que o t tabelado, indicando novamente a maior eficiência de extração do diclorometano. Portanto, o diclorometano foi escolhido para fazer a otimização do método de extração utilizando planejamento experimental.

Tabela 15 - Valores de t calculado para a eficiência de extração dos solventes orgânicos.

\begin{tabular}{ccc}
\hline \multirow{2}{*}{ FQs } & \multicolumn{2}{c}{ t calculado } \\
\cline { 2 - 3 } & $\begin{array}{c}\text { Diclorometanol } \\
\text { Clorofórmio }\end{array}$ & $\begin{array}{c}\text { Diclorometanol } \\
\text { Acetato de Etila }\end{array}$ \\
OFLO & 0,7 & $15,4^{*}$ \\
ENRO & 0,1 & $7,3^{*}$ \\
PEF & 1,1 & $17,2^{*}$ \\
CIP & $7,6^{*}$ & $16,7^{*}$ \\
NOR & $8,0^{*}$ & $12,3^{*}$ \\
\hline
\end{tabular}

*valor de t calculado maior que $t$ tabelado (Significativamente diferentes com $95 \%$ de confiança). 


\subsubsection{Planejamento Experimental}

A partir das áreas absolutas obtidas por meio do planejamento experimental $2^{3}$ composto central, em que se avaliou o volume de solvente orgânico, a concentração de sulfato de sódio e o tempo de agitação (Tabela 16) foram construídos diagramas de Pareto, apresentados na Figura 15.

Tabela 16 - Variáveis e fatores do planejamento experimental $2^{3}$ composto central.

\begin{tabular}{|c|c|c|c|c|c|c|c|c|}
\hline \multicolumn{4}{|c|}{ Fatores } & \multicolumn{2}{|r|}{-1} & $\overline{P C}$ & \multicolumn{2}{|c|}{+1} \\
\hline \multicolumn{4}{|c|}{$\begin{array}{c}\text { Volume } \mathrm{Cl}_{2} \mathrm{CH}_{2}(\mathrm{~V}) \\
{\left[\mathrm{Na}_{2} \mathrm{SO}_{4}\right](\mathrm{C})}\end{array}$} & \multicolumn{2}{|c|}{$\begin{array}{c}500 \mu \mathrm{L} \\
0,0 \mathrm{~mol} \mathrm{~L}^{-1}\end{array}$} & $\begin{array}{c}750 \mu \mathrm{L} \\
0,5 \mathrm{~mol} \mathrm{~L}^{-1} \\
600 \mathrm{~s}\end{array}$ & \multicolumn{2}{|c|}{$\begin{array}{c}1000 \mu \mathrm{L} \\
1,0 \mathrm{~mol} \mathrm{~L}^{-1}\end{array}$} \\
\hline Ensaios & $\overline{\mathbf{V}}$ & $\mathrm{C}$ & $T$ & OFLO & ENRO & $\overline{P E F}$ & $\overline{C I P}$ & $\overline{N O R}$ \\
\hline$\overline{1}$ & $\overline{-1}$ & -1 & -1 & 2073759 & 4685664 & 2546332 & 488905 & 203137 \\
\hline 2 & 0 & 0 & 0 & 1068483 & 1993742 & 1215353 & 205633 & 84606 \\
\hline 3 & -1 & +1 & -1 & 3161364 & 6082606 & 3760718 & 553449 & 218482 \\
\hline 4 & +1 & +1 & -1 & 4978808 & 7135198 & 5014482 & 1072912 & 449038 \\
\hline 5 & +1 & -1 & -1 & 4303084 & 8191546 & 4997734 & 1250194 & 547609 \\
\hline 6 & -1 & -1 & +1 & 1110554 & 2820526 & 862001 & 214447 & 106798 \\
\hline 7 & +1 & +1 & +1 & 3081 & 3194284 & 3233439 & 679389 & 224415 \\
\hline 8 & 0 & 0 & 0 & 986590 & 1947320 & 1141186 & 204788 & 83913 \\
\hline 9 & 0 & 0 & 0 & 1150354 & 2039984 & 1289299 & 206057 & 85287 \\
\hline 10 & -1 & +1 & +1 & 1186918 & 2114039 & 1710085 & 292876 & 72648 \\
\hline 11 & +1 & -1 & +1 & 1001250 & 1206541 & 917966 & 241565 & 107224 \\
\hline
\end{tabular}

Figura 15 - Diagrama de Pareto do planejamento experimental $2^{3}$ composto central representando a extração das FQs.
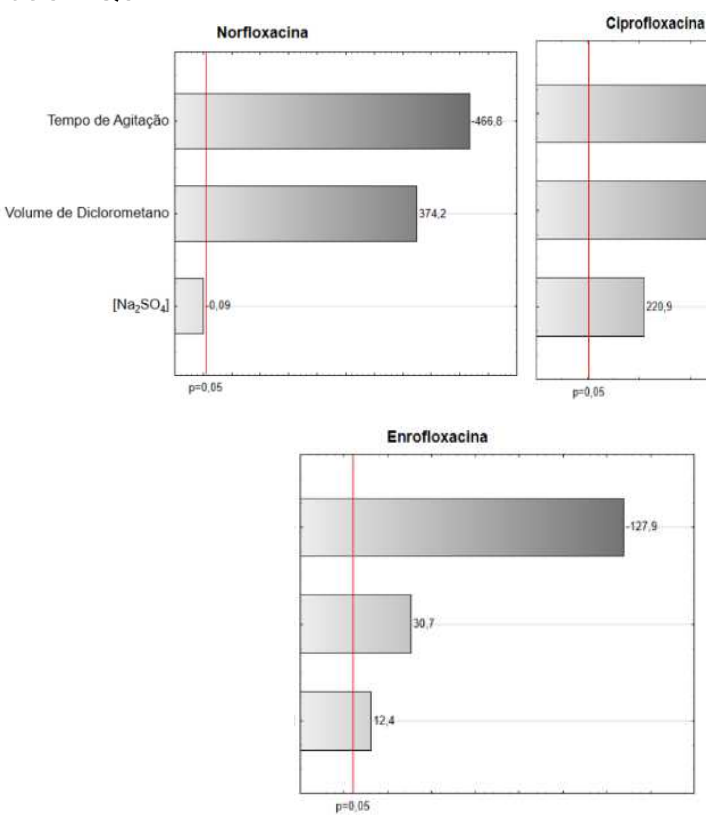

Ciprofloxacina

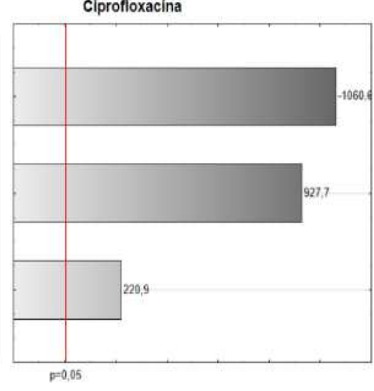

ofloxacina

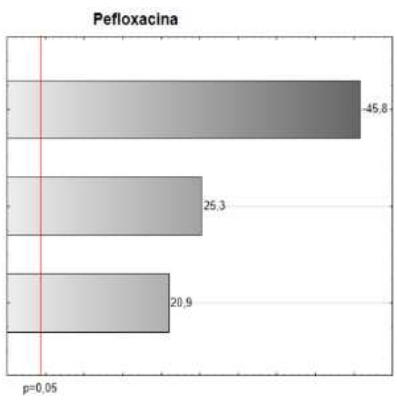

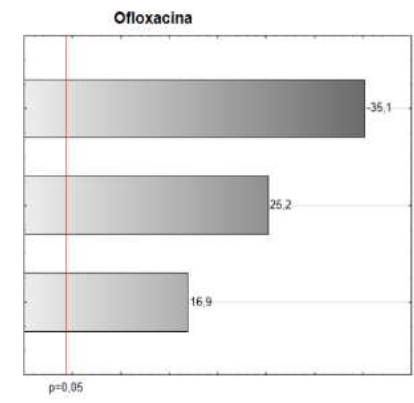


Como mostra os diagramas de Pareto (Figura 15) e as superfícies/contornos da desejabilidade (Figura 16) os três fatores estudados no planejamento (volume de $\mathrm{Cl}_{2} \mathrm{CH}_{2}$, a concentração de $\mathrm{Na}_{2} \mathrm{SO}_{4}$ e o tempo de agitação) foram significativos com 95\% de confiança. Porém com este planejamento não foi possível determinar o ponto ótimo para a extração, pois como mostram as superfícies/contornos têm-se uma tendência para os níveis mais altos do planejamento para os fatores volume de solvente e concentração de sal, e para o tempo de agitação o planejamento indicou uma tendência para o nível mais baixo, ou seja, 300 segundos. Desta maneira foi necessário refinar o planejamento experimental. Para o novo planejamento não foi otimizado o fator volume de solvente orgânico, pois acima de 1,0 $\mathrm{mL}$ de solvente orgânico já estaria em contraste com um dos objetivos deste trabalho que consiste em manter consonância aos princípios da Química Verde. Portanto para refinar esse novo planejamento foi escolhido um planejamento experimental composto central $2^{2} \mathrm{com}$ estrela, para otimização das condições de extração das FQs.

Figura 16 - Superfícies de respostas para a desejabilidade do método desenvolvido.

Desirability Surface/Contours; Method: Spline Fit
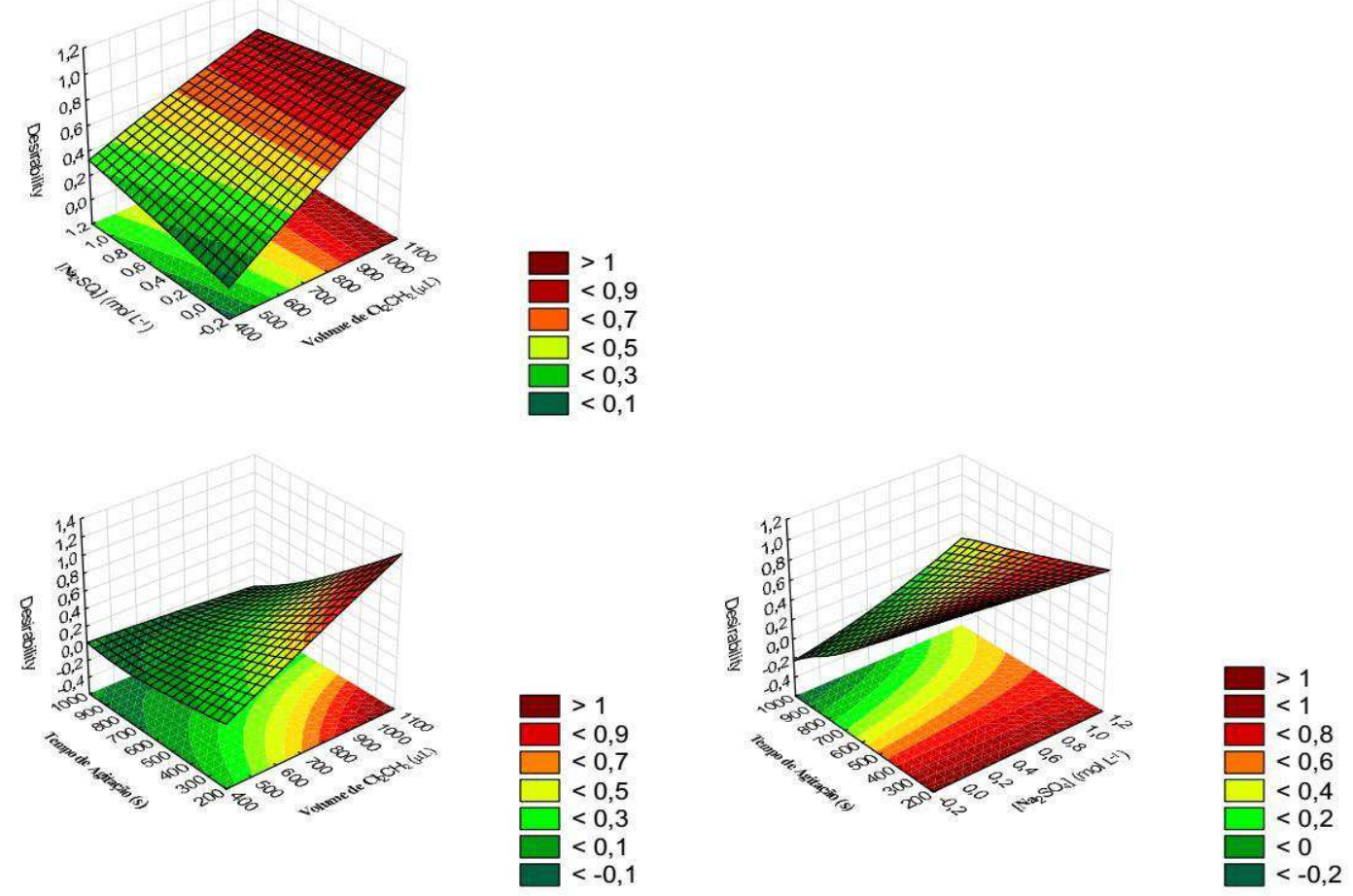

Como mostra a Tabela 17 uma nova distribuição dos níveis foi feita com uma menor faixa para refinar o planejamento e consequentemente construir uma superfície de resposta com o ponto ótimo para a extração. 
Tabela 17 - Variáveis e fatores do planejamento experimental composto central $2^{2}$ estrela.

\begin{tabular}{|c|c|c|c|c|c|c|c|}
\hline \multicolumn{3}{|c|}{ Fatores } & $-1,41$ & -1 & PC & +1 & $+1,41$ \\
\hline \multirow{2}{*}{\multicolumn{3}{|c|}{$\begin{array}{c}{\left[\mathrm{Na}_{2} \mathrm{SO}_{4}\right](\mathrm{C})} \\
\text { Tempo de Agitação } \\
(\mathrm{T})\end{array}$}} & $0,5 \mathrm{~mol} \mathrm{~L}^{-1}$ & $0,8 \mathrm{~mol} \mathrm{~L}^{-1}$ & $1,5 \mathrm{~mol} \mathrm{~L}^{-1}$ & $2,2 \mathrm{~mol} \mathrm{~L}^{-1}$ & $2,5 \mathrm{~mol} \mathrm{~L}^{-1}$ \\
\hline & & & $60 \mathrm{~s}$ & $130 \mathrm{~s}$ & $300 \mathrm{~s}$ & $470 \mathrm{~s}$ & $540 \mathrm{~s}$ \\
\hline Ensaios & C & $T$ & OFLO & ENRO & PEF & CIP & NOR \\
\hline 1 & 0 & 0 & 3871878 & 3731863 & 2936678 & 830793 & 411177 \\
\hline 2 & 0 & 0 & 3796272 & 3526773 & 2919777 & 796513 & 354834 \\
\hline 3 & 0 & 0 & 3729298 & 3533372 & 2818378 & 797835 & 387871 \\
\hline 4 & 0 & 0 & 3641387 & 3559562 & 2800839 & 778248 & 371266 \\
\hline 5 & -1 & -1 & 2331581 & 3294065 & 2089125 & 437924 & 177018 \\
\hline 6 & 1 & -1 & 3643774 & 2730100 & 2398486 & 1185711 & 626674 \\
\hline 7 & -1 & 1 & 2769931 & 3306124 & 2465138 & 486175 & 199758 \\
\hline 8 & 1 & 1 & 2393958 & 2237481 & 1688339 & 814574 & 387970 \\
\hline 9 & $\overline{1,41}$ & 0 & 2359710 & 3966203 & 2345867 & 447985 & 191612 \\
\hline 10 & 0 & $-1,41$ & 2822255 & 2547895 & 2184406 & 649436 & 288940 \\
\hline 11 & 1,41 & 0 & 2890961 & 2213959 & 1886846 & 1121157 & 575708 \\
\hline 12 & 0 & 1,41 & 2998881 & 2872085 & 2307599 & 637081 & 296352 \\
\hline
\end{tabular}

Utilizando os softwares Microsoft Office Excel 2013, Matlab R2013a e Statistica 10.0, foram construídos os modelos de regressão quadrática para as cinco $F Q s$ estudadas. As tabelas 18, 19 e figura 17 mostram somente os tratamentos estatísticos realizados para a pefloxacina, este mesmo procedimento foi realizado para as demais FQs com resultados semelhantes. Como pode ser observado na tabela ANOVA para a PEF, o modelo possui um valor de $\mathrm{F}$ calculado para a regressão maior que o valor de $\mathrm{F}$ tabelado indicando que o modelo é válido, outro fator que comprova a validade do modelo é o valor de $\mathrm{R}^{2}$ que foi de 0,986 , um valor relativamente alto. O modelo não possui falta de ajuste pois o valor de $\mathrm{F}$ calculado para o erro puro foi menor que o valor tabelado, desta maneira foram utilizados os graus de liberdade do resíduo para gerar o modelo. Os coeficientes determinados estão na Tabela 19, apenas o coeficiente $b_{2}$ não foi significativo, fato este que pode ser observado na Figura 17D onde mostra o coeficiente b2 passando pelo valor zero. Observando a Figura 17C, é possível perceber que os resíduos estão dispersos e não possuem tendência, indicando novamente a validade do modelo. 
Tabela 18: Tabela ANOVA para a norfloxacina.

\begin{tabular}{cccccc}
\hline & $\begin{array}{c}\text { Soma } \\
\text { Quadrática }\end{array}$ & g.l. & $\begin{array}{c}\text { Médias } \\
\text { Quadráticas }\end{array}$ & $\mathbf{F}$ calculado & F tabelado \\
\hline Regressão & $1,9 \times 10^{-3}$ & 2 & $9,6 \times 10^{-4}$ & 31,95 & 4,256 \\
Resíduo & $2,7 \times 10^{-4}$ & 9 & $3,0 \times 10^{-5}$ & & \\
Total & $2,2 \times 10^{-3}$ & 11 & $2,0 \times 10^{-4}$ & & \\
Erro Puro & $1,2 \times 10^{-4}$ & 5 & $2,4 \times 10^{-5}$ & 1,51 & 6,256 \\
Falta de & $1,5 \times 10^{-4}$ & 4 & $3,7 \times 10^{-5}$ & & \\
Ajuste & 0,877 & 0,936 & & & \\
$\mathrm{R}^{2}$ & 0,944 & 0,972 & & & \\
$\mathrm{R}^{2}$ máx & 0,972 & & \\
\hline
\end{tabular}

Tabela 19: Coeficientes significativos do modelo proposto para a norfloxacina.

\begin{tabular}{ccccc}
\hline \multicolumn{2}{l}{ Coeficientes } & (Erro) & Coeficiente - erro & Coeficiente + erro \\
\hline b $_{0}$ & 0,0356 & 0,0037 & 0,0319 & 0,0392 \\
b $_{1}$ & 0,0148 & 0,0045 & 0,0103 & 0,0192 \\
$\mathrm{~b}_{12}$ & $-0,0066$ & 0,0063 & $-0,0129$ & $-0,0002$ \\
\hline
\end{tabular}

Figura 17: Gráficos do modelo proposto para norfloxacina: A) Médias Quadráticas, B) Testes F, C) Resíduos e D) Significância dos coeficientes.
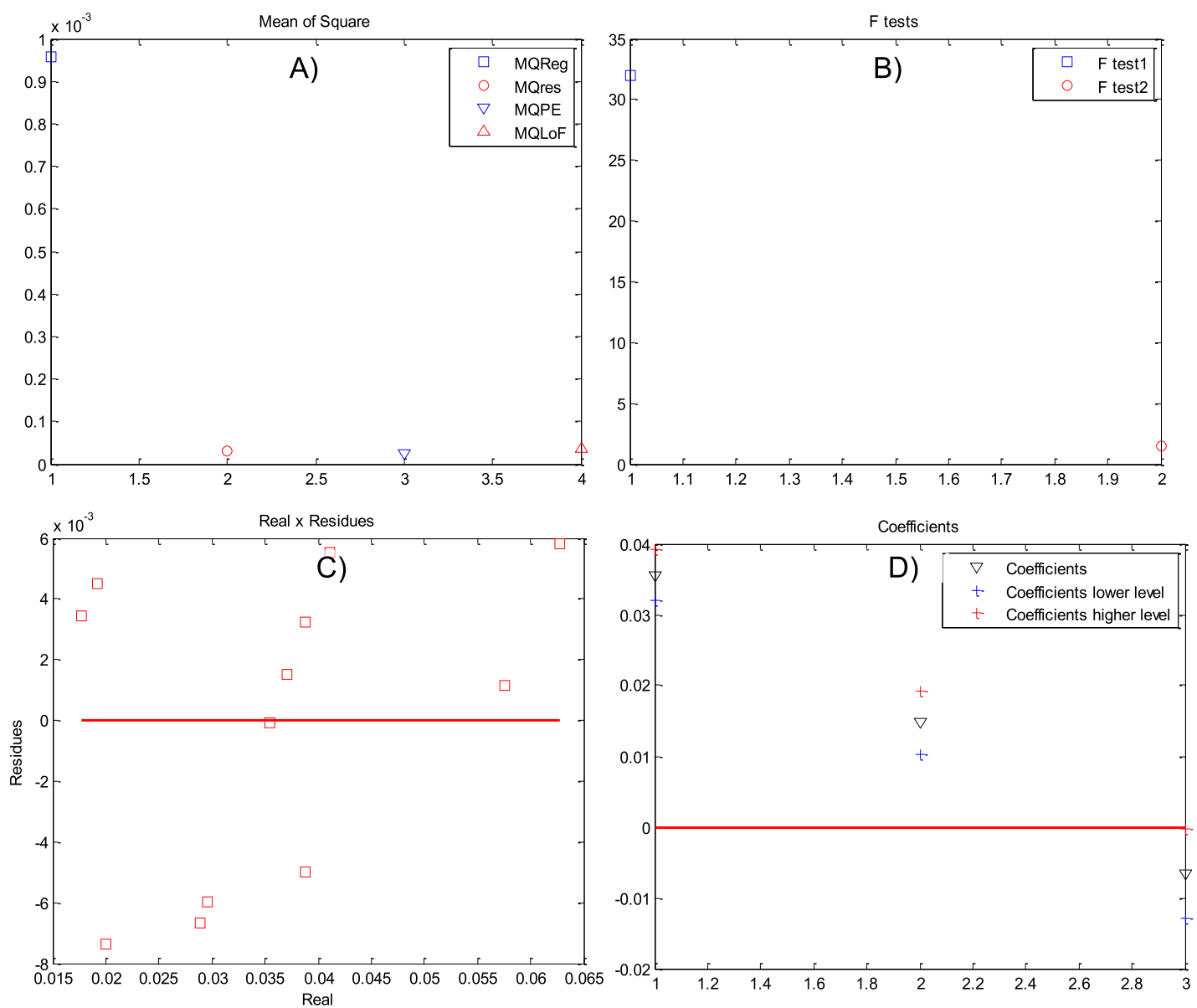
Tabela 20: Tabela ANOVA para a ciprofloxacina.

\begin{tabular}{|c|c|c|c|c|c|}
\hline & $\begin{array}{l}\text { Soma } \\
\text { Quadrática }\end{array}$ & g.l. & $\begin{array}{l}\text { Médias } \\
\text { Quadráticas }\end{array}$ & F calculado & F tabelado \\
\hline Regressão & $6,1 \times 10^{-3}$ & 4 & $1,5 \times 10^{-2}$ & 67,35 & 4,12 \\
\hline Resíduo & $1,6 \times 10^{-4}$ & 7 & $2,3 \times 10^{-5}$ & & \\
\hline Total & $6,3 \times 10^{-3}$ & 11 & $5,7 \times 10^{-4}$ & & \\
\hline Erro Puro & $1,4 \times 10^{-5}$ & 3 & $4,8 \times 10^{-6}$ & 7,49 & 9,12 \\
\hline $\begin{array}{l}\text { Falta de } \\
\text { Ajuste }\end{array}$ & $1,4 \times 10^{-4}$ & 4 & $3,6 \times 10^{-5}$ & & \\
\hline & 0,975 & 0,987 & & & \\
\hline $\mathrm{R}^{2}$ máx & 0,998 & 0,999 & & & \\
\hline
\end{tabular}

Tabela 21 - Coeficientes significativos do modelo proposto para a ciprofloxacina.

\begin{tabular}{ccccc}
\hline \multicolumn{2}{l}{ Coeficientes } & (Erro) & Coeficiente - erro & Coeficiente + erro \\
\hline b $_{0}$ & 0,0798 & 0,0045 & 0,0753 & 0,0843 \\
b $_{1}$ & 0,0254 & 0,0041 & 0,0212 & 0,0295 \\
b $_{2}$ & $-0,0042$ & 0,0041 & $-0,0084$ & $-0,0001$ \\
b $_{2}{ }^{2}$ & $-0,0074$ & 0,0045 & $-0,0119$ & $-0,0029$ \\
b $_{12}$ & $-0,0105$ & 0,0058 & $-0,0163$ & $-0,0047$ \\
\hline
\end{tabular}

Figura 18: Gráficos do modelo proposto para ciprofloxacina: A) Médias Quadráticas, B) Testes F, C) Resíduos e D) Significância dos coeficientes.
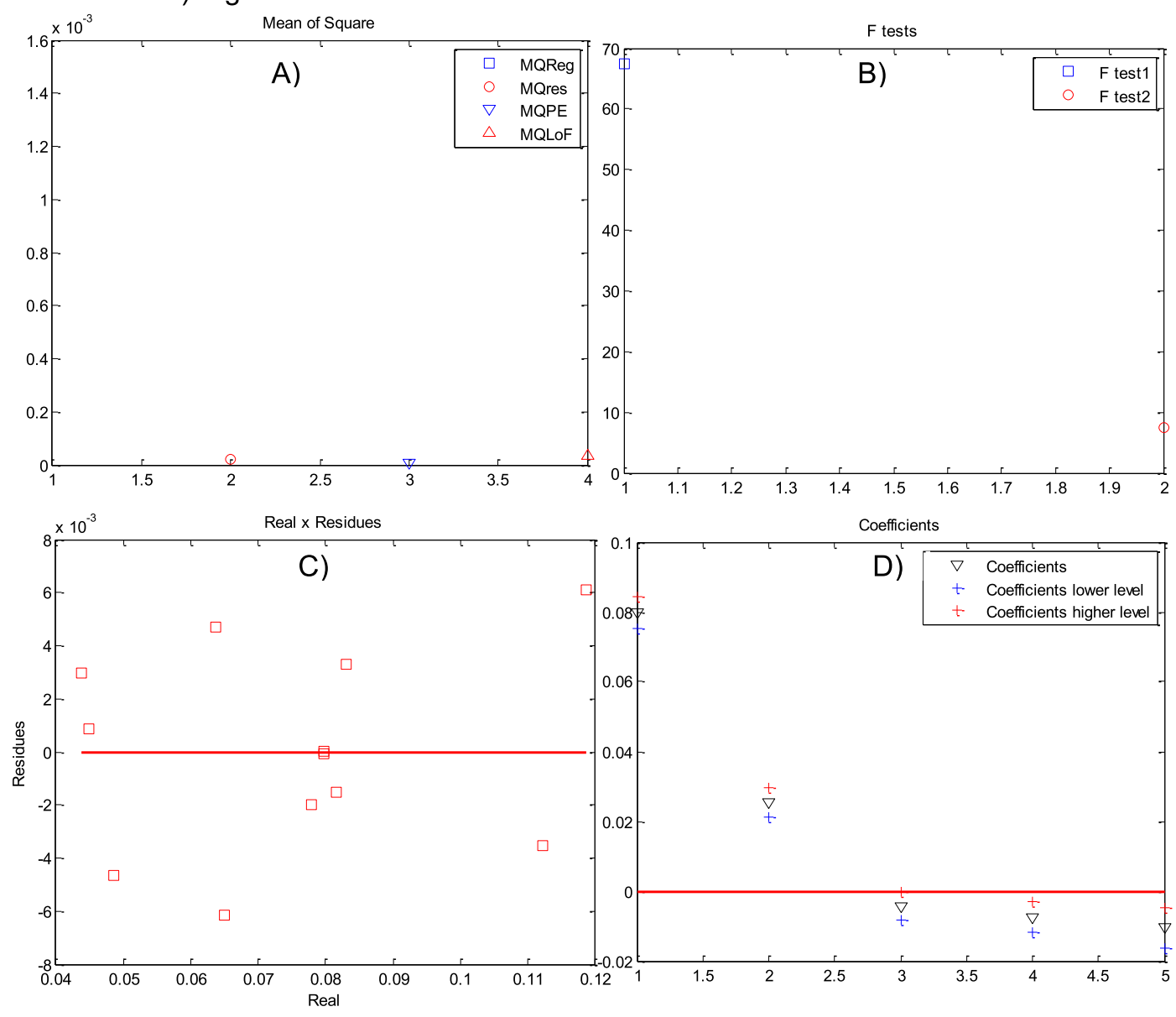
Tabela 22 - Tabela ANOVA para a pefloxacina.

\begin{tabular}{|c|c|c|c|c|c|}
\hline & $\begin{array}{l}\text { Soma } \\
\text { Quadrática }\end{array}$ & g.l. & $\begin{array}{l}\text { Médias } \\
\text { Quadráticas }\end{array}$ & F calculado & F tabelado \\
\hline Regressão & $1,8 \times 10^{-2}$ & 4 & $4,4 \times 10^{-3}$ & 56,37 & 6,094 \\
\hline Resíduo & $5,5 \times 10^{-4}$ & 7 & $7,8 \times 10^{-5}$ & & \\
\hline Total & $1,8 \times 10^{-2}$ & 11 & $1,7 \times 10^{-3}$ & & \\
\hline Erro Puro & $1,4 \times 10^{-4}$ & 3 & $4,8 \times 10^{-5}$ & 2,11 & 9,117 \\
\hline $\begin{array}{l}\text { Falta de } \\
\text { Ajuste }\end{array}$ & $4,0 \times 10^{-4}$ & 4 & $1,0 \times 10^{-4}$ & & \\
\hline & 0,970 & 0,985 & & & \\
\hline $\mathrm{R}^{2}$ máx & 0,992 & 0,996 & & & \\
\hline
\end{tabular}

Tabela 23 - Coeficientes significativos do modelo proposto para a pefloxacina.

\begin{tabular}{ccccc}
\hline \multicolumn{2}{l}{ Coeficientes } & (Erro) & Coeficiente - erro & Coeficiente + erro \\
\hline b $_{0}$ & 0,2869 & 0,0108 & 0,2761 & 0,2977 \\
b $_{1}$ & $-0,0140$ & 0,0077 & $-0,0216$ & $-0,0063$ \\
b $_{1}{ }^{2}$ & $-0,0382$ & 0,0086 & $-0,0467$ & $-0,0296$ \\
b $_{2}{ }^{2}$ & $-0,0317$ & 0,0086 & $-0,0402$ & $-0,0231$ \\
b $_{12}$ & $-0,0272$ & 0,0108 & $-0,0380$ & $-0,0163$ \\
\hline
\end{tabular}

Figura 19 - Gráficos do modelo proposto para pefloxacina: A) Médias Quadráticas, B) Testes F, C) Resíduos e D) Significância dos coeficientes.
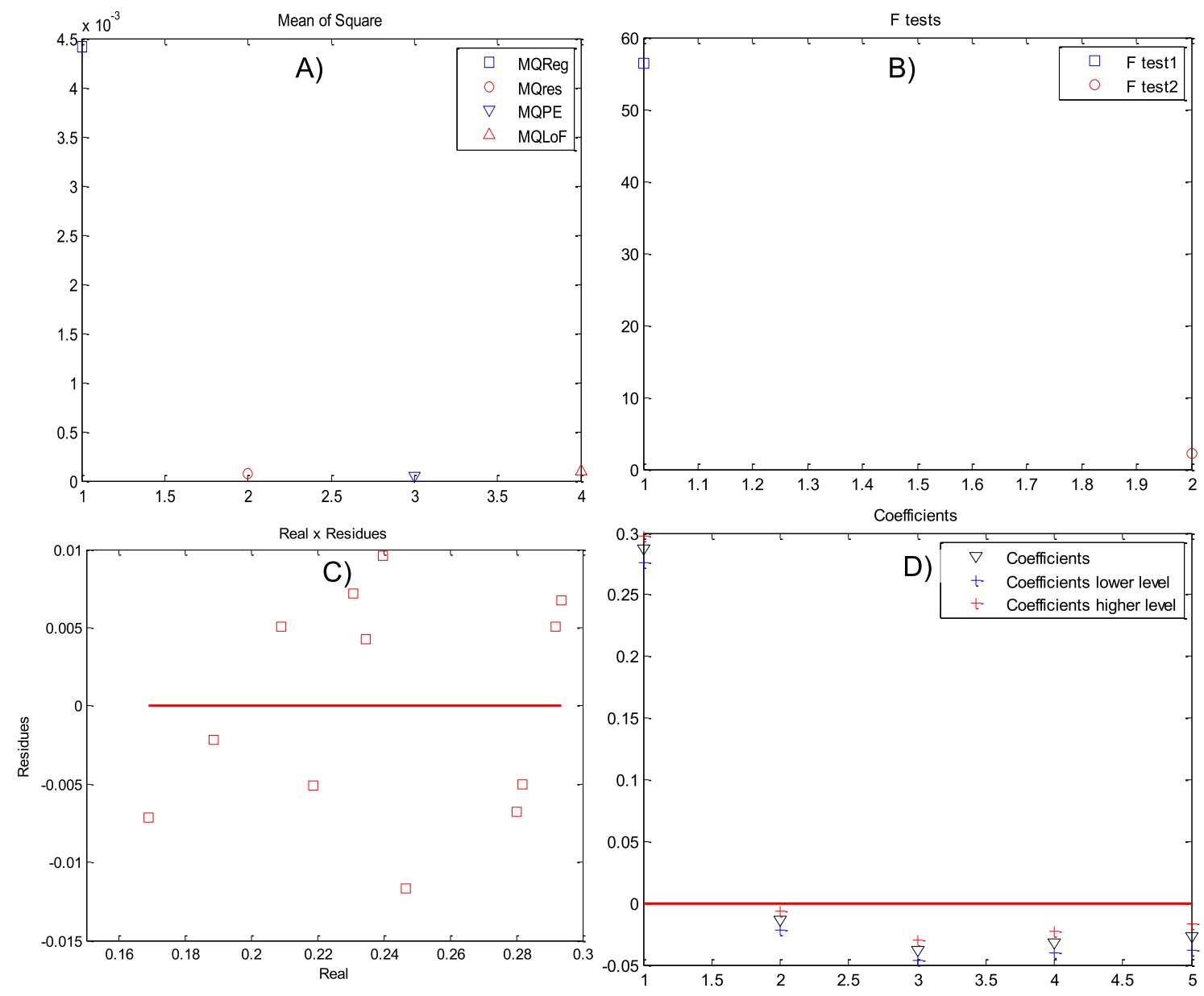
Tabela 24 - Tabela ANOVA para a enrofloxacina.

\begin{tabular}{llllll}
\hline & $\begin{array}{l}\text { Soma } \\
\text { Quadrática }\end{array}$ & g.l. & $\begin{array}{l}\text { Médias } \\
\text { Quadráticas }\end{array}$ & F calculado & F tabelado \\
\hline Regressão & $3,5 \times 10^{-2}$ & 3 & $1,2 \times 10^{-2}$ & 32,31 & 4,07 \\
Resíduo & $2,9 \times 10^{-3}$ & 8 & $3,6 \times 10^{-4}$ & & \\
Total & $3,8 \times 10^{-2}$ & 11 & $3,5 \times 10^{-3}$ & & \\
Erro Puro & $2,0 \times 10^{-3}$ & 6 & $3,4 \times 10^{-4}$ & 1,33 & 5,14 \\
Falta de & $8,9 \times 10^{-4}$ & 2 & $4,5 \times 10^{-4}$ & & \\
Ajuste & & & & \\
$\mathrm{R}^{2}$ & 0,924 & 0,961 & & \\
$\mathrm{R}^{2}$ máx & 0,947 & 0,973 & & & \\
\hline
\end{tabular}

Tabela 25 - Coeficientes significativos do modelo proposto para a enrofloxacina.

\begin{tabular}{ccccc}
\hline \multicolumn{2}{l}{ Coeficientes } & (Erro) & Coeficiente - erro & Coeficiente + erro \\
\hline $\mathrm{b}_{0}$ & 0,3588 & 0,0226 & 0,3362 & 0,3814 \\
$\mathrm{~b}_{1}$ & $-0,0514$ & 0,0160 & $-0,0673$ & $-0,0354$ \\
$\mathrm{~b}_{1}{ }^{2}$ & $-0,0251$ & 0,0179 & $-0,0430$ & $-0,0073$ \\
$\mathrm{~b}_{2}{ }^{2}$ & $-0,0441$ & 0,0179 & $-0,0620$ & $-0,0263$ \\
\hline
\end{tabular}

Figura 20 - Gráficos do modelo proposto para enrofloxacina: A) Médias Quadráticas, B) Testes F, C) Resíduos e D) Significância dos coeficientes.
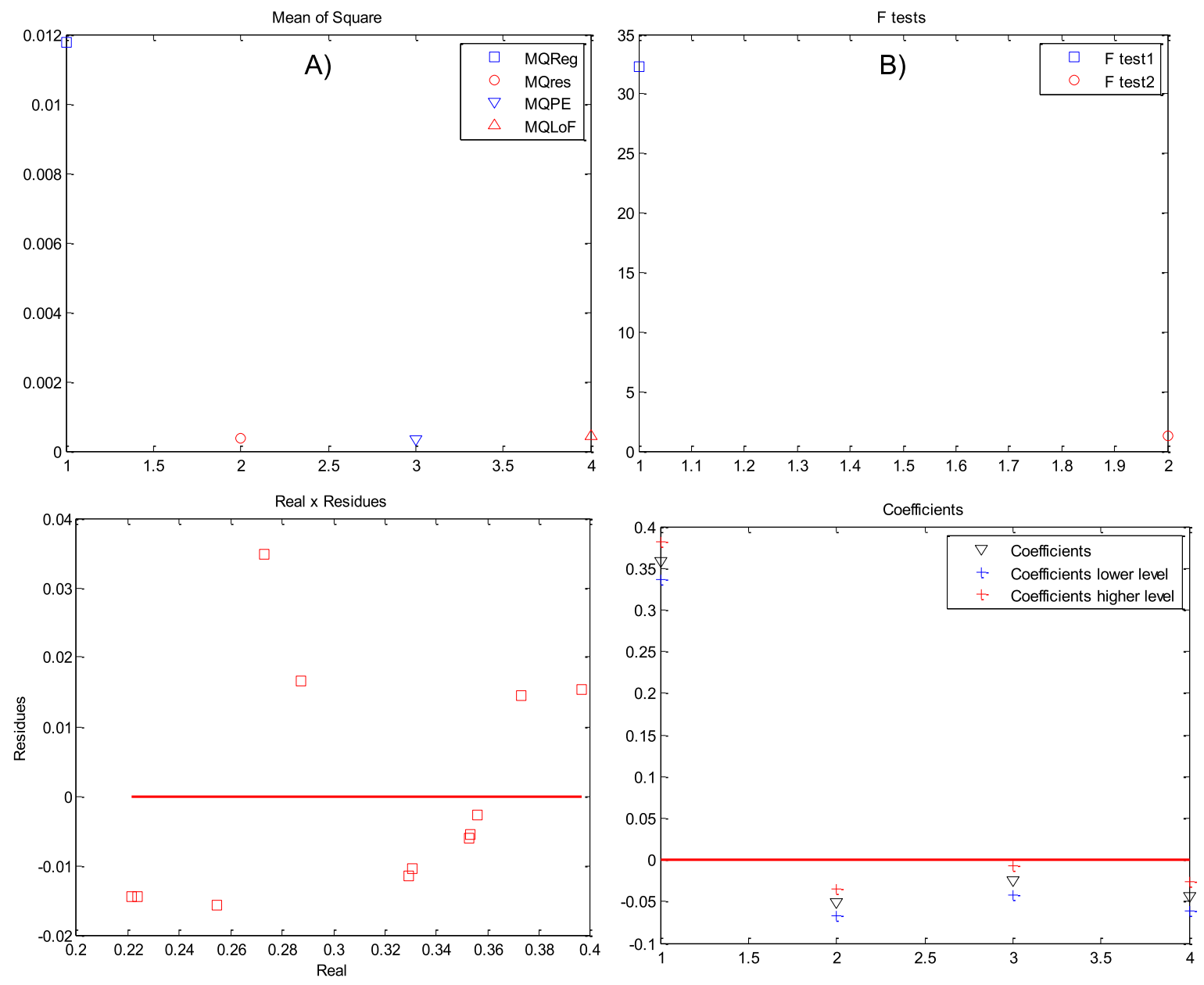
Tabela 26 - Tabela ANOVA para a ofloxacina.

\begin{tabular}{|c|c|c|c|c|c|}
\hline & $\begin{array}{l}\text { Soma } \\
\text { Quadrática }\end{array}$ & g.l. & $\begin{array}{l}\text { Médias } \\
\text { Quadráticas }\end{array}$ & F calculado & F tabelado \\
\hline Regressão & $3,7 \times 10^{-2}$ & 4 & $9,3 \times 10^{-3}$ & 30,42 & 4,12 \\
\hline Resíduo & $2,1 \times 10^{-3}$ & 7 & $3,1 \times 10^{-4}$ & & \\
\hline Total & $3,9 \times 10^{-2}$ & 11 & $3,6 \times 10^{-3}$ & & \\
\hline Erro Puro & $4,4 \times 10^{-4}$ & 4 & $1,1 \times 10^{-4}$ & 5,10 & 6,59 \\
\hline $\begin{array}{l}\text { Falta de } \\
\text { Ajuste }\end{array}$ & $1,7 \times 10^{-3}$ & 3 & $5,7 \times 10^{-4}$ & & \\
\hline & 0,946 & 0,972 & & & \\
\hline $\mathrm{R}^{2}$ máx & 0,989 & 0,994 & & & \\
\hline
\end{tabular}

Tabela 27 - Coeficientes significativos do modelo proposto para a ofloxacina.

\begin{tabular}{ccccc}
\hline \multicolumn{2}{l}{ Coeficientes } & (Erro) & Coeficiente - erro & Coeficiente + erro \\
\hline b $_{0}$ & 0,3760 & 0,0214 & 0,3545 & 0,3974 \\
b $_{1}$ & 0,0211 & 0,0152 & 0,0059 & 0,0362 \\
b $_{1}{ }^{2}$ & $-0,0563$ & 0,0169 & $-0,0732$ & $-0,0393$ \\
b $_{2}{ }^{2}$ & $-0,0420$ & 0,0169 & $-0,0590$ & $-0,0251$ \\
b $_{12}$ & $-0,0422$ & 0,0214 & $-0,0636$ & $-0,0208$ \\
\hline
\end{tabular}

Figura 21 - Gráficos do modelo proposto para ofloxacina: A) Médias Quadráticas, B) Testes F, C) Resíduos e D) Significância dos coeficientes.
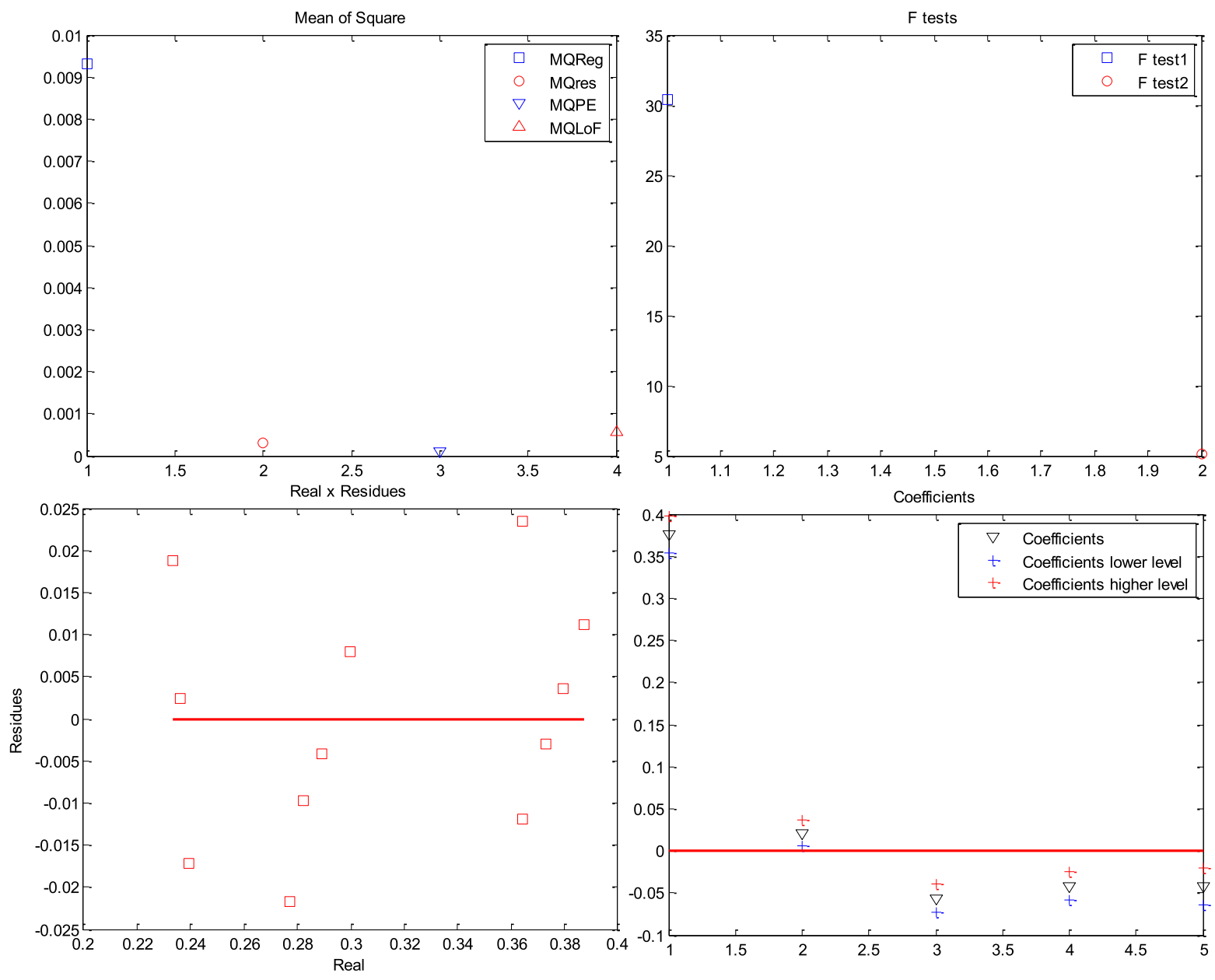
Depois do modelo ter sido proposto, foram plotadas as superfícies de respostas para as FQs como mostra a Figura 22. O método foi otimizado para fazer a extração simultânea das cinco FQs, portanto foi necessário determinar o ponto ótimo para a extração de todas as FQs, desta maneira foram plotados o gráfico e a superfície de resposta para a desejabilidade do modelo como mostra a Figura 22.

Figura 22 - Superfícies de Respostas paras as FQs avaliadas.
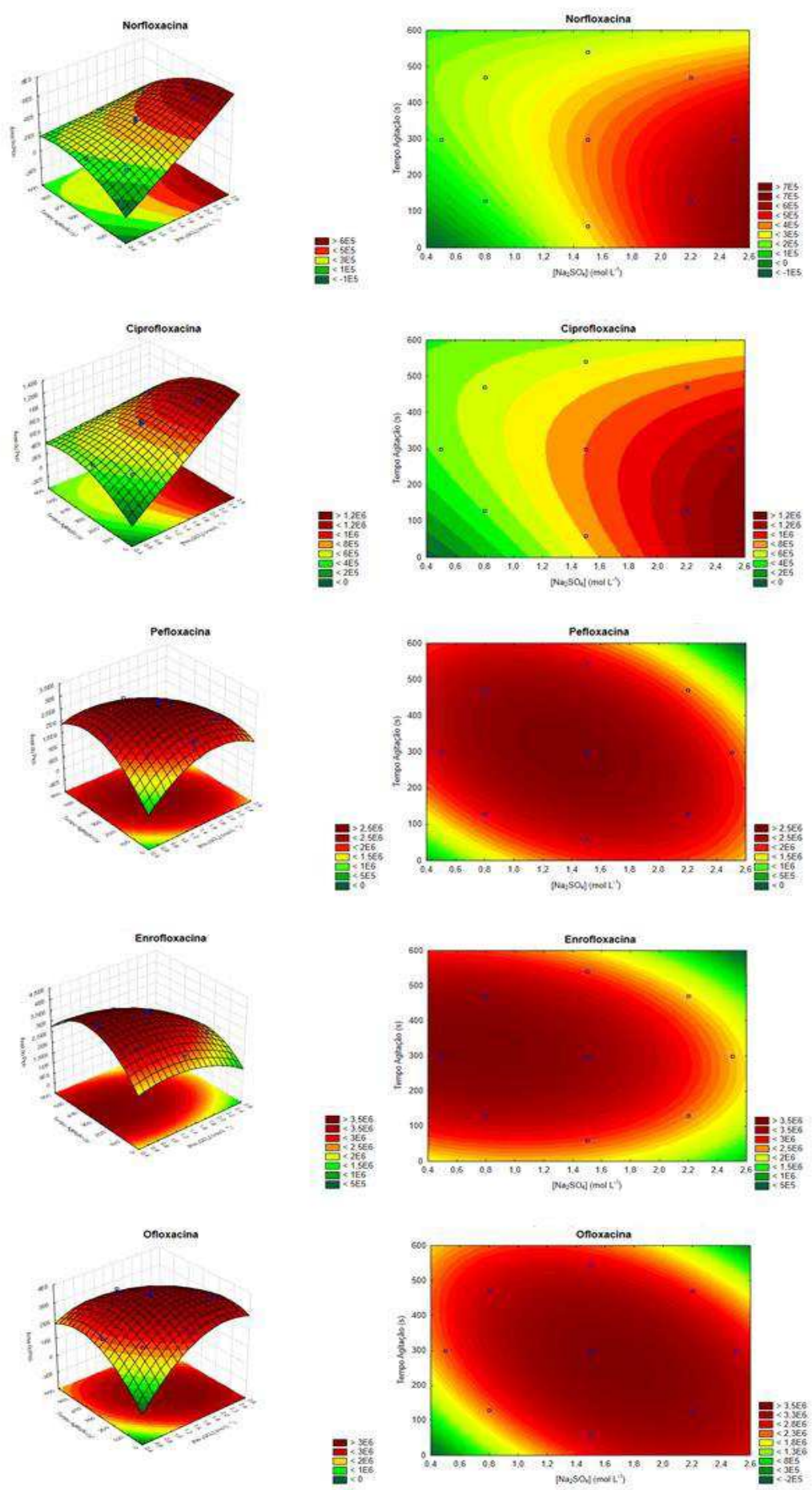
Figura 23: Superfície de resposta para a desejabilidade.

Desirability Surface/Contours; Method: Spline Fit

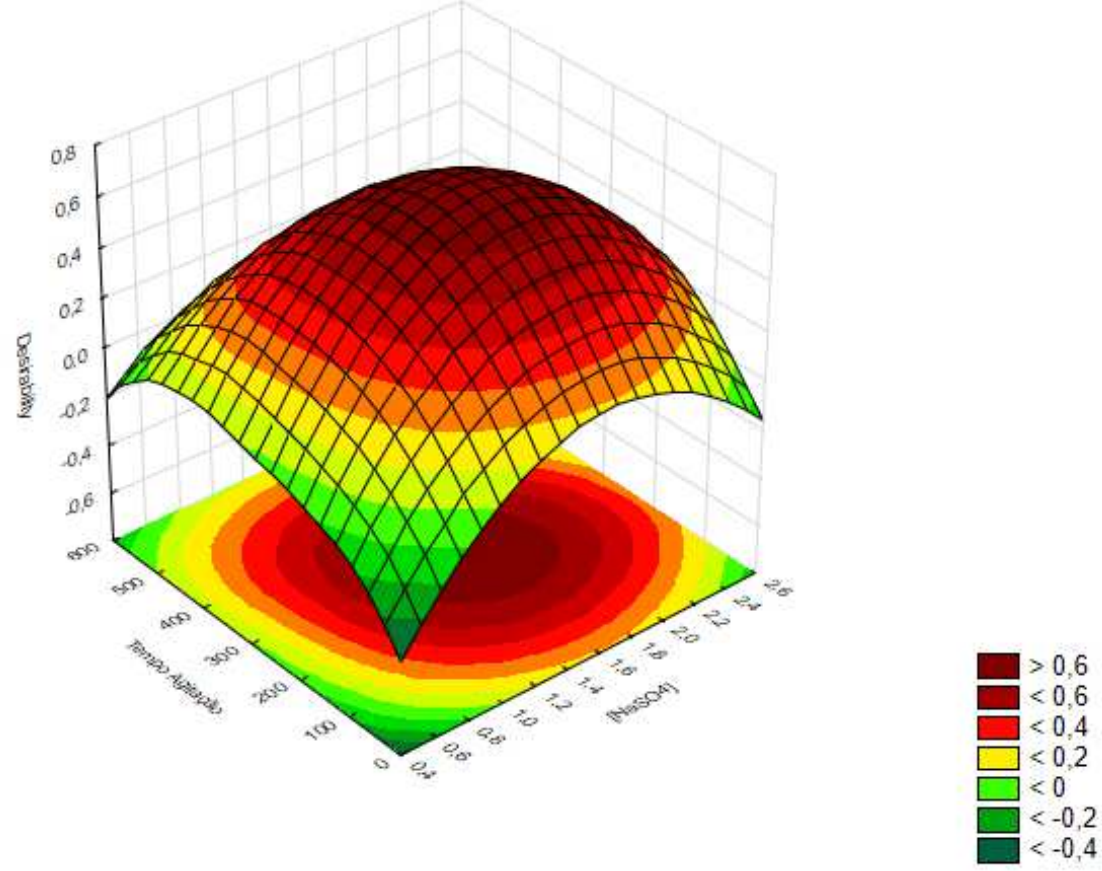

Desta maneira o ponto ótimo para a extração definido pelo modelo foi 180 s de agitação e 2,0 mol L-1 de $\mathrm{Na}_{2} \mathrm{SO}_{4}$ como mostra a Figura 24.

Figura 24: Ponto ótimo para o modelo proposto.

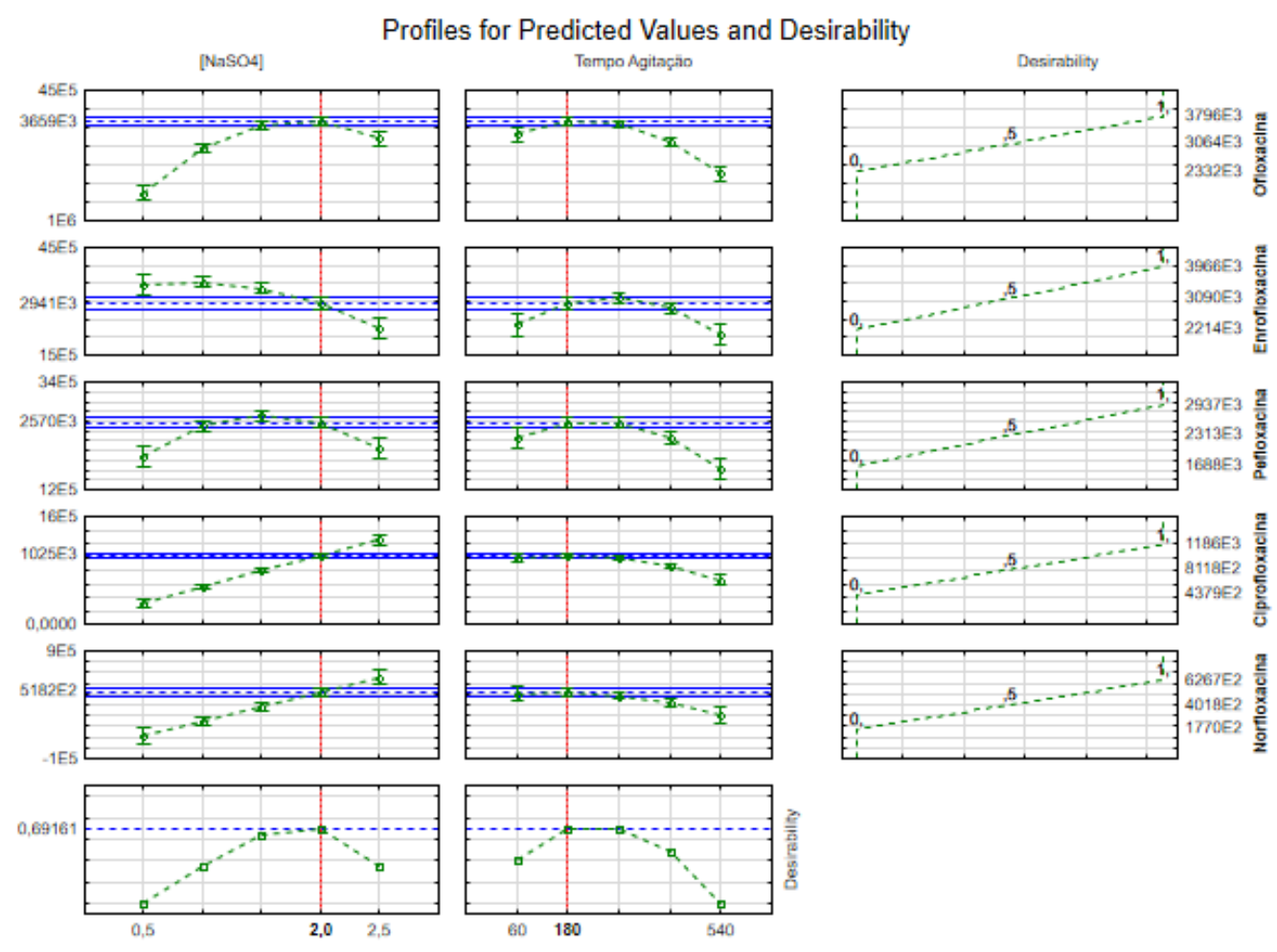


Foi testado o valor de desejabilidade fazendo um experimento nas condições ótimas. A Tabela 28 mostra os valores das áreas absolutas das FQs e o valor da desejabilidade calculada. Como pode ser observado o valor foi de 0,762 , um valor relativamente próximo com o valor proposto pelo modelo que foi de 0,692.

Tabela 28: Avaliação da desejabilidade proposta pelo modelo.

\begin{tabular}{cccccc}
\hline & OFLO & ENRO & PEF & CIP & NOR \\
\hline Área Absoluta no & 3733071 & 3710269 & 2952722 & 814178 & 394985 \\
ponto ótimo & 2331581 & 2213959 & 1688339 & 437924 & 177018 \\
L (menor) & 3796272 & 3966203 & 2936678 & 1185711 & 626674 \\
T (Maior) & 1 & 1 & 1 & 1 & 1 \\
s (Peso) & 0,957 & 0,854 & 1,013 & 0,503 & 0,485 \\
$\begin{array}{c}\text { Desejabilidade } \\
\text { Desejabilidade } \\
\text { Global }\end{array}$ & & & 0,762 & & \\
\hline
\end{tabular}

\subsubsection{Validação do método desenvolvido}

A linearidade do método LLME-LC-CS-QTRAP/MS foi avaliada através da curva analítica construída em amostras de esgoto labmade fortificadas em seis níveis diferentes (Figura 25). A faixa de quantificação analítica, os coeficientes de determinação e correlação e as equações de regressão linear para cada antimicrobiano estão apresentados na tabela 29. As curvas de calibração foram construídas utilizando as transições de $\mathrm{m} / \mathrm{z}$ com maior intensidade para cada analito. 
Figura 25: Curvas analíticas para as fluoroquinolonas processadas por LLME-LC-CS-QTRAP/MS.
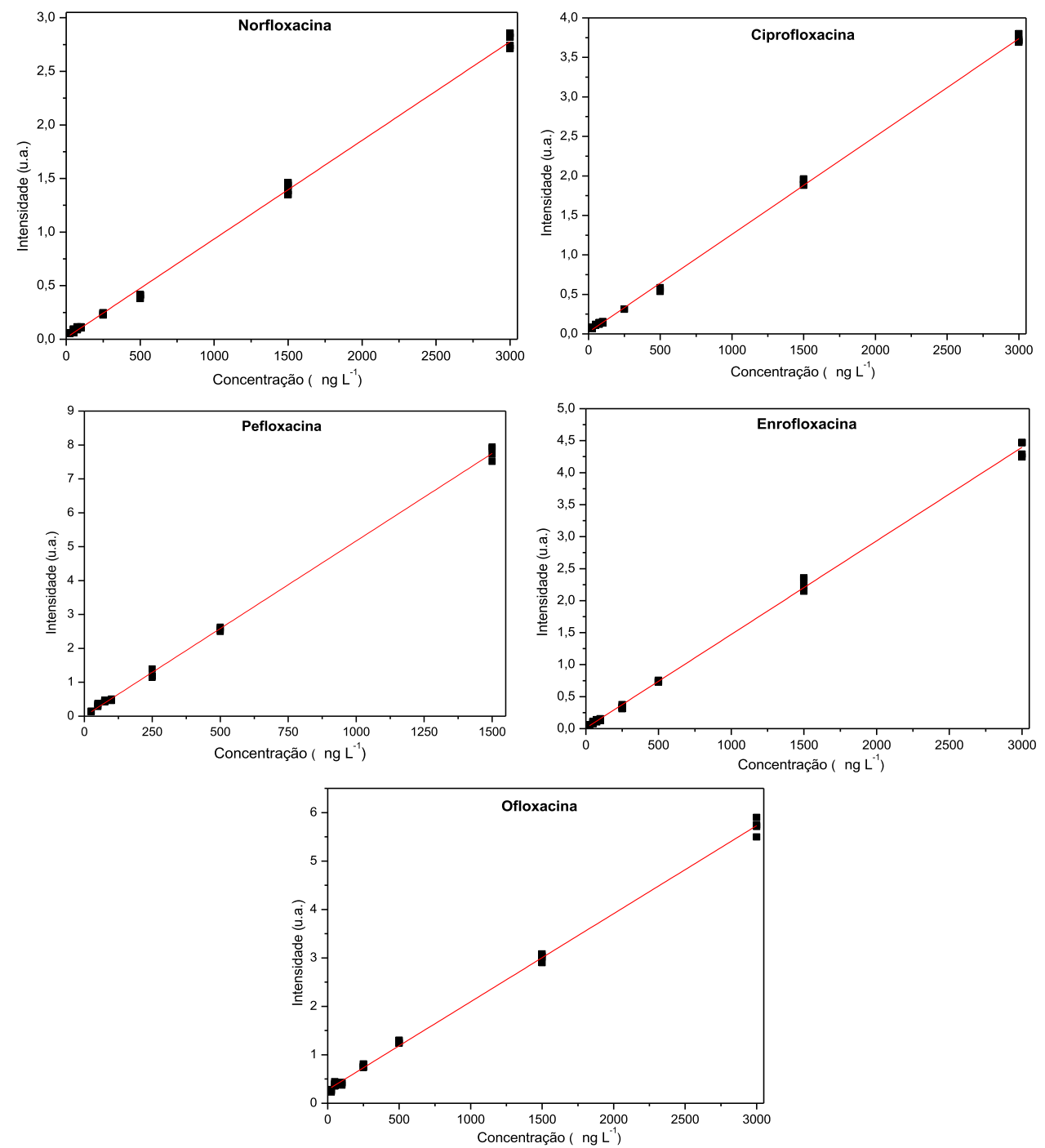

Os dados obtidos com a regressão linear estão contidos na Tabela 29. Os intervalos de confianças para os valores de " $r$ ", "a" e "b" foram calculados multiplicando os seus respectivos valores de desvio padrão pelo valor de t tabelado com 95\% de confiança. Os limites de detecção (LD) e limites de quantificação (LQ) estão mostrados na tabela 29 e foram de 25 e $50 \mathrm{ng} \mathrm{L}^{-1}$, utilizando apenas $5,0 \mathrm{~mL}$ de amostra.

Tabela 29: Dados da Curva Analítica.

\begin{tabular}{|c|c|c|c|c|c|c|}
\hline FQs & $\mathbf{r}^{2}$ & a & b & $\begin{array}{c}\text { Faixa } \\
\text { Linear } \\
\left(\text { ng L-1) }^{-1}\right)\end{array}$ & $\begin{array}{c}\text { LD } \\
\left(\mathrm{ng} \mathrm{L}^{-1}\right)\end{array}$ & $\begin{array}{c}\mathrm{LQ} \\
\left(\mathrm{ng} \mathrm{L}^{-1}\right)\end{array}$ \\
\hline $\begin{array}{c}\text { NOR } \\
320-276\end{array}$ & $\begin{array}{c}0,9981 \pm \\
0,100\end{array}$ & $\begin{array}{c}0,0146 \pm \\
0,0090\end{array}$ & $\begin{array}{c}0,00092 \\
\pm \\
0,00001\end{array}$ & $\begin{array}{l}75- \\
3000\end{array}$ & 50 & 75 \\
\hline $\begin{array}{c}\text { CIP } \\
332-288 \\
\end{array}$ & $\begin{array}{c}0,9987 \pm \\
0,143\end{array}$ & $\begin{array}{c}0,0231 \pm \\
0,0096\end{array}$ & $\begin{array}{c}0,0012 \pm \\
0,0001\end{array}$ & $\begin{array}{l}50- \\
3000\end{array}$ & 25 & 50 \\
\hline
\end{tabular}




\begin{tabular}{ccccccc}
\hline PEF & $0,9987 \pm$ & $0,00052 \pm$ & $0,0057 \pm$ & $50-$ & \multirow{2}{*}{25} & \multirow{2}{*}{50} \\
$334-233$ & 0,0340 & 0,0250 & 0,00004 & 1500 & & \\
\hline ENR & $0,9984 \pm$ & $0,0102 \pm$ & $0,0015 \pm$ & $50-$ & 25 & \multirow{2}{*}{50} \\
$360-316$ & 0,0322 & 0,0126 & 0,0001 & 3000 & & \\
\hline OFL & $0,9982 \pm$ & $0,2795 \pm$ & 0,00182 & $50-$ & \multirow{2}{*}{25} & \multirow{2}{*}{50} \\
$362-318$ & 0,0900 & 0,010 & $\pm 0,0002$ & 3000 & &
\end{tabular}

Adicionalmente, para avaliar a linearidade da curva, foi feita a construção do gráfico de resíduos em relação à área relativa (eixo y da curva) para todos os analitos avaliados. Podemos observar que os resíduos estão bem dispersos e sem indícios de algum tipo de tendência (Figura 26).

Figura 26: Gráficos de resíduos em relação a concentração das fluoroquinolonas.
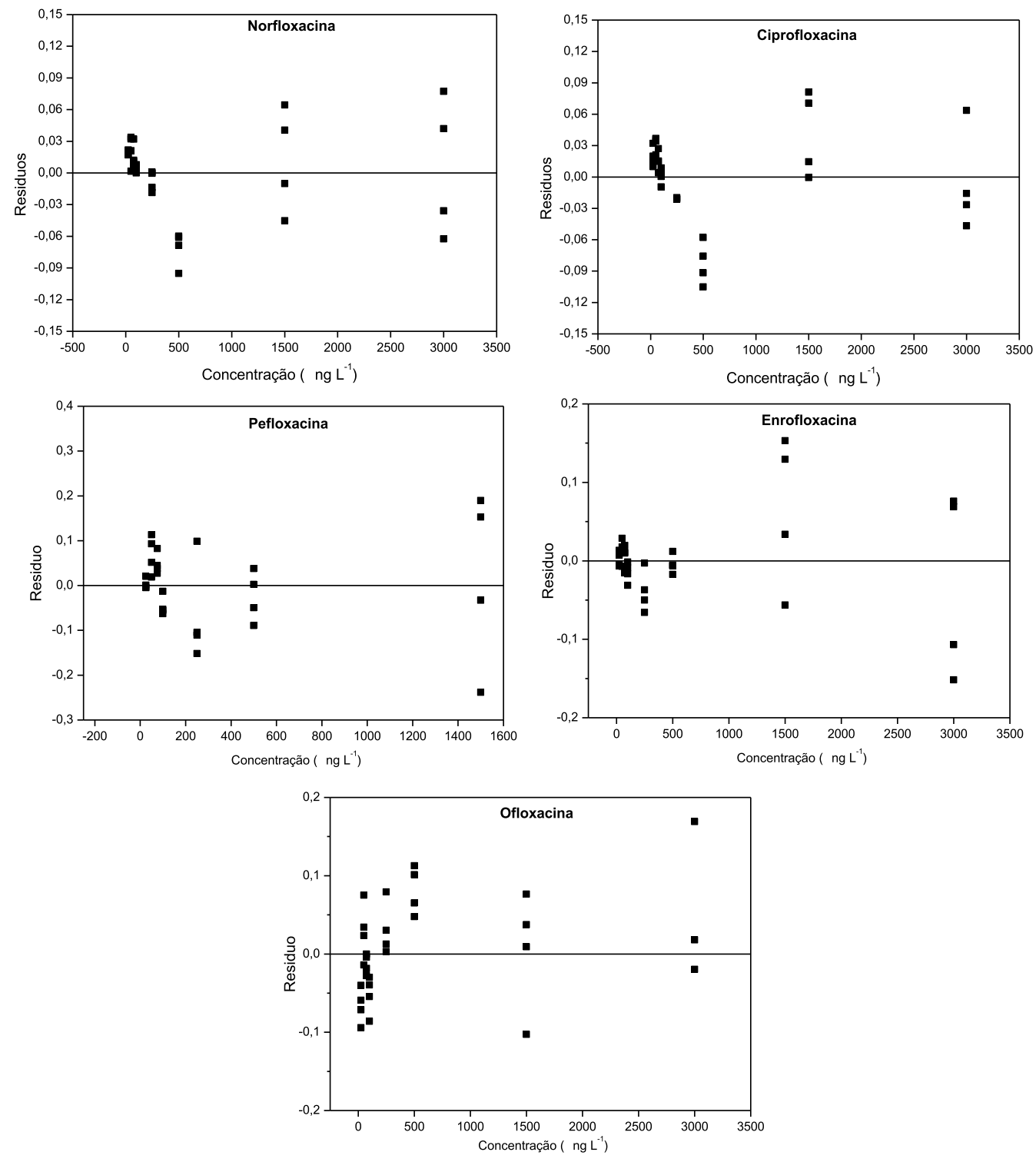
O estudo de precisão intradia e interdias foi expresso em desvio padrão relativo (DPR, \%) sendo obtidos valores abaixo de $20 \%$ para o nível baixo (LQ) e 15\% para os demais níveis (Tabela 30). Já os estudos de exatidão (bias) também apresentaram valores aceitáveis (menores do que $\pm 20 \%$ ) para o nível baixo (LQ) e menores do que $\pm 15 \%$ para os demais níveis. Esses limites de referência são utilizados pela maior parte das agências regulamentadoras e adicionalmente estão totalmente coerentes com o que é regulamentado pelo EPA para análise de compostos orgânicos em resíduo aquoso $(46,55)$.

Um teste adicional foi feito para confirmar se o valor de exatidão obtido para o método desenvolvido era confiável. Portanto para fazer esta avaliação foi utilizado um teste t bicaudal com 4 graus de liberdade e 95\% de confiança, para estas condições o valor de t tabelado é 2,776. Para fazer estes cálculos foi utilizada a equação abaixo:

$$
|t|=\frac{(\text { ymedido }- \text { ypredito }) * \sqrt{n}}{s}
$$

Equação 17

Tabela 30: Valores de precisão e exatidão obtidos para o método LLME desenvolvido.

\begin{tabular}{|c|c|c|c|c|c|}
\hline FQs & Níveis & $\begin{array}{c}\text { Precisão } \\
\text { intra-dia } \\
\text { DPR (\%) } \\
(n=5)\end{array}$ & $\begin{array}{c}\text { Precisão } \\
\text { inter- } \\
\text { dias } \\
\text { DPR }(\%) \\
(\mathrm{n}=10) \\
\end{array}$ & $\begin{array}{c}\text { Exatidão } \\
\text { (\% bias) } \\
\text { DPR (\%) } \\
(n=5)\end{array}$ & t calculado \\
\hline \multirow{3}{*}{ NOR } & Baixo & 12,1 & 10,7 & 9,2 & 1,302 \\
\hline & Médio & 4,4 & 8,1 & $-5,4$ & 1,600 \\
\hline & Alto & 2,0 & 3,9 & 3,4 & 1,885 \\
\hline \multirow{3}{*}{ CIP } & Baixo & 4,8 & 11,6 & 17,0 & 2,573 \\
\hline & Médio & 3,4 & 4,2 & $-8,1$ & 2,254 \\
\hline & Alto & 4,6 & 4,2 & 5,0 & 2,508 \\
\hline \multirow{3}{*}{ PEF } & Baixo & 3,0 & 11,6 & 10,2 & 0,555 \\
\hline & Médio & 12,5 & 6,5 & $-6,2$ & 2,269 \\
\hline & Alto & 6,0 & 7,7 & $-13,8$ & 2,762 \\
\hline \multirow{3}{*}{ ENR } & Baixo & 1,3 & 14,8 & 7,5 & 0,241 \\
\hline & Médio & 10,0 & 5,5 & 2,3 & 0,912 \\
\hline & Alto & 8,2 & 7,5 & 6,4 & 1,789 \\
\hline \multirow{3}{*}{ OFLO } & Baixo & 0,1 & 2,5 & 8,0 & 0,075 \\
\hline & Médio & 13,8 & 11,9 & 6,7 & 0,713 \\
\hline & Alto & 8,1 & 6,7 & 8,7 & 1,283 \\
\hline
\end{tabular}


Analisando os valores de $\mathrm{t}$ calculados, pode-se afirmar que o método desenvolvido possui exatidão nos três níveis avaliados, pois todos os valores de $\mathrm{t}$ calculados foram menores que o valor de $\mathrm{t}$ tabelado para 4 graus de liberdade $(2,7764)$, portanto os valores de y (área relativa) medidos não tem diferença significativa em relação aos valores de y preditos pela curva analítica. Com base nos estudos feitos por Matuszewski et. al foi realizado o estudo do efeito de matriz, recuperação e eficiência total do método (48). Os valores de ME, PE e RE (Tabela 31) foram calculados a partir das áreas absolutas nos três níveis (baixo, médio e alto).

A recuperação e a eficiência total do processo para as FQs mais polares (NOR e CIP) foram mais baixas comparando com as demais FQs menos polares, isso é explicado pois o solvente utilizado para a extração foi o diclorometano, um solvente menos polar. O efeito de matriz não foi influenciado pela concentração no analito, pois para os três níveis foram aproximadamente iguais os $M E$, porém por se tratar de uma matriz complexa existe efeito de matriz, indicando a ocorrência de uma provável supressão da ionização nos níveis de concentração das análises feitas por espectrometria de massas. Esse efeito pode estar relacionado a possíveis interferentes presentes na matriz e que impedem, de alguma forma, a ionização total dos analitos. Todavia, a presença de certo grau de efeito de matriz em amostras complexas é, de alguma forma, esperada.

Tabela 31: Valores de recuperação, efeito matriz e eficiência total do método LLME validado.

\begin{tabular}{ccccc}
\hline FQs & Níveis & $\begin{array}{c}\text { Recuperação } \\
(\mathbf{\%}) \\
(\mathbf{n = 3})\end{array}$ & $\begin{array}{c}\text { Efeito de } \\
\text { Matriz } \mathbf{( \% )} \\
(\mathbf{n = 3})\end{array}$ & $\begin{array}{c}\text { Eficiência total } \\
\text { do Processo (\%) } \\
(\mathbf{n = 3})\end{array}$ \\
\hline \multirow{3}{*}{ NOR } & Baixo & 14,3 & 66,7 & 9,5 \\
& Médio & 10,3 & 63 & 6,5 \\
& Alto & 20,1 & 67,1 & 13,5 \\
\hline \multirow{3}{*}{ CIP } & Baixo & 12,6 & 29,4 & 3,7 \\
& Médio & 39,0 & 58,1 & 22,6 \\
& Alto & 32,0 & 67,5 & 21,6 \\
\hline \multirow{3}{*}{ PEF } & Baixo & 49,8 & 58,5 & 29,1 \\
& Médio & 77,1 & 55,0 & 42,8 \\
& Alto & 100,2 & 62,2 & 62,4 \\
\hline \multirow{3}{*}{ ENR } & Baixo & 57,1 & 61,3 & 35,0 \\
& Médio & 47,8 & 64,5 & 30,8 \\
& Alto & 80,1 & 65,9 & 52,8 \\
\hline \multirow{3}{*}{ OFLO } & Baixo & 85,8 & 56,3 & 48,3 \\
& Médio & 59,1 & 75,3 & 44,5 \\
& Alto & 82,4 & 70,6 & 58,2 \\
\hline
\end{tabular}




\subsubsection{Aplicação do Método}

Para aplicação do método em amostra real foram determinados 4 pontos de amostragem, o ponto 1 refere-se a esgoto de característica puramente doméstica (representativo dos bairros circunvizinhos ao Campus 2 da USP São Carlos); o ponto 2 refere-se ao rio Monjolinho (localizado próximo a USP São Carlos - Campus 1); o ponto 3 refere-se ao rio Monjolinho (local próximo ao Shopping Iguatemi) e o ponto 4 refere-se à estação de tratamento de esgoto da cidade de São Carlos.

Os cromatogramas obtidos por meio do método desenvolvido para a extração das FQs avaliadas estão contidos nas figuras 28-31, para facilitar a identificação das FQs avaliadas, as amostras reais foram fortificadas com os padrões para comparar com as amostras sem fortificação. 
Figura 27: Cromatogramas obtido no método LLME-LC-CS-QTRAP/MS para extração de fluoroquinolonas em amostras de água coletadas no ponto 1 da amostragem: Foram monitoradas duas transições de m/z 320-276 e 320-233 para a norfloxacina, 332-288, 332-245 e 332-231 para a ciprofloxacina e 362-318 e 362-261 para a ofloxacina. a), c), e) Amostra real fortificada com $500 \mathrm{ng} \mathrm{L}^{-1}$ de NOR, CIP e OFLO respectivamente e b), d), f) amostra real sem fortificação. As demais fluoroquinolonas ficaram abaixo do limite de detecção do método desenvolvido.

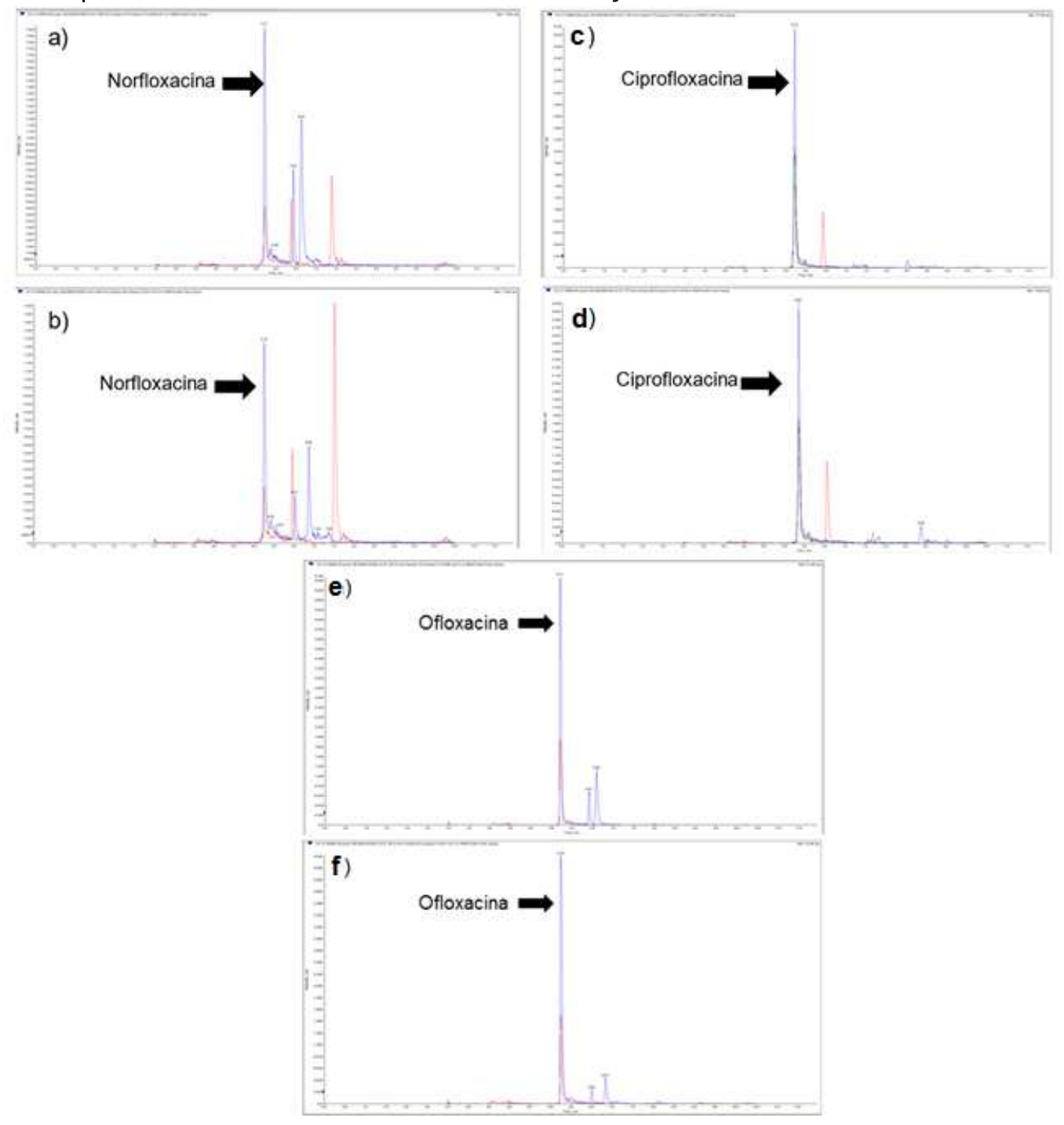


Figura 28: Cromatogramas obtido no método LLME-LC-CS-QTRAP/MS para extração de fluoroquinolonas em amostras de água coletadas no ponto 1 da amostragem: Foram monitoradas duas transições de m/z 332-288, 332-245 e 332-231 para a ciprofloxacina e 362-318 e 362-261 para a ofloxacina. a), c) Amostra real fortificada com $500 \mathrm{ng} \mathrm{L}^{-1}$ de CIP e OFLO respectivamente e b), d) amostra real sem fortificação. As demais fluoroquinolonas ficaram abaixo do limite de detecção do método desenvolvido.
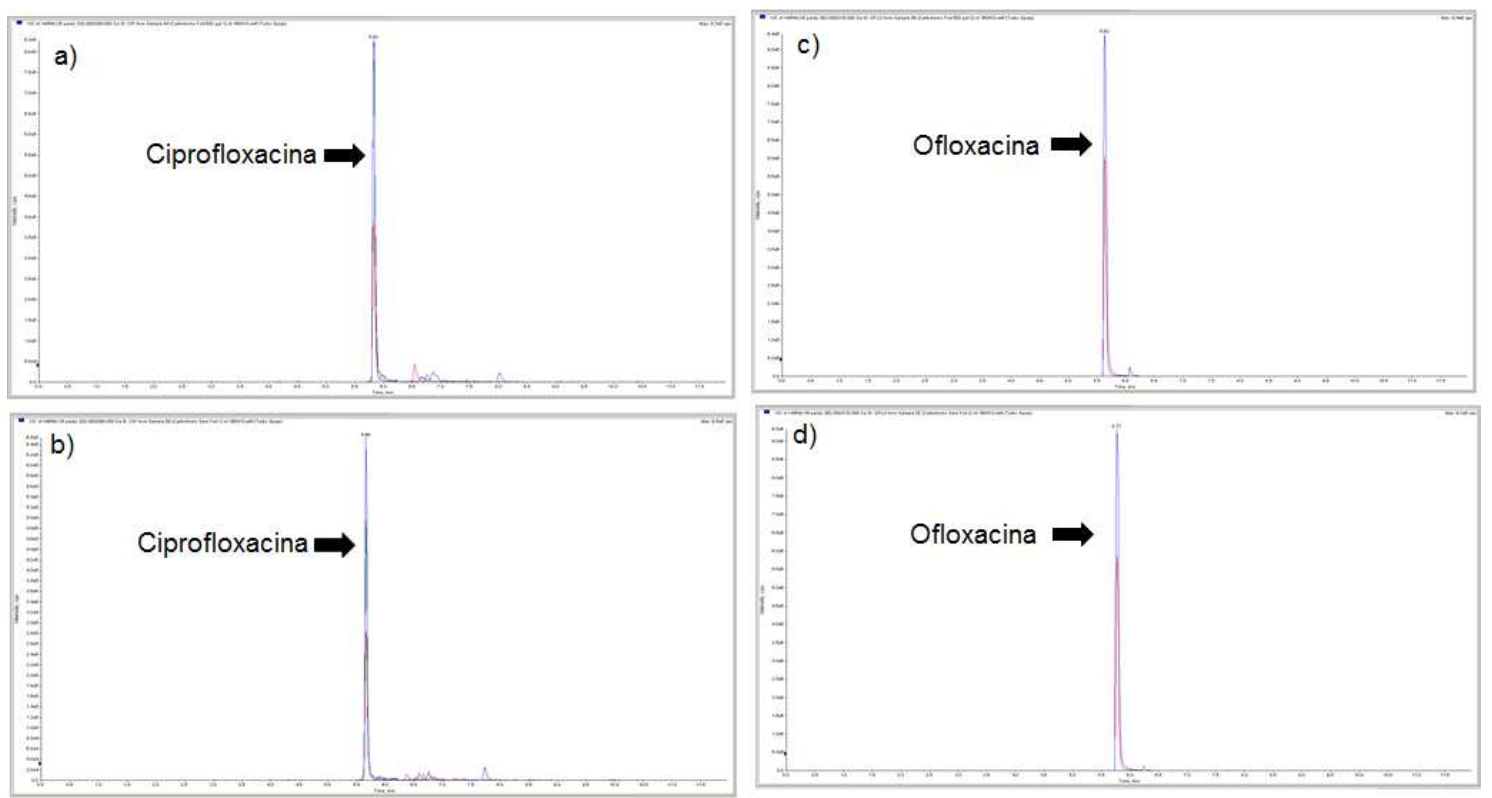

Figura 29: Cromatogramas obtido no método LLME-LC-CS-QTRAP/MS para extração de fluoroquinolonas em amostras de água coletadas no ponto 1 da amostragem: Foram monitoradas duas transições de $\mathrm{m} / \mathrm{z}$ 332-288, 332-245 e 332-231 para a ciprofloxacina e 362-318 e 362-261 para a ofloxacina. a), c) Amostra real fortificada com $500 \mathrm{ng} \mathrm{L}^{-1}$ de CIP e OFLO respectivamente e b), d) amostra real sem fortificação. As demais fluoroquinolonas ficaram abaixo do limite de detecção do método desenvolvido.
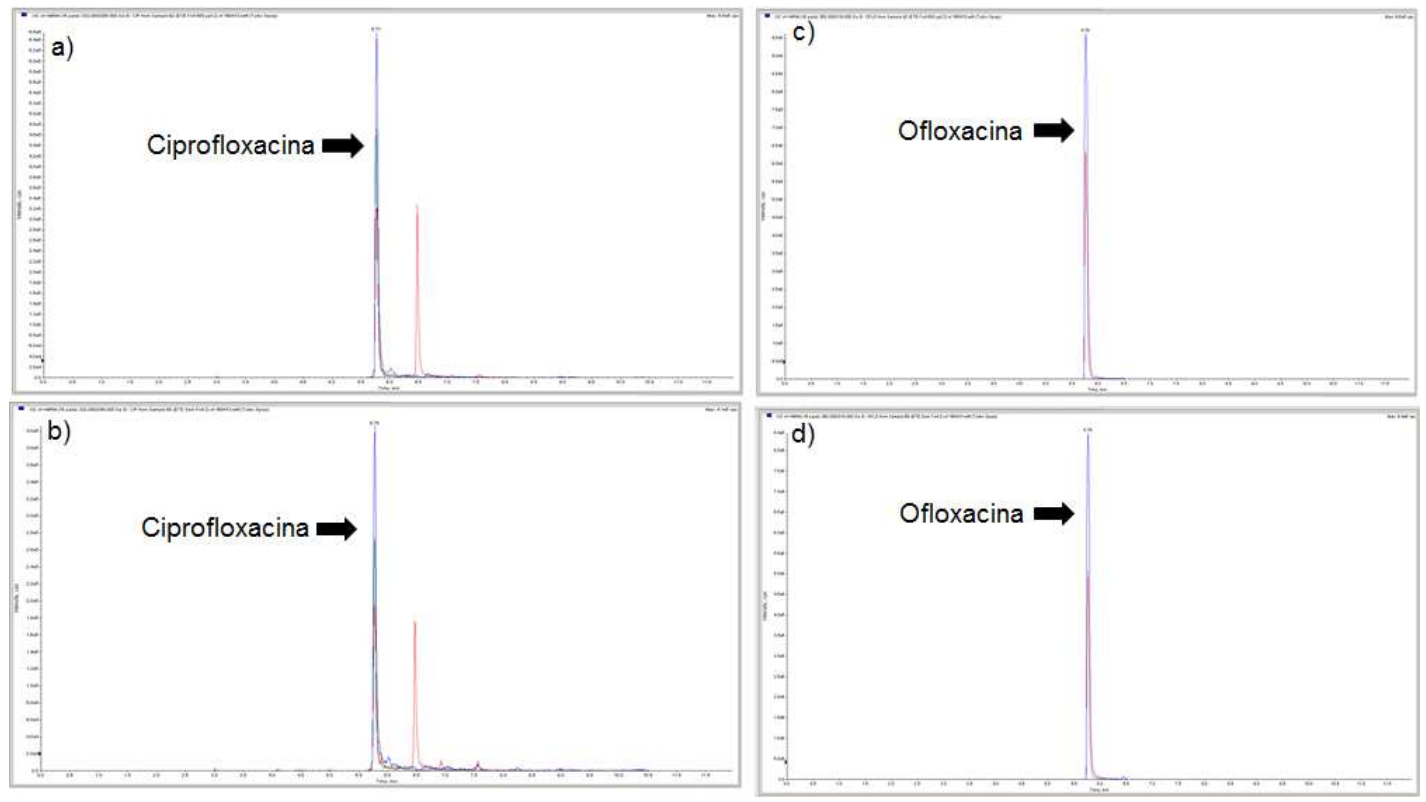
Figura 30: Cromatogramas obtido no método LLME-LC-CS-QTRAP/MS para extração de fluoroquinolonas em amostras de água coletadas no ponto 1 da amostragem: Foram monitoradas duas transições de m/z 320-276 e 320-233 para a norfloxacina, 332-288, 332-245 e 332-231 para a ciprofloxacina, 360-316, 360-245 e 360-286 para a enrofloxacina e 362-318 e 362-261 para a ofloxacina. a), c), e), g) Amostra real fortificada com $500 \mathrm{ng} \mathrm{L}^{-1}$ de NOR, CIP e OFLO respectivamente e b), d), f), h) amostra real sem fortificação. As demais fluoroquinolonas ficaram abaixo do limite de detecção do método desenvolvido.

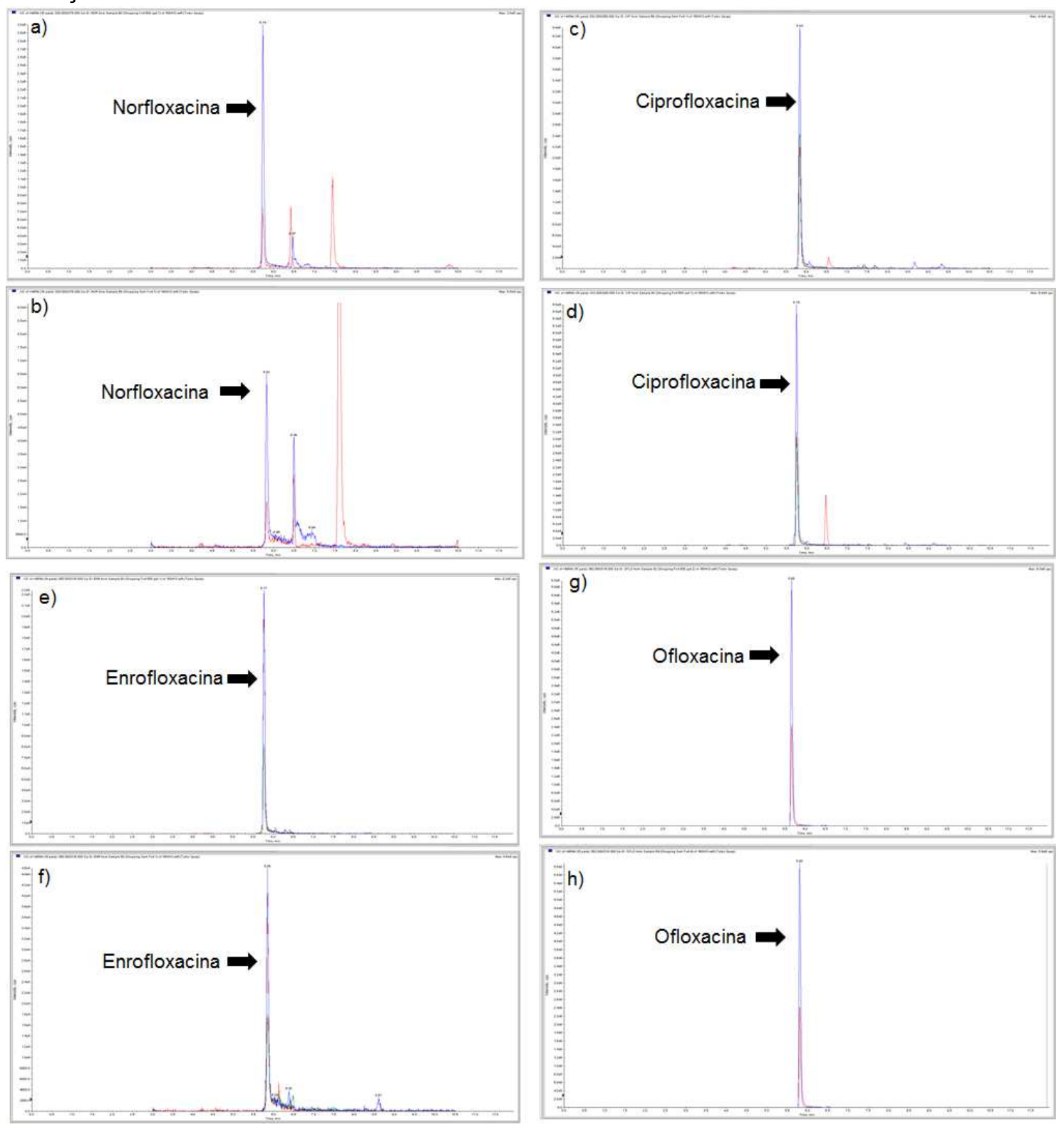

Dentre as amostras reais utilizadas para aplicação do método, foi possível detectar e quantificar algumas contaminações por esses antimicrobianos, conforme a Tabela 32. As análises mostraram contaminação por norfloxacina, ciprofloxacina, enrofloxacina e ofloxacina na maioria dos pontos de coleta avaliados e em níveis quantificáveis. Dentre as FQs estudas a norfloxacina e a ciprofloxacina são provavelmente as mais amplamente utilizadas para diversas infecções - norfloxacina 
(principal aplicação em infecções urinárias e em tratamentos oftalmológicos) e ciprofloxacina (aplicação contra infecções dos rins e/ou do trato urinário, infecções dos órgãos genitais, infecções da pele e infecções ósseas e articulares). A enrofloxacina é muito utilizada para tratamento de infecções em animais.

Tabela 32: Concentração dos antibióticos detectados nas amostras de água coletadas nos pontos 1 ao 4 indicados na figura 3.

\begin{tabular}{ccccc}
\hline FQs & $\begin{array}{c}\text { Ponto 1 } \\
\left(\text { ng L}^{-1}\right)\end{array}$ & $\begin{array}{c}\text { Ponto 2 } \\
\text { (ng L-1) }\end{array}$ & $\begin{array}{c}\text { Ponto 3 } \\
\left(\text { ng L }^{-1}\right)\end{array}$ & $\begin{array}{c}\text { Ponto 4 } \\
\text { (ng L-1) }\end{array}$ \\
\hline Norfloxacina & $344 \pm 32$ & $\mathrm{ND}$ & $177 \pm 24$ & $\mathrm{ND}$ \\
\hline Ciprofloxacina & $1011 \pm 70$ & $1090 \pm 125$ & $917 \pm 105$ & $594 \pm 27$ \\
\hline Pefloxacina & $\mathrm{ND}$ & $\mathrm{ND}$ & $\mathrm{ND}$ & $\mathrm{ND}$ \\
\hline Enrofloxacina & $\mathrm{ND}$ & $\mathrm{ND}$ & $74,6 \pm 9$ & $\mathrm{ND}$ \\
\hline Ofloxacina & $484 \pm 53$ & $1614 \pm 23$ & $7992 \pm 814$ & $8737 \pm 553$ \\
\hline
\end{tabular}

\subsection{Microextração em gota suspensa (SDME-LC-MS/MS) para a determinação de sulfonamidas e fluoroquinolonas em amostra de água}

\subsubsection{Avaliação do melhor solvente de extração}

Foram avaliados alguns solventes para a extração simultânea das duas classes de antimicrobianos, sulfonamidas e fluoroquinolonas. Os solventes avaliados foram: diclorometano $(A)$, clorofórmio $(B)$ e acetato de etila $(C)$ como mostra a figura 31. O solvente que foi mais eficiente na extração das duas classes simultaneamente utilizando a técnica miniaturizada conhecida como "single drop" foi a mistura de diclorometano/acetato de etila na proporção de 50/50. 
Figura 31: Avaliação do melhor solvente de extração para de sulfas e FQs.

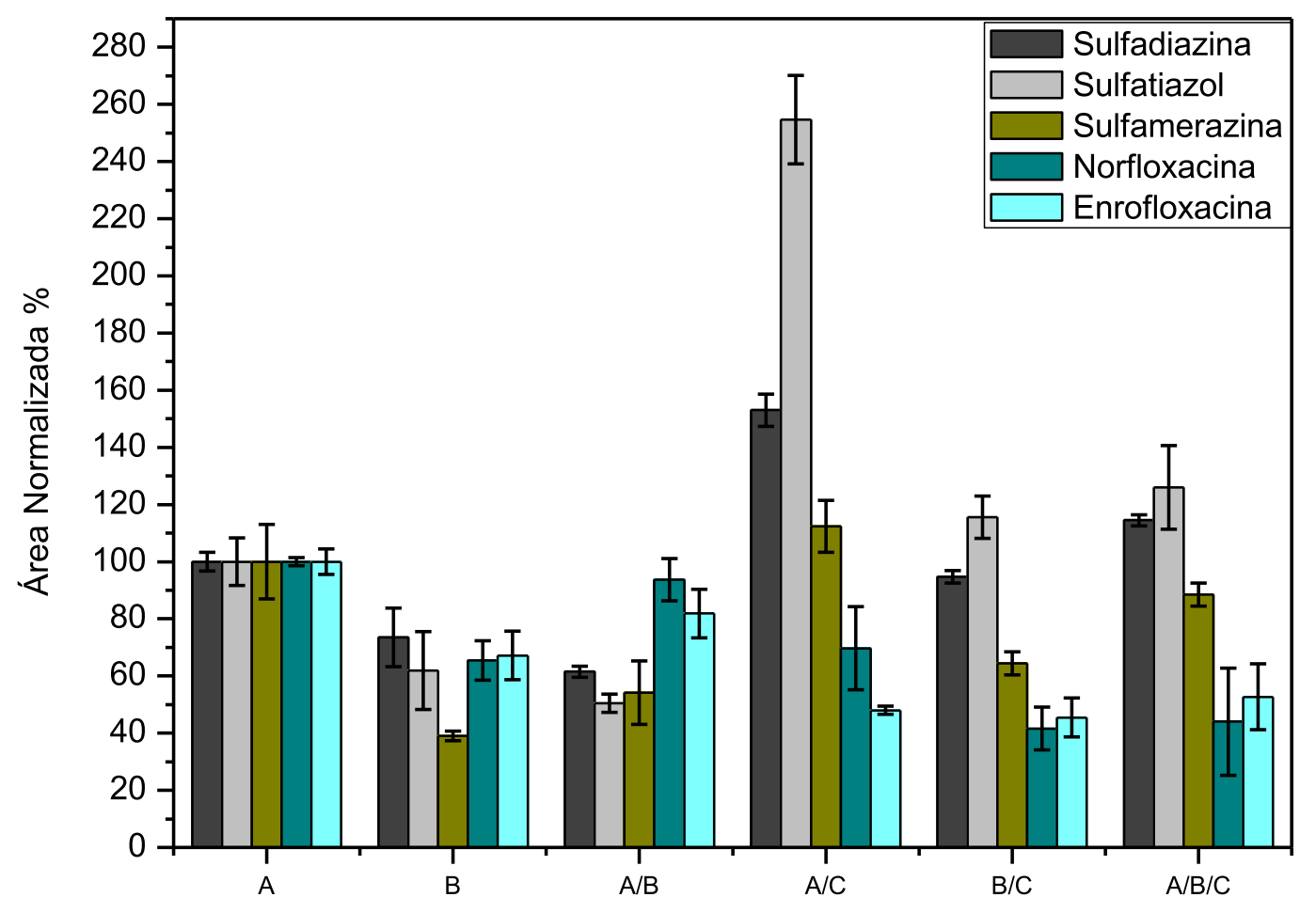

Determinada a mistura mais eficiente para a extração, foi realizado um planejamento experimental $2^{2}$ composto central estrela para avaliar a melhor condição para a extração dos analitos.

\subsubsection{Automatização do método de microextração em gota suspensa}

Para facilitar o uso da técnica de microextração em gota suspensa foi utilizado um sistema desenvolvido no Laboratório de Cromatografia para realizar as extrações. O sistema consiste de uma seringa de HPLC de $250 \mu \mathrm{L}$ acoplada em um sistema metálico automatizado controlado por um computador conforme mostra a Figura 32. O uso deste sistema facilita a extração e minimiza os erros, consequentemente aumentando a precisão e exatidão do método desenvolvido. 
Figura 32: Microextração em gota suspensa
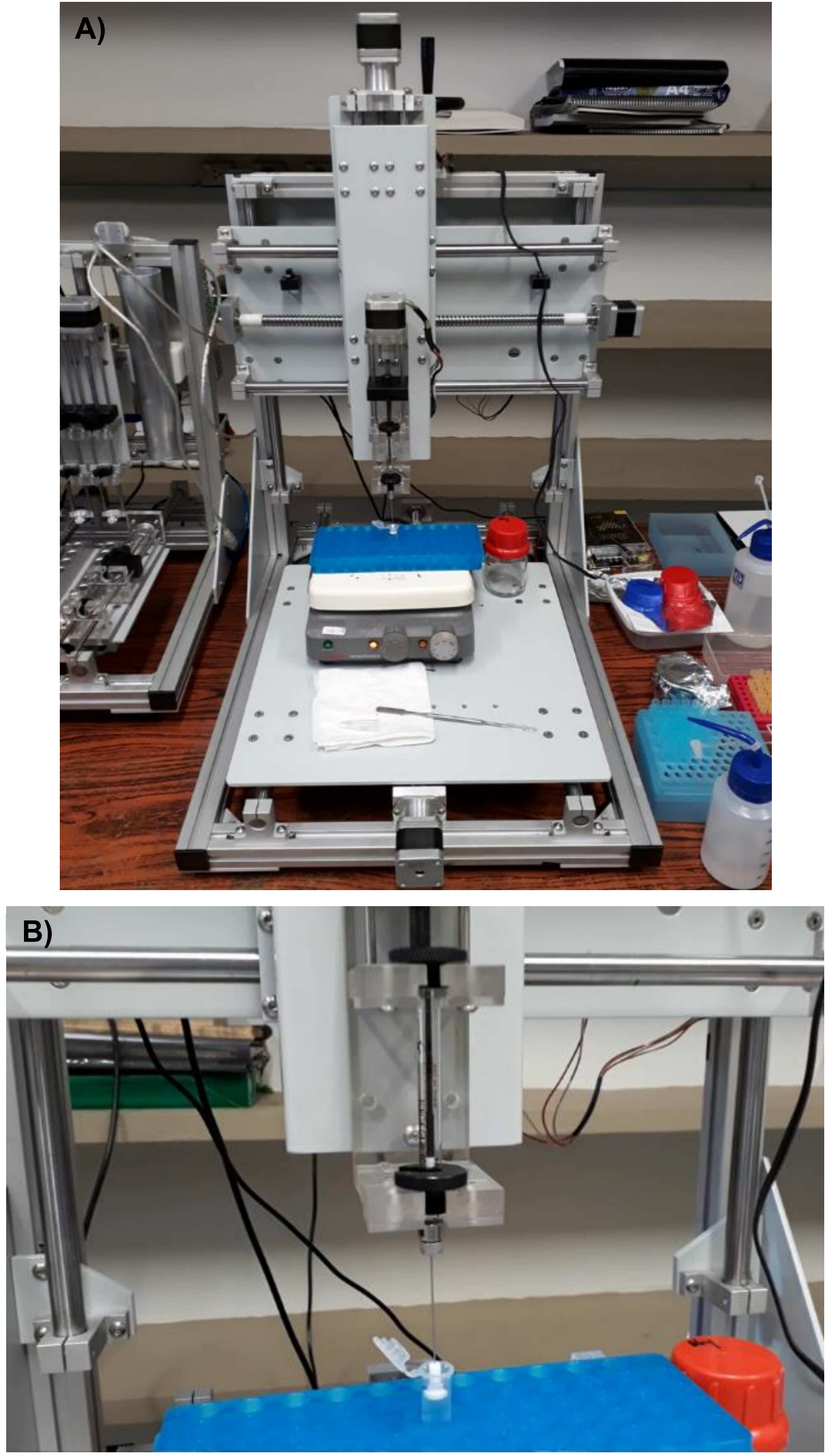


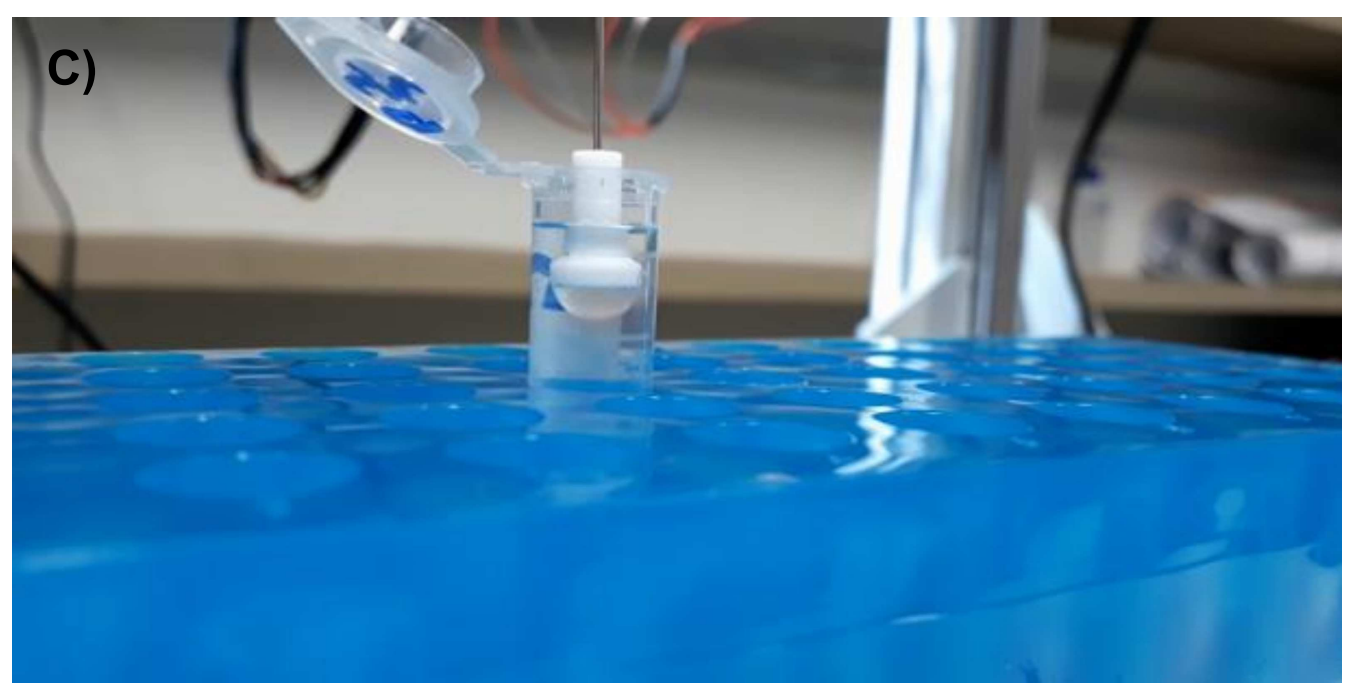

\subsubsection{Planejamento Experimental}

A partir das áreas absolutas obtidas por meio do planejamento experimental composto central $2^{2}$ com estrela, em que se avaliou o número de ciclos da formação da gota e o tempo de exposição da gota na amostra (Tabela 33) foram construídos diagramas de Pareto, apresentados na Figura 33. Conforme pode ser observado nos Diagramas de Pareto, as variáveis avaliadas foram significativas, o número de ciclo com efeito negativo para os analitos estudados e o tempo de exposição com efeito negativo para as sulfas e positivo para as FQs.

Tabela 33: Variáveis e fatores do planejamento experimental composto central $2^{2}$ com estrela.

\begin{tabular}{|c|c|c|c|c|c|c|c|}
\hline \multicolumn{3}{|c|}{ Fatores } & $-1,41$ & -1 & $P C(0)$ & +1 & $+1,41$ \\
\hline \multirow{2}{*}{\multicolumn{3}{|c|}{$\begin{array}{c}\text { Número de Ciclos }(\mathrm{N}) \\
\text { Tempo de Exposição } \\
\text { da gota }(\mathrm{T})\end{array}$}} & 30 & 42 & 70 & 98 & 109 \\
\hline & & & $5 \mathrm{~s}$ & $8 \mathrm{~s}$ & $15 \mathrm{~s}$ & $22 \mathrm{~s}$ & $25 \mathrm{~s}$ \\
\hline Ensaios & C & $\bar{T}$ & SDZ & $\overline{\text { STZ }}$ & SMR & NOR & ENR \\
\hline 1 & 0 & 0 & 7286 & 11537 & 22825 & 12015 & 157152 \\
\hline 2 & 0 & 0 & 7105 & 10112 & 21589 & 11072 & 142180 \\
\hline 3 & 0 & 0 & 7288 & 10218 & 24003 & 10033 & 151167 \\
\hline 4 & 0 & 0 & 7104 & 11018 & 21648 & 11009 & 146415 \\
\hline 5 & -1 & -1 & 5650 & 6632 & 11954 & 3192 & 15707 \\
\hline 6 & 1 & -1 & 4540 & 6947 & 17735 & 4825 & 62438 \\
\hline 7 & -1 & 1 & 5185 & 8115 & 16879 & 7747 & 111931 \\
\hline 8 & 1 & 1 & 3836 & 6619 & 14143 & 3147 & 67169 \\
\hline 9 & $\begin{array}{c}- \\
1,41\end{array}$ & 0 & 4182 & 5632 & 11110 & 6394 & 76074 \\
\hline 10 & 0 & $-1,41$ & 6175 & 8114 & 20843 & 8846 & 153858 \\
\hline 11 & 1,41 & 0 & 6738 & 9990 & 23204 & 10617 & 184990 \\
\hline 12 & 0 & 1,41 & 7961 & 11240 & 24136 & 15570 & 179255 \\
\hline
\end{tabular}


Figura 33: Diagrama de Pareto para as sulfas e FQs avaliadas.
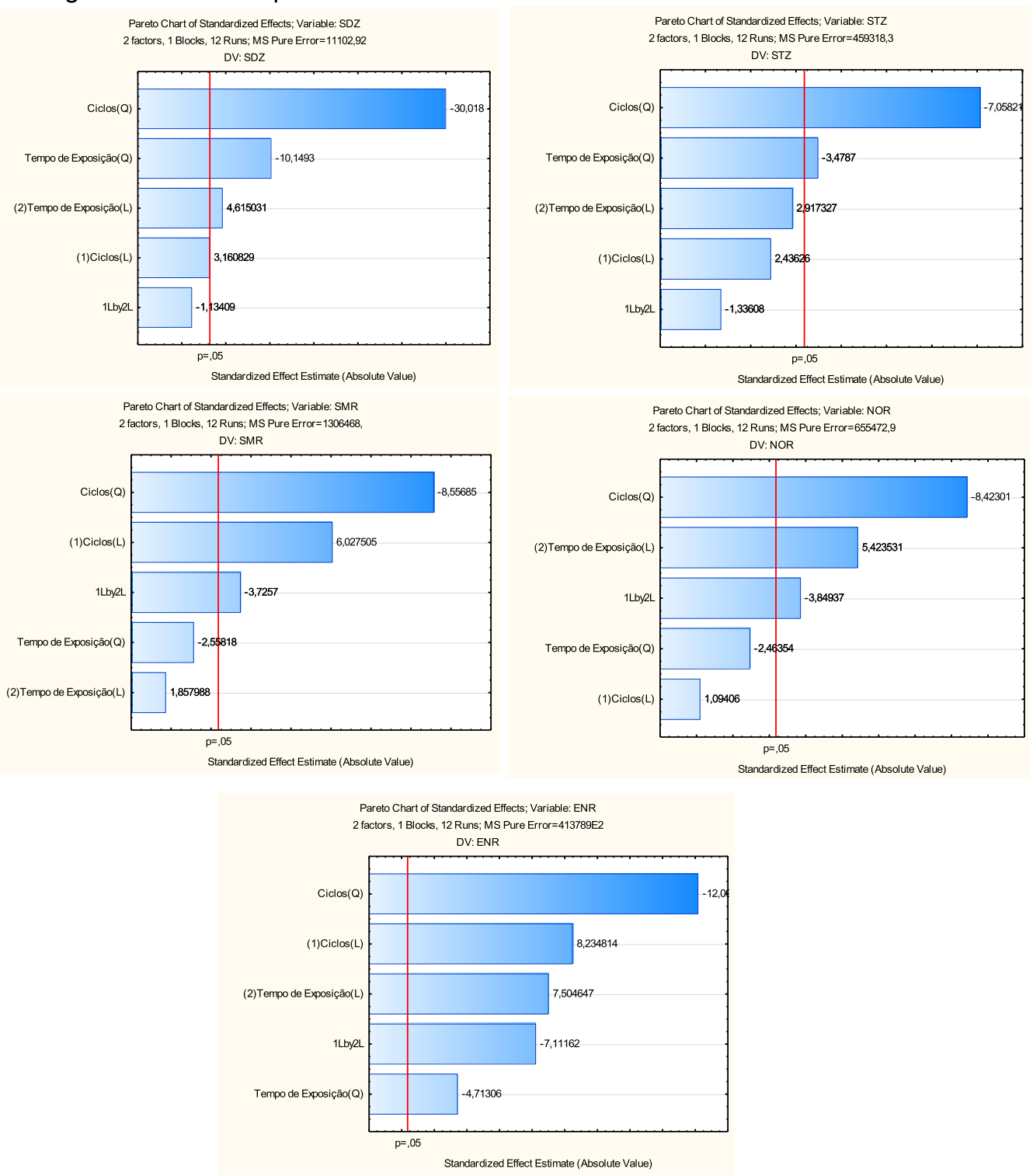

Depois do modelo ter sido proposto, foram plotadas as superfícies de respostas para as sulfas e FQs como mostra a Figura 34. O método foi otimizado para fazer a extração simultânea das duas classes de antimicrobianos, portanto foi necessário determinar o ponto ótimo para a extração de todos os analitos, desta maneira foram plotados o gráfico e a superfície de resposta para a desejabilidade do modelo como mostra a Figura 35. 
Figura 34: Superfícies de respostas paras as sulfas e FQs avaliadas.
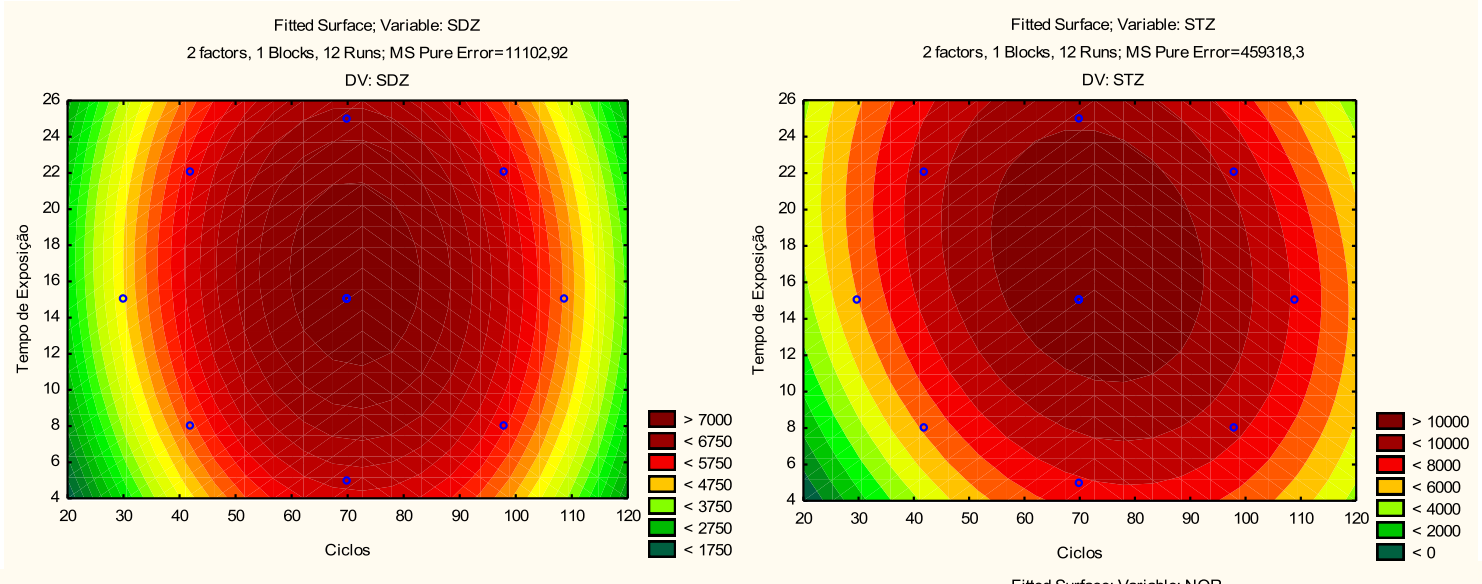

Fited Surface; Variable: SMR

Fitted Surface; Variable: NOR

2 factors, 1 Blocks, 12 Runs; MS Pure Error=1306468,

DV: SMR

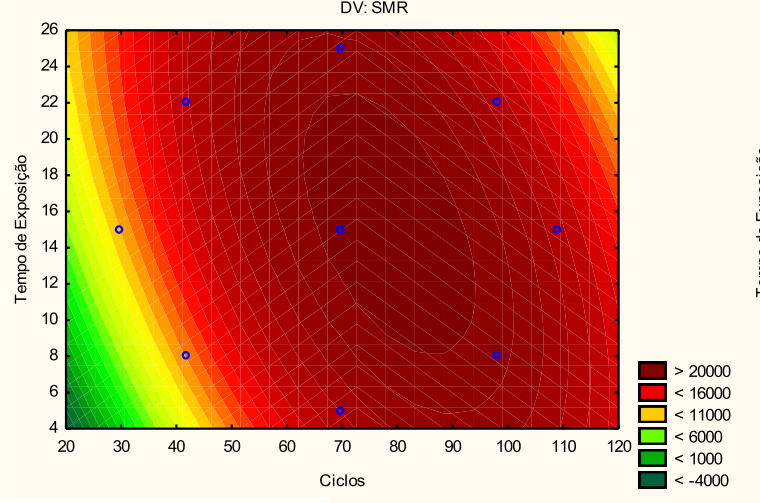

2 factors, 1 Blocks, 12 Runs: MS Pure Error $=655472,9$ DV: NOR

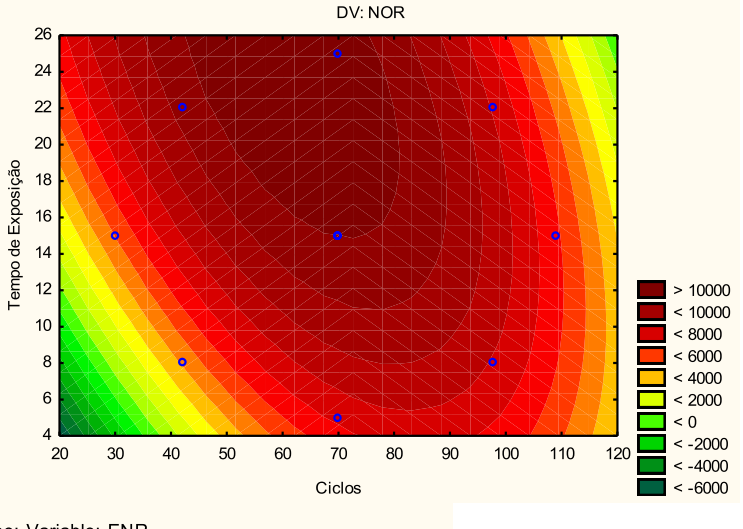

Fitted Surface; Variable: ENR

2 factors, 1 Blocks, 12 Runs; MS Pure Error=413789E2

DV: ENR

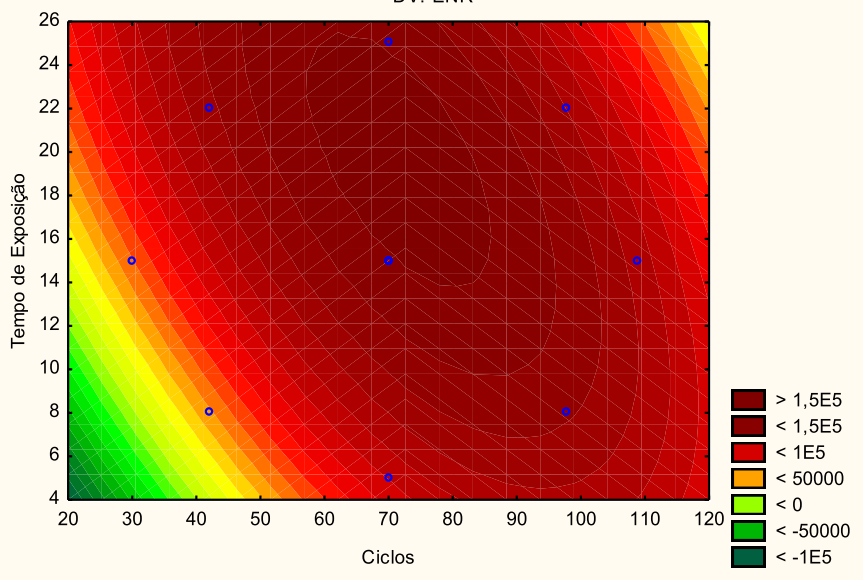


Figura 35: Desejabilidade e ponto ótimo para o modelo proposto

Profiles for Predicted Values and Desirability
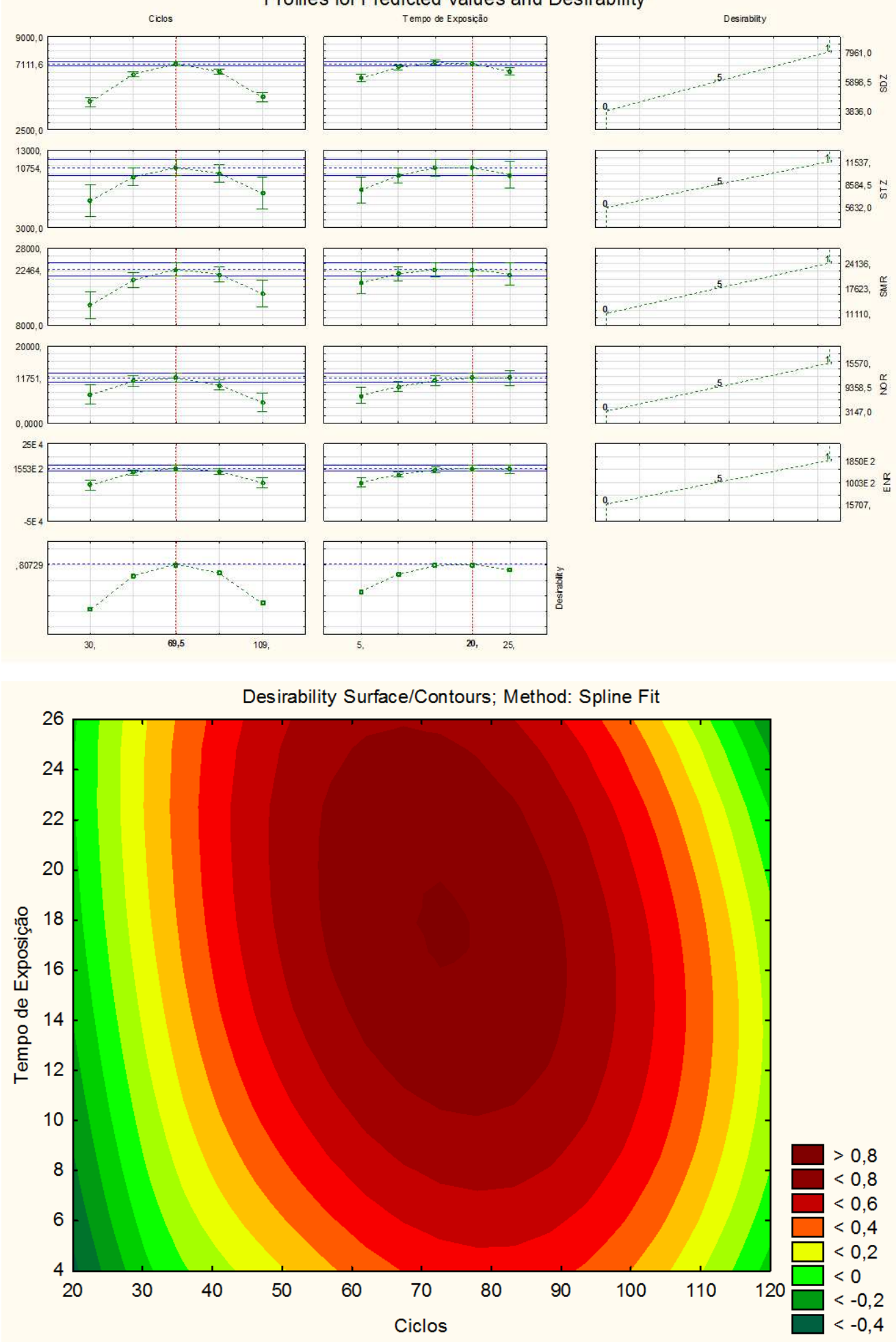

Desta maneira o ponto ótimo para a extração definido pelo modelo foi de 70 ciclos e 20 segundos de exposição da gota na amostra. 


\subsubsection{Validação do método desenvolvido}

A linearidade do método LLME-LC-MS/MS foi avaliada através da curva analítica construída em amostras de esgoto sintético fortificadas em seis níveis diferentes (Figura 36). A faixa de quantificação analítica, os coeficientes de determinação e correlação e as equações de regressão linear para cada antimicrobiano estão apresentados na Tabela 34. As curvas de calibração foram construídas utilizando as transições de $\mathrm{m} / \mathrm{z}$ com maior intensidade para cada analito.

Figura 36: Curvas analíticas para as sulfas e FQs processadas por LLME-LC-MS/MS.
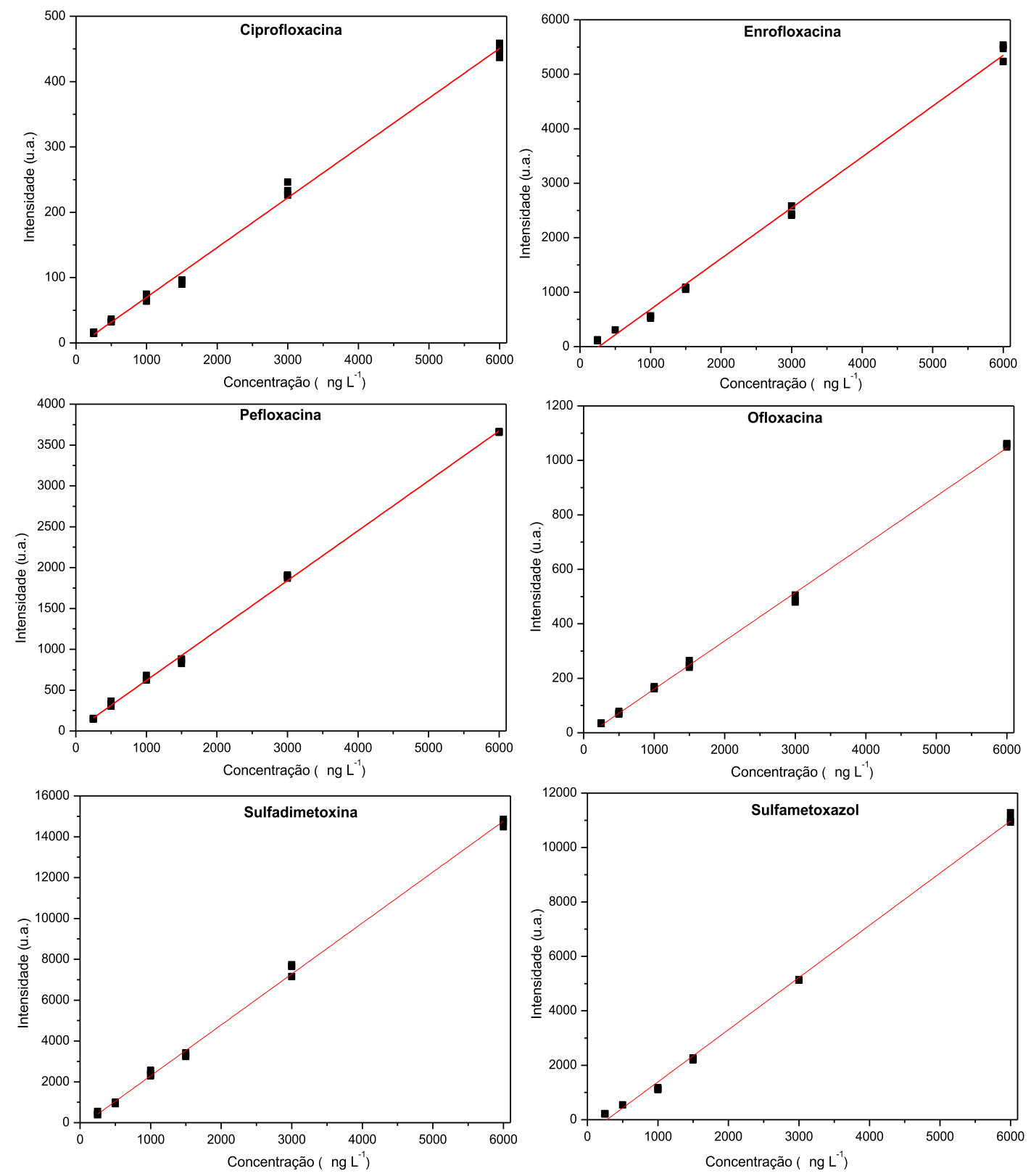
Os dados obtidos com a regressão linear estão contidos na Tabela 34 . Os limites de detecção (LD) e limites de quantificação (LQ) estão mostrados na Tabela 34 e foram de 100 e $250 \mathrm{ng} \mathrm{L} \mathrm{L}^{-1}$, utilizando apenas 2,0 mL de amostra.

Tabela 34: Dados da curva analítica.

\begin{tabular}{ccccccc}
\hline Analitos & $\mathbf{r}^{2}$ & $\mathbf{a}$ & $\mathbf{b}$ & $\begin{array}{c}\text { Faixa Linear } \\
\left(\mathbf{n g ~ L} \mathbf{L}^{-1}\right)\end{array}$ & $\begin{array}{c}\text { LD } \\
\left(\mathbf{n g ~ L} \mathbf{L}^{-1}\right)\end{array}$ & $\begin{array}{c}\mathbf{L Q} \\
\left(\mathbf{n g ~ L} \mathbf{~}^{-1}\right)\end{array}$ \\
\hline SMX & 0,99752 & $-425,6$ & 1,9 & $250-6000$ & 100 & 250 \\
\hline SDMX & 0,99826 & $-202,9$ & 2,5 & $250-6000$ & 100 & 250 \\
\hline CIP & 0,99567 & $-6,2$ & 0,08 & $250-6000$ & 100 & 250 \\
\hline PEF & 0,99877 & 8,5 & 0,61 & $250-6000$ & 100 & 250 \\
\hline ENRO & 0,99577 & $-148,2$ & 0,93 & $250-6000$ & 100 & 250 \\
\hline OFLO & 0,99844 & $-16,8$ & 0,18 & $250-6000$ & 100 & 250 \\
\hline
\end{tabular}

Adicionalmente, para avaliar a linearidade da curva, foi feita a construção do gráfico de resíduos em relação à área absoluta (eixo y da curva) para todos os analitos avaliados. Podemos observar que os resíduos estão bem dispersos e sem indícios de algum tipo de tendência (Figura 37). 
Figura 37: Gráficos de resíduos absolutos em relação a concentração das Sulfas e FQs.
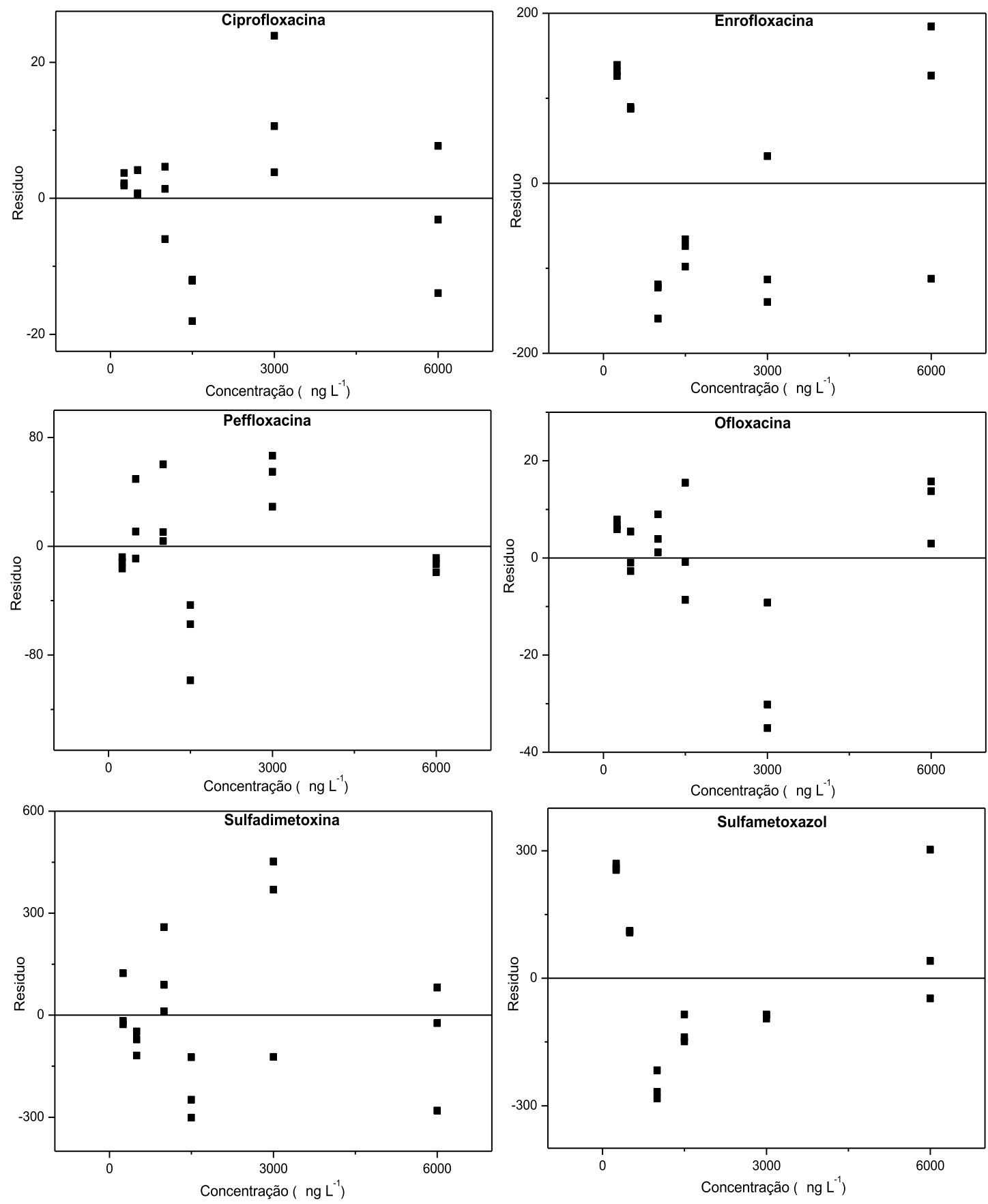

O estudo de precisão intradia e interdias foi expresso em desvio padrão relativo (DPR, \%) sendo obtidos valores abaixo de $20 \%$ para o nível baixo (LQ) e 15\% para os demais níveis (Tabela 35). Já os estudos de exatidão (bias) também apresentaram valores aceitáveis (menores do que $\pm 20 \%$ ) para o nível baixo (LQ) e menores do que $\pm 15 \%$ para os demais níveis. Esses limites de referência são utilizados pela maior parte das agências regulamentadoras e adicionalmente estão totalmente coerentes 
com o que é regulamentado pelo EPA para análise de compostos orgânicos em resíduo aquoso $(46,55)$.

Tabela 35: Valores de precisão e exatidão obtidos para o método SDME desenvolvido.

\begin{tabular}{|c|c|c|c|c|}
\hline Analitos & Níveis & $\begin{array}{c}\text { Precisão intra-dia } \\
\text { DPR (\%) } \\
(n=5)\end{array}$ & $\begin{array}{c}\text { Precisão } \\
\text { inter-dias } \\
\text { DPR (\%) } \\
(n=10)\end{array}$ & $\begin{array}{c}\text { Exatidão } \\
\text { (\% bias) } \\
\text { DPR (\%) } \\
(\mathrm{n}=5)\end{array}$ \\
\hline \multirow{3}{*}{ SMX 254-92 } & Baixo & 0,4 & 7,6 & 9,3 \\
\hline & Médio & 3,1 & 5,5 & $-10,2$ \\
\hline & Alto & 1,6 & 2,4 & 1,4 \\
\hline \multirow{3}{*}{ SDMX 311-92 } & Baixo & 3,7 & 2,4 & $-8,1$ \\
\hline & Médio & 5,3 & 4,3 & 0,6 \\
\hline & Alto & 1,3 & 1,6 & $-0,6$ \\
\hline \multirow{3}{*}{ CIP 332-245 } & Baixo & 6,0 & 4,5 & 6,7 \\
\hline & Médio & 7,8 & 6,2 & 4,1 \\
\hline & Alto & 4,8 & 4,7 & 7,3 \\
\hline \multirow{3}{*}{ PEF 334-233 } & Baixo & 9,0 & 6,2 & 6,8 \\
\hline & Médio & 4,8 & 4,4 & 4,7 \\
\hline & Alto & 3,1 & 3,3 & $-1,1$ \\
\hline \multirow{3}{*}{ ENRO 360-245 } & Baixo & 0,4 & 12,1 & 12,7 \\
\hline & Médio & 4,0 & 4,4 & $-14,1$ \\
\hline & Alto & 4,0 & 4,0 & $-2,8$ \\
\hline \multirow{3}{*}{ OFLO 362-318 } & Baixo & 5,9 & 4,3 & 0,7 \\
\hline & Médio & 2,4 & 2,7 & 5,9 \\
\hline & Alto & 2,3 & 2,0 & 1,2 \\
\hline
\end{tabular}

Com base nos estudos feitos por Matuszewski et. al, foi realizado o estudo do efeito de matriz, recuperação e eficiência total do método (48). Os valores de ME, PE e RE (Tabela 36) foram calculados a partir das áreas dos picos nos três níveis (baixo, médio e alto).

A recuperação e a eficiência total do processo para as FQs tiveram resultados mais baixos comparados com os resultados das sulfonamidas avaliadas. Mesmo com valores baixos de recuperação dos analitos avaliados o método obteve precisão e exatidão. O efeito de matriz não é influenciado pela concentração no analito, pois para os três níveis foram aproximadamente iguais os $\mathrm{ME}$, porém por se tratar de uma matriz complexa existe efeito de matriz, indicando a ocorrência de uma provável supressão da ionização nos níveis de concentração das análises feitas por espectrometria de massas principalmente para as sulfonamidas. Esse efeito pode estar relacionado a 
possíveis interferentes presentes na matriz e que impedem, de alguma forma, a ionização total dos analitos. Todavia, a presença de certo grau de efeito de matriz em amostras complexas é, de alguma forma, esperada.

Tabela 36: Resultados para recuperação, efeito de matriz e eficiência total do processo.

\begin{tabular}{ccccc}
\hline Sulfas & Níveis & $\begin{array}{c}\text { Recuperação (\%) } \\
(\mathbf{n = 3})\end{array}$ & $\begin{array}{c}\text { Efeito de } \\
\text { Matriz (\%) } \\
(\mathbf{n = 3})\end{array}$ & $\begin{array}{c}\text { Eficiência total } \\
\text { do Processo (\%) } \\
(\mathbf{n}=\mathbf{3})\end{array}$ \\
\hline \multirow{3}{*}{ SMX 254-92 } & Baixo & 17,6 & 33,2 & 5,8 \\
& Médio & 26,3 & 30,6 & 8,0 \\
& Alto & 46,3 & 26,0 & 12,0 \\
\hline \multirow{3}{*}{ SDMX 311-92 } & Baixo & 36,4 & 38,2 & 13,9 \\
& Médio & 46,9 & 37,4 & 17,6 \\
& Alto & 40,9 & 38,7 & 15,8 \\
\hline \multirow{3}{*}{ CIP 332-245 } & Baixo & 9,9 & 108,5 & 10,7 \\
& Médio & 10,7 & 98,8 & 10,5 \\
& Alto & 12,4 & 102,1 & 12,7 \\
\hline \multirow{3}{*}{ PEF 334-233 } & Baixo & 10,6 & 100,7 & 10,6 \\
& Médio & 10,5 & 95,4 & 10,0 \\
& Alto & 9,1 & 104,3 & 9,5 \\
\hline \multirow{3}{*}{ ENRO 360-245 } & Baixo & 10,3 & 95,6 & 9,8 \\
& Médio & 14,2 & 77,5 & 11,0 \\
& Alto & 16,2 & 100,3 & 16,3 \\
\hline \multirow{3}{*}{ OFLO 362-318 } & Baixo & 3,5 & 97,1 & 3,4 \\
& Médio & 3,5 & 97,4 & 3,4 \\
& Alto & 3,7 & 104,5 & 3,8 \\
\hline
\end{tabular}

\subsubsection{Aplicação do Método}

O ponto 1 apresentado no mapa (Figura 38), refere-se a esgoto de característica puramente doméstica (representativo dos bairros circunvizinhos do Campus 2 da USP São Carlos); o ponto 2 se refere ao rio Monjolinho (localizado próximo a USP São Carlos - Campus 1) e o ponto 3 refere-se ao rio Monjolinho (local próximo ao Shopping Iguatemi). 
Figura 38: Mapa representativo, para indicação dos pontos de coleta realizados na cidade de São Carlos-SP. Tais amostras foram aplicados nos métodos LLME-LC-MS/MS.

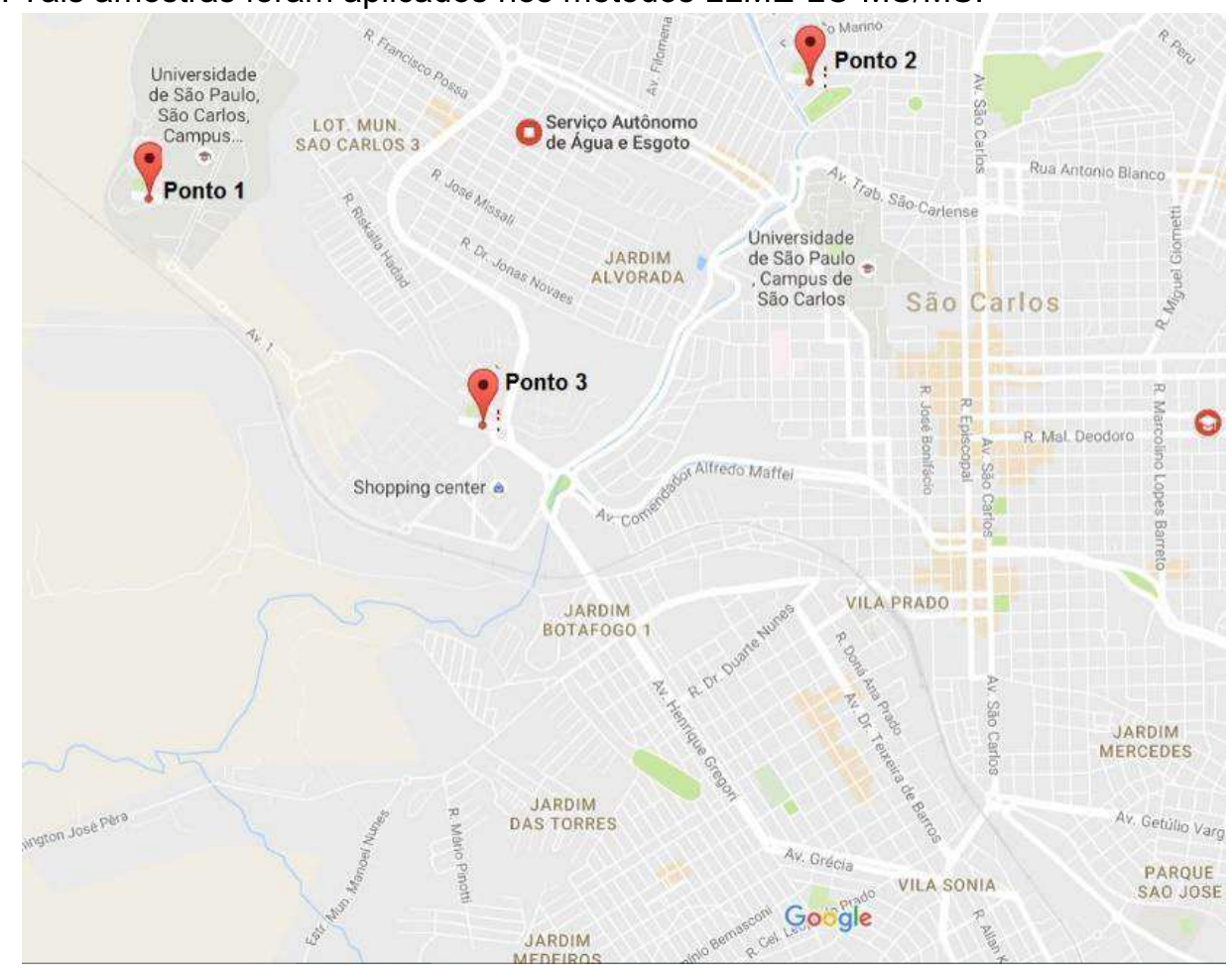

Os cromatogramas obtidos no método desenvolvido para a extração das sulfas e FQs avaliadas simultaneamente estão contidos nas figuras $40-42$, para facilitar a identificação, foram monitoradas duas transições para cada analito. 
Figura 39: Cromatogramas obtido no método LLME-LC-MS/MS para extração de Sulfas e FQs simultaneamente em amostras de água coletadas no ponto 1 da amostragem: a) Foram monitoradas duas transições de m/z 362-318 e 362-261 para a ofloxacina; b) transições de m/z 311-156 e 311-92 para a Sulfadimetoxina e c) transições de m/z 254-156 e 254-92 para o Sulfametoxazol.

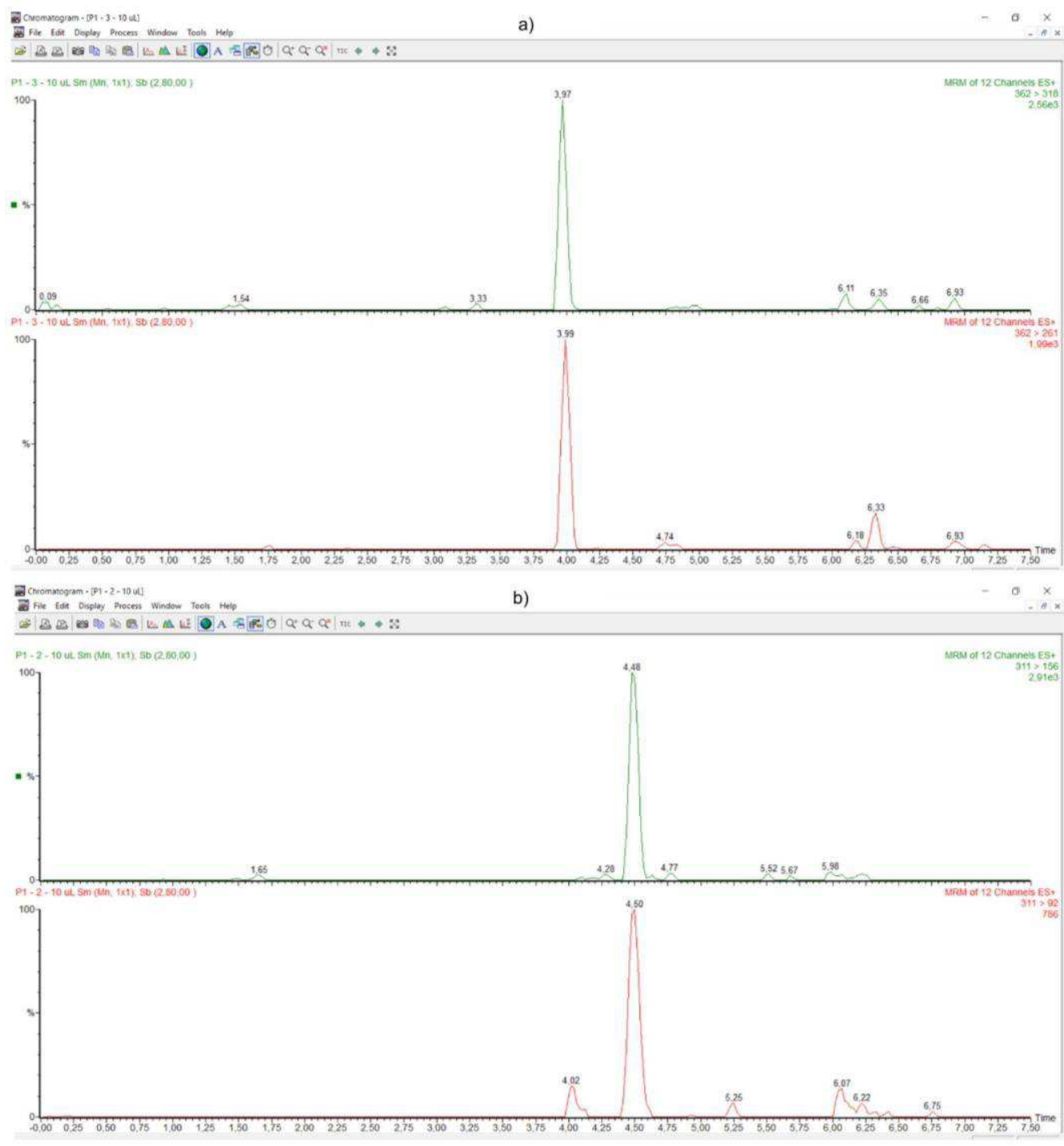

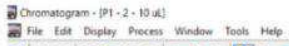

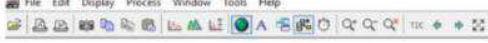

c)

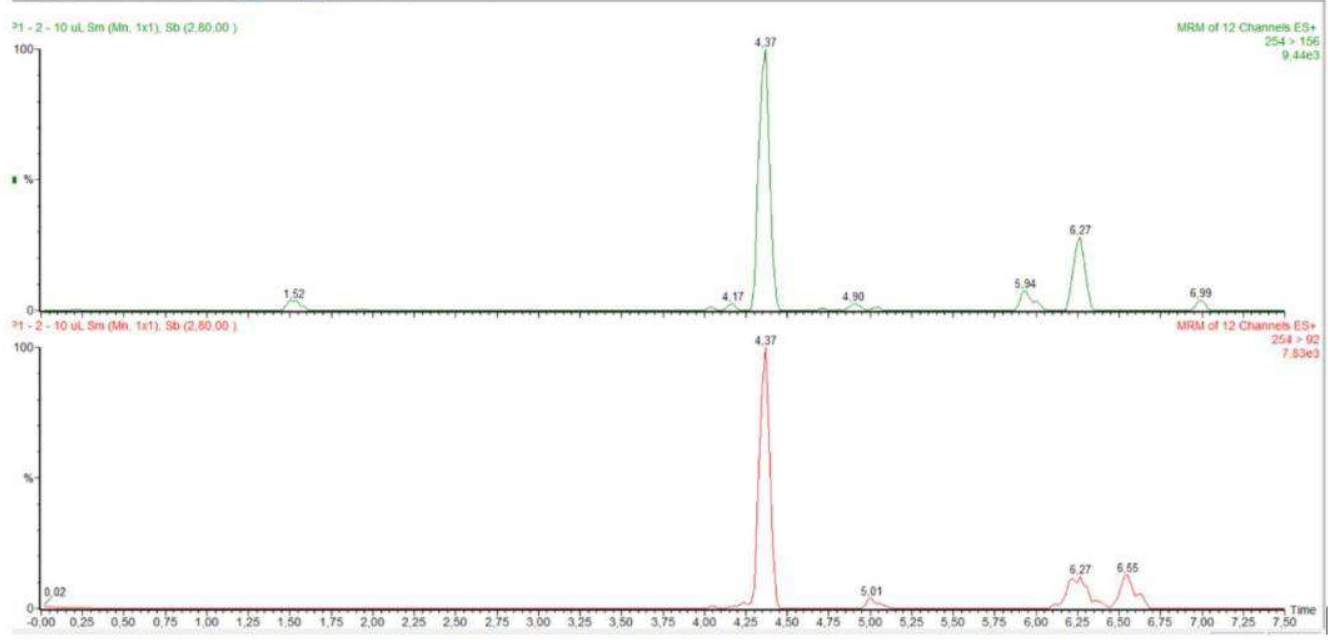


Figura 40: Cromatogramas obtido no método LLME-LC-MS/MS para extração de Sulfas e FQs simultaneamente em amostras de água coletadas no ponto 2 da amostragem: a) Foram monitoradas duas transições de m/z 362-318 e 362-261 para a ofloxacina; b) transições de m/z 311-156 e 311-92 para a Sulfadimetoxina e c) transições de m/z 254-156 e 254-92 para o Sulfametoxazol.

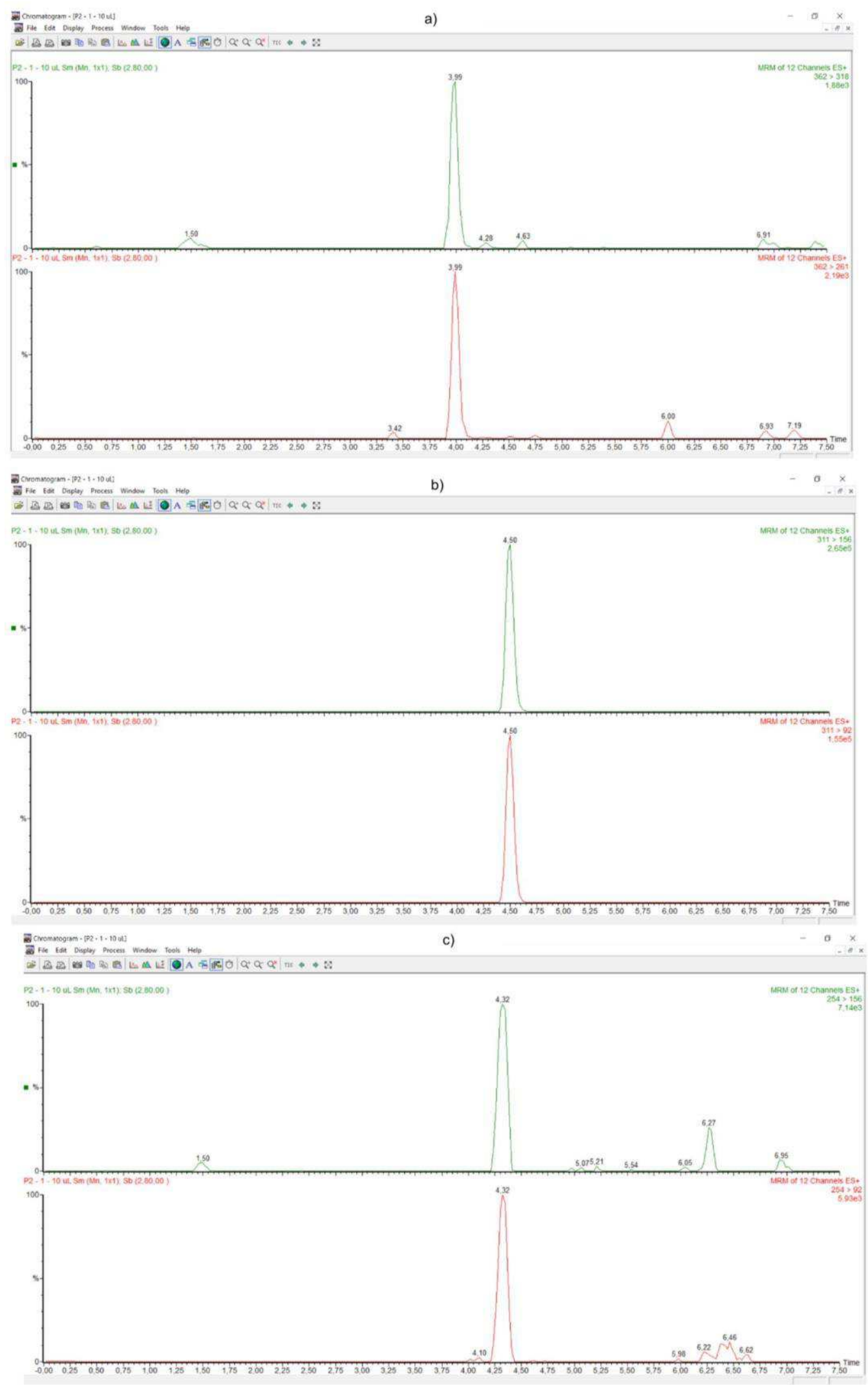


Figura 41: Cromatogramas obtido no método LLME-LC-MS/MS para extração de Sulfas e FQs simultaneamente em amostras de água coletadas no ponto 3 da amostragem: a) Foram monitoradas duas transições de m/z 362-318 e 362-261 para a ofloxacina; b) transições de m/z 311-156 e 311-92 para a Sulfadimetoxina.

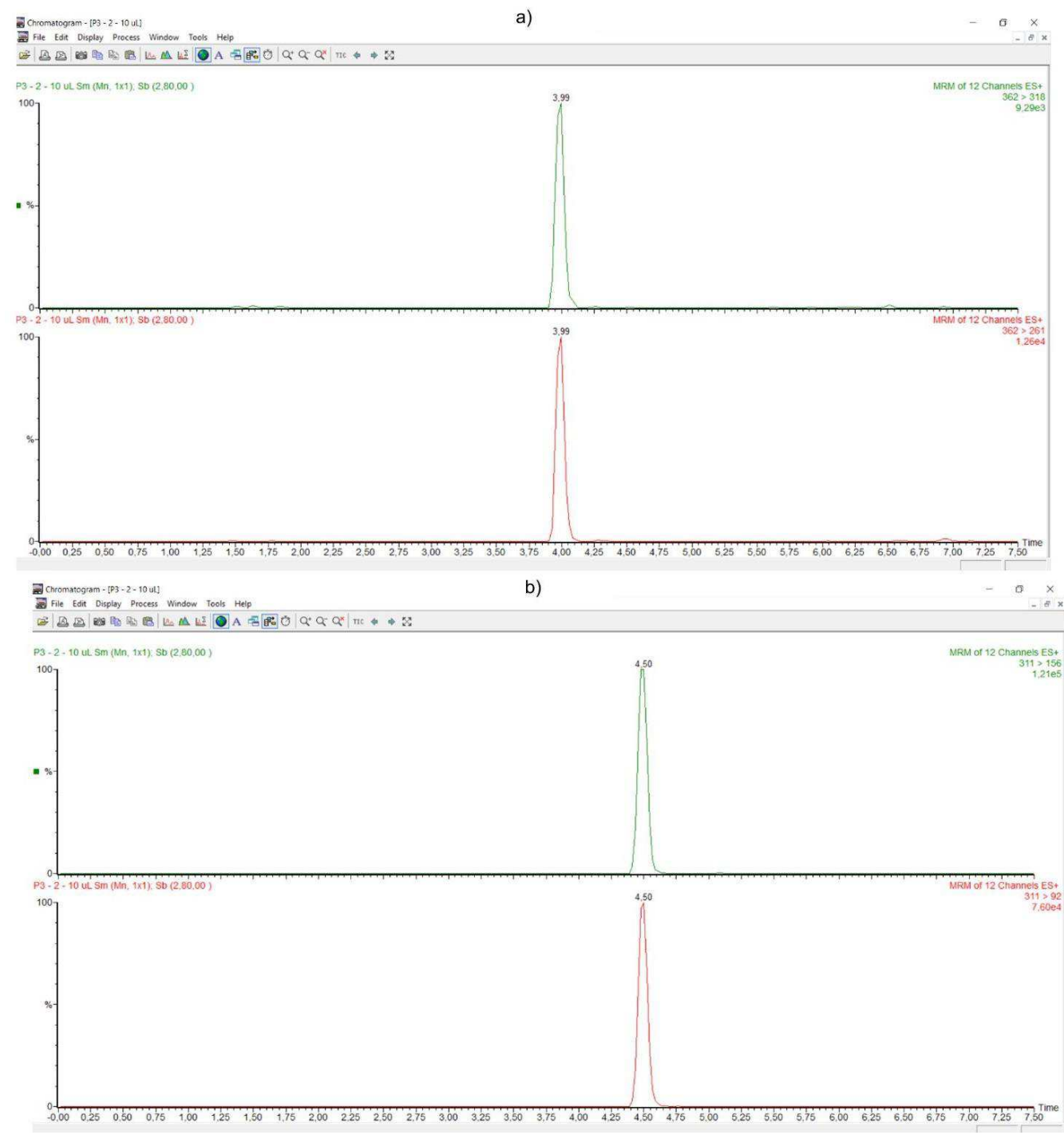

Dentre as amostras reais utilizadas para aplicação do método, foi possível detectar e quantificar algumas contaminações por esses antimicrobianos, conforme a Tabela 37. As análises mostraram contaminação por ofloxacina, sulfadimetoxina e sulfametoxazol na maioria dos pontos de coleta avaliados em níveis quantificáveis, em amostra real. Dentre os analitos avaliados as sulfas e FQs detectadas são amplamente utilizadas em fármacos veterinários, por isso é importante desenvolver métodos eficientes para extração e detecção destes fármacos. 
Tabela 37: Concentração dos antibióticos detectados nas amostras de água coletadas nos pontos 1 ao 3 indicados na Figura 38.

\begin{tabular}{cccc}
\hline Sulfas-FQs & $\begin{array}{c}\text { Ponto 1 } \\
\text { (ng L-1) }\end{array}$ & $\begin{array}{c}\text { Ponto 2 } \\
\text { (ng L-1) }\end{array}$ & $\begin{array}{c}\text { Ponto 3 } \\
\text { (ng L-1) }\end{array}$ \\
\hline Sulfametoxazol & $560 \pm 68$ & $324 \pm 5$ & $\mathrm{ND}$ \\
\hline Sulfadimetoxina & $284 \pm 5$ & $5012 \pm 226$ & $3055 \pm 135$ \\
\hline Ciprofloxacina & $\mathrm{ND}$ & $\mathrm{ND}$ & $\mathrm{ND}$ \\
\hline Pefloxacina & $\mathrm{ND}$ & $\mathrm{ND}$ & $\mathrm{ND}$ \\
\hline Enrofloxacina & $\mathrm{ND}$ & $\mathrm{ND}$ & $\mathrm{ND}$ \\
\hline Ofloxacina & $646 \pm 66$ & $1212 \pm 32$ & $5588 \pm 203$ \\
\hline
\end{tabular}




\section{CONCLUSÃO}

\subsection{Conclusão Geral e perspectivas futuras}

O desenvolvimento desse trabalho possibilita condições para a configuração de métodos analíticos eficientes e com baixo gasto de solventes orgânicos. O método LLME-CS-CLC-MS mostrou-se eficiente para a extração e quantificação de sulfonamidas em águas residuárias, utilizando um volume pequeno de amostra (7,0 $\mathrm{mL}$ ) e um volume reduzido de solvente orgânico $(1,0 \mathrm{~mL})$ em relação a extração líquido-líquido convencional. O método apresentou linearidade, seletividade, precisão, exatidão e recuperação adequada.

$\mathrm{O}$ uso de planejamento experimental mostrou-se muito eficiente para a otimização dos métodos LLME-CS-LC-MS/MS e SDME-LC-MS/MS para extração e detecção das sulfonamidas e fluoroquinolonas avaliadas. Outro fator importante foi a automatização do método de extração utilizando a microextração em gota suspensa (SDME), facilitando as extrações e diminuindo os erros. Desta maneira este método pode ser utilizado de forma simples e prática para análise de sulfonamidas e fluoroquinolonas simultaneamente em amostras ambientais.

A automatização é muito utilizada dentro da química analítica, possuindo como principal vantagem a economia de tempo e eficiência no processo. $\mathrm{O}$ uso de métodos de extração automatizados aumenta a eficiência de extração, diminui os erros analíticos e aumenta a exatidão e precisão do método desenvolvido, portanto os métodos desenvolvidos nesta tese podem ser automatizados e talvez buscar um acoplamento direto ao HPLC para facilitar a injeção e retirar uma etapa do processo.

Os métodos desenvolvidos neste trabalho foram aplicados para duas classes de antibióticos, as sulfonamidas e fluoroquinolonas, porém estes métodos podem ser aplicados para outras classes de fármacos aumentando a utilidade e eficiência destes métodos de microextração líquido-líquido. 


\section{REFERÊNCIAS BIBLIOGRÁFICAS}

1 JOSS, A. et al. Removal of pharmaceuticals and fragrances in biological wastewater treatment. Water Research, v. 39, n. 14, p. 3139-3152, 2005.

2 KUMMERER, K. Drugs in the environment: emission of drugs, diagnostic aids and disinfectants into wastewater by hospitals in relation to other sources - a review.

Chemosphere, v. 45, n. 6-7, p. 957-969, 2001.

3 BOWER, C. K.; DAESCHEL, M. A. Resistance responses of microorganisms in food environments. International journal of food microbiology, v. 50, n. 1-2, p. 33-44, 1999.

4 GUARDABASSI, L.; LO FO WONG, D. M. A; DALSGAARD, A. The effects of tertiary wastewater treatment on the prevalence of antimicrobial resistant bacteria. Water research, v. 36, n. 8, p. 1955-64, 2002.

5 MCKEON, D. M.; CALABRESE, J. P.; BISSONNETTE, G. K. Antibiotic-Resistant Gram-Negative Bacteria in Rural Groundwater Supplies. Water Research, v. 29, n. 8, p. 1902-1908, 1995.

6 WISE, R. Antimicrobial resistance: priorities for action. Journal of Antimicrobial Chemotherapy, v. 49, n. 4, p. 585-586, 2002.

7 CALISTO, V.; ESTEVES, V. I. Psychiatric pharmaceuticals in the environment. Chemosphere, v. 77, n. 10, p. 1257-1274, 2009.

8 LE-MINH, N. et al. Fate of antibiotics during municipal water recycling treatment processes. Water Research, v. 44, n. 15, p. 4295-4323, 2010.

9 BATT, A. L.; BRUCE, I. B.; AGA, D. S. Evaluating the vulnerability of surface waters to antibiotic contamination from varying wastewater treatment plant discharges. Environmental Pollution, v. 142, n. 2, p. 295-302, 2006.

10 TURIEL, E.; BORDIN, G.; RODRÍGUEZ, A. R. Trace enrichment of (fluoro)quinolone antibiotics in surface waters by solid-phase extraction and their determination by liquid chromatography-ultraviolet detection. Journal of Chromatography A, v. 1008, n. 2, p. 145-155, 2003.

11 BAJAJ, M.; GALLERT, C.; WINTER, J. Treatment of phenolic wastewater in an anaerobic fixed bed reactor (AFBR) - recovery after shock loading. Journal of Hazardous Materials, v. 162, n. 2-3, p. 1330-1339, 2009.

12 FARZADKIA, M. et al. The Effect of Organic Loading on Propylene Glycol Removal Using Fixed Bed Activated Sludge Hybrid Reactor. Chemical and 
Biochemical Engineering Quarterly, v. 24, n. 2, p. 227-234, 2010.

13 DAMIANOVIC, M. H. et al. Pentachlorophenol (PCP) dechlorination in horizontalflow anaerobic immobilized biomass (HAIB) reactors. Bioresource Technology, v. 100, n. 19, p. 4361-4367, 2009.

14 WU, J.; ZHANG, L.; YANG, Z. A Review on the Analysis of Emerging Contaminants in Aquatic Environment. Critical Reviews in Analytical Chemistry, v. 40, n. 4, p. 234-245, 2010.

15 ARMENTA, S.; GARRIGUES, S.; DE LA GUARDIA, M. Green Analytical Chemistry. TrAC Trends in Analytical Chemistry, v. 27, n. 6, p. 497-511, 2008. 16 FARRÉ, M. et al. Green analytical chemistry in the determination of organic pollutants in the aquatic environment. TrAC Trends in Analytical Chemistry, v. 29, n. 11, p. 1347-1362, 2010.

17 BOSCH OJEDA, C.; SÁNCHEZ ROJAS, F. Separation and Preconcentration by Dispersive Liquid-Liquid Microextraction Procedure: A Review. Chromatographia, v. 69, n. 11-12, p. 1149-1159, 2009.

18 PEDERSEN-BJERGAARD, S. et al. Liquid-phase microextraction of basic drugs Selection of extraction mode based on computer calculated solubility data. Journal of Separation Science, v. 28, n. 11, p. 1195-1203, 2005.

19 BALTUSSEN, E.; CRAMERS, C. A.; SANDRA, P. J. Sorptive sample preparation -- a review. Analytical and Bioanalytical Chemistry, v. 373, n. 1-2, p. 3-22, 2002. $20 \mathrm{KAWAGUCHI}, \mathrm{M}$. et al. Development of vial wall sorptive extraction and its application to determination of progesterone in human serum. J Chromatogr A, v. 1216, n. 44, p. 7553-7557, 2009.

21 ROSALES-CONRADO, N. et al. Multiresidue determination of chlorophenoxy acid herbicides in human urine samples by use of solid-phase extraction and capillary LC-UV detection. Analytical and Bioanalytical Chemistry, v. 390, n. 2, p. 759-768, 2008.

22 LEVY, S. B. Resistance to Antibiotics, Genetics of. In: Brenner's Encyclopedia of Genetics.

$23 \mathrm{YAO}$, L. et al. Occurrence and risk assessment of antibiotics in surface water and groundwater from different depths of aquifers: A case study at Jianghan Plain, central China. Ecotoxicology and Environmental Safety, v. 135, p. 236-242, 2017.

24 DU, J. et al. Antibiotics in the coastal water of the South Yellow Sea in China: 
Occurrence, distribution and ecological risks. Science of The Total Environment, v. 595, p. 521-527, 2017.

25 KÜMMERER, K. Antibiotics in the aquatic environment--a review--part I.

Chemosphere, v. 75, n. 4, p. 417-34, 2009.

26 WELCH, C. J. et al. Greening analytical chromatography. TrAC Trends in

Analytical Chemistry, v. 29, n. 7, p. 667-680, 2010.

27 SARAFRAZ-YAZDI, A.; AMIRI, A. Liquid-phase microextraction. TrAC Trends in Analytical Chemistry, v. 29, n. 1, p. 1-14, 2010.

28 JEANNOT, M. A.; CANTWELL, F. F. Solvent microextraction into a single drop.

Analytical Chemistry, v. 68, n. 13, p. 2236-2240, 1996.

29 JEANNOT, M. A.; PRZYJAZNY, A.; KOKOSA, J. M. Single drop microextraction-

Development, applications and future trends. Journal of Chromatography A, v. 1217, n. 16, p. 2326-2336, 2010.

30 AN, J.; RAHN, K. L.; ANDERSON, J. L. Headspace single drop microextraction versus dispersive liquid-liquid microextraction using magnetic ionic liquid extraction solvents. Talanta, v. 167, p. 268-278, 2017.

31 HATAMI, A.; BASTANI, D.; NAJAFI, F. Investigation the effect of super hydrophobic titania nanoparticles on the mass transfer performance of single drop liquid-liquid extraction process. Separation and Purification Technology, v. 176, p. 107-119, 2017.

32 MILLER, J. N.; MILLER, J. C. Statistics and Chemometrics for Analytical Chemistry. Sixth ed.

33 BARROS NETO, B.; SCARMINIO, I. S.; BRUNS, R. E. Como Fazer

Experimentos. 4 ${ }^{\mathrm{a}}$ ed. Porto Alegre: Bookman, 2010.

34 PEREIRA FILHO, E. R. Planejamento fatorial em química: Maximizando a obtenção de resultados. São Carlos - SP: EdUFSCar, 2015.

35 GARTISER, S. et al. Ultimate biodegradation and elimination of antibiotics in inherent tests. Chemosphere, v. 67, n. 3, p. 604-613, 2007.

36 KÜMMERER, K.; AL-AHMAD, A.; MERSCH-SUNDERMANN, V. Biodegradability of some antibiotics, elimination of the genotoxicity and affection of wastewater bacteria in a simple test. Chemosphere, v. 40, n. 7, p. 701-710, 2000.

37 BROWN, K. D. et al. Occurrence of antibiotics in hospital, residential, and dairy effluent, municipal wastewater, and the Rio Grande in New Mexico. Science of The 
Total Environment, v. 366, n. 2, p. 772-783, 2006.

38 RICHARDSON, S. D.; TERNES, T. A. Water analysis: emerging contaminants and current issues. Analytical Chemistry, v. 83, n. 12, p. 4614-4648, 2011. 39 CHÁFER-PERICÁS, C.; MAQUIEIRA, Á.; PUCHADES, R. Fast screening methods to detect antibiotic residues in food samples. TrAC Trends in Analytical Chemistry, v. 29, n. 9, p. 1038-1049, 2010.

40 GAO, P.; MUNIR, M.; XAGORARAKI, I. Correlation of tetracycline and sulfonamide antibiotics with corresponding resistance genes and resistant bacteria in a conventional municipal wastewater treatment plant. The Science of the total environment, v. 421-422, p. 173-83, 2012.

41 HIGGINS, P.; FLUIT, A.; SCHMITZ, F.-. Fluoroquinolones: Structure and Target Sites. Current Drug Targets, v. 4, n. 2, p. 181-190, 2003.

42 SARMAH, A. K.; MEYER, M. T.; BOXALL, A. B. A. A global perspective on the use, sales, exposure pathways, occurrence, fate and effects of veterinary antibiotics (VAs) in the environment. Chemosphere, v. 65, n. 5, p. 725-59, 2006.

43 COMPANYÓ, R. et al. Antibiotics in food: legislation and validation of analytical methodologies. Analytical and bioanalytical chemistry, v. 395, n. 4, p. 877-91, 2009.

44 LOZADA, P. T. Desempenho de um reator anaeróbio de manta de lodo (UASB) de bancada no tratamento de subst rato sintético simulando esgotos sanitário sob diferentes condições de operação. Universidade de São Paulo, 1992.

45 RIBANI, M. et al. Validação em métodos cromatográficos e eletroforéticos.

Química Nova, v. 27, n. 5, p. 771-780, 2004.

46 (EPA), E. P. A. Methods for the Determination of Organic .Compounds in Drinking Water (Supplement III). 1995.

47 (EPA), E. P. A. Method 1694: Pharmaceuticals and Personal Care Products in Water, Soil, Sediment, and Biosolids by HPLC/MS/MS. 2007.

48 MATUSZEWSKI, B. K.; CONSTANZER, M. L.; CHAVEZ-ENG, C. M. Strategies for the assessment of matrix effect in quantitative bioanalytical methods based on HPLC-MS/MS. Analytical chemistry, v. 75, n. 13, p. 3019-30, 2003.

49 MATUSZEWSKI, B. K. Standard line slopes as a measure of a relative matrix effect in quantitative HPLC-MS bioanalysis. Journal of chromatography. B, 
Analytical technologies in the biomedical and life sciences, v. 830, n. 2, p. 293300, 2006.

50 YOUDEN, W. J.; STEINER, E. H. Statistical Manual of the AOAC. [s.I.] Association of Official Analytical Chemists, 1975.

51 KARAGEORGOU, E.; SAMANIDOU, V. Youden test application in robustness assays during method validation. Journal of chromatography. A, v. 1353, p. 131-9, 2014.

52 LIU, J. et al. Miniaturized salting-out liquid-liquid extraction of sulfonamides from different matrices. Analytica Chimica Acta, v. 679, n. 1, p. 74-80, 2010.

53 ERRAYESS, S. A. et al. A sensitive method for the determination of Sulfonamides in seawater samples by Solid Phase Extraction and UV-Visible spectrophotometry. Spectrochimica Acta Part A: Molecular and Biomolecular Spectroscopy, v. 181, p. 276-285, 2017.

54 DMITRIENKO, S. G. et al. Comparison of adsorbents for the preconcentration of sulfanilamides from aqueous solutions prior to HPLC determination. Journal of Analytical Chemistry, v. 68, n. 10, p. 871-879, 2013.

55 INTERNATIONAL, A. Guidelines for Single Laboratory Validation of Chemical Methods for Dietary Supplements and Botanicals. 